

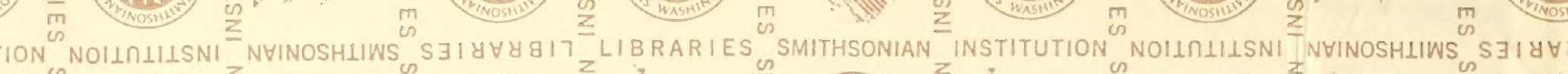

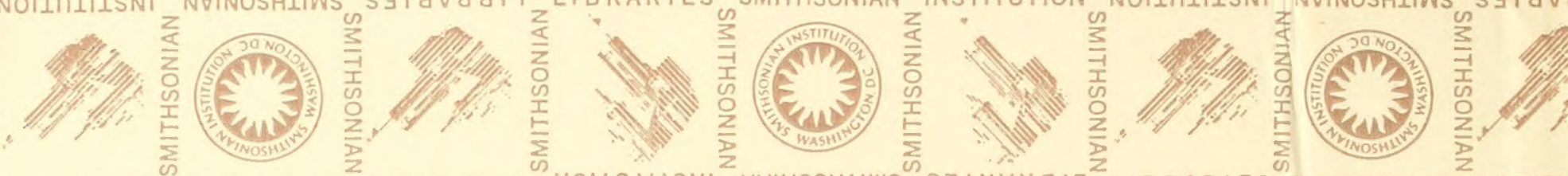

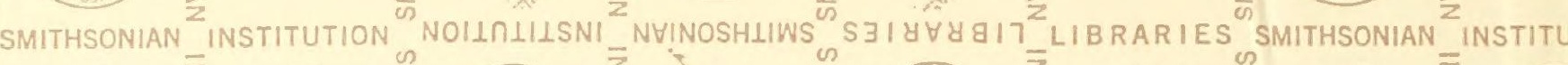

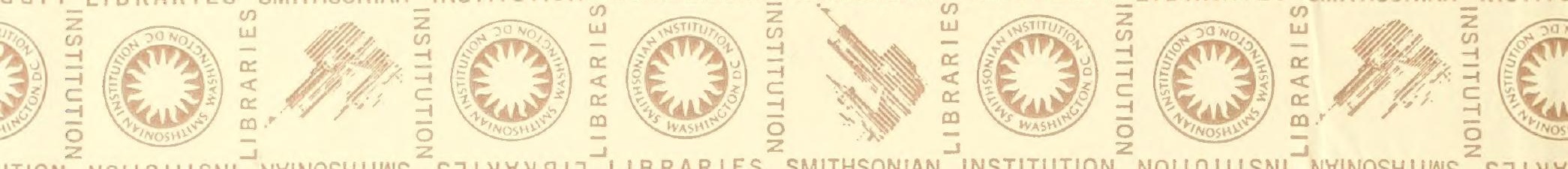
ITION NOILIIISNI NYINOSHLIWS S

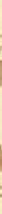

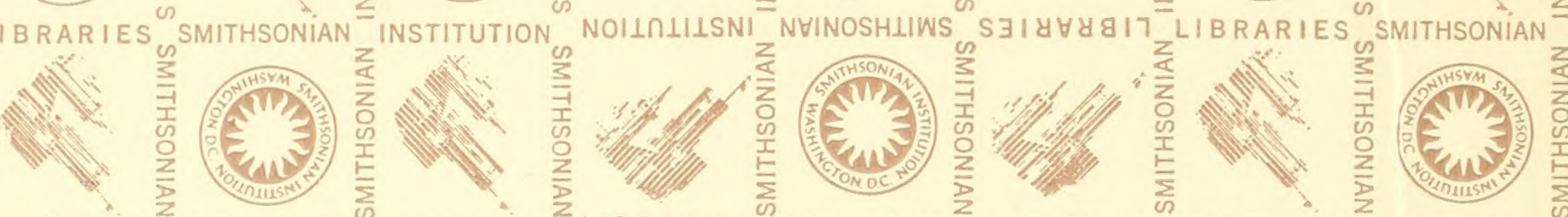

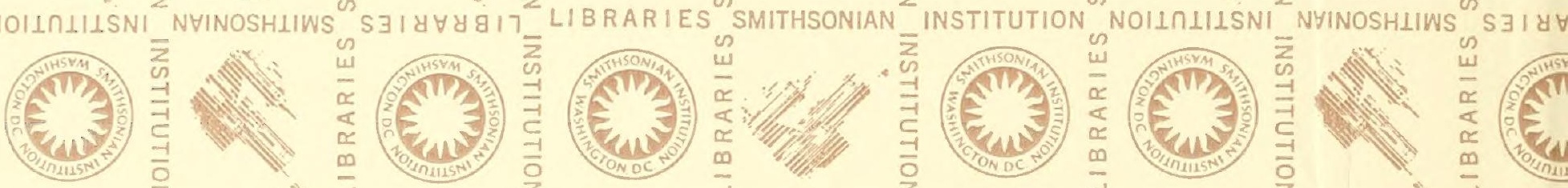

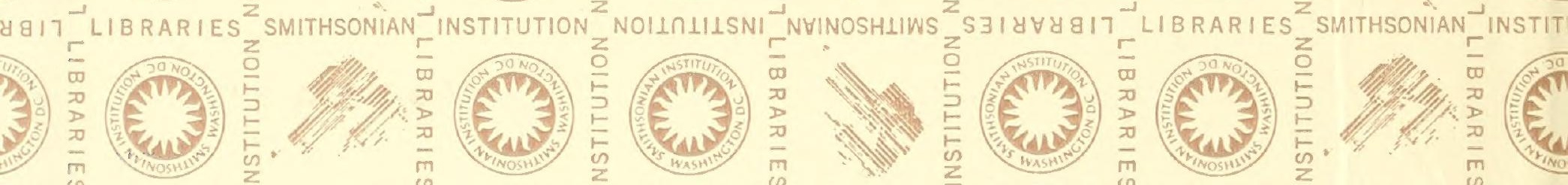

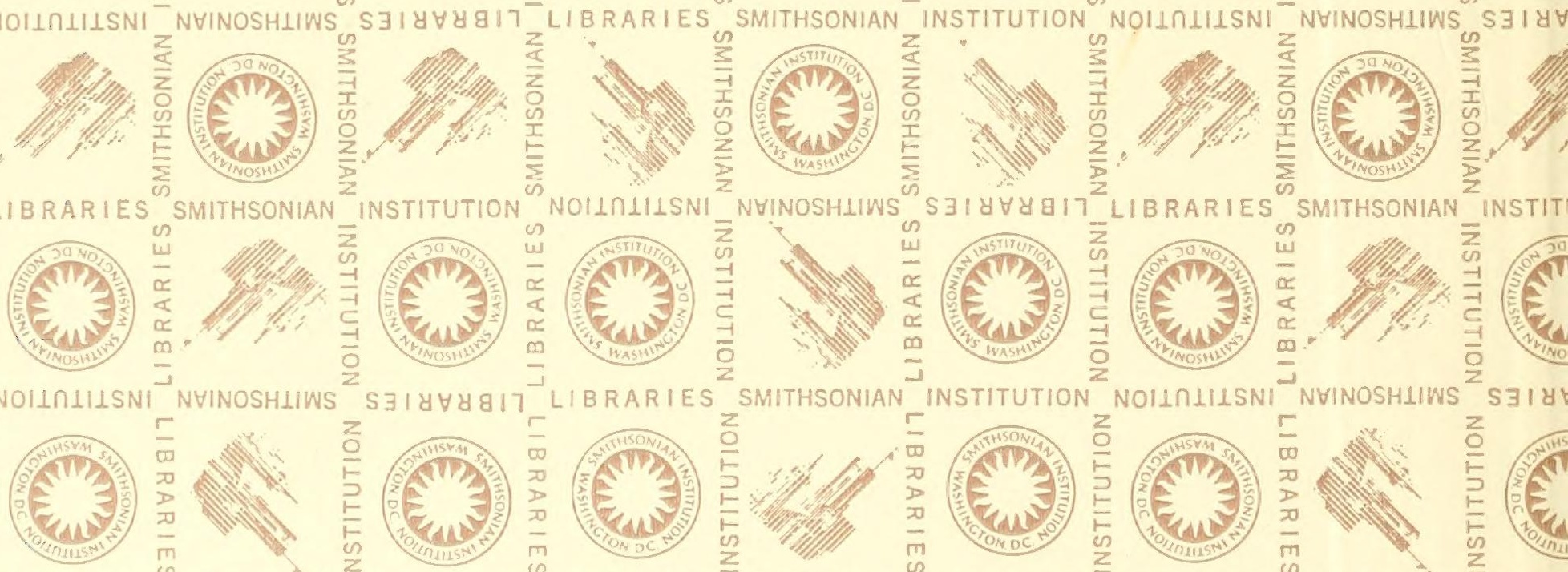

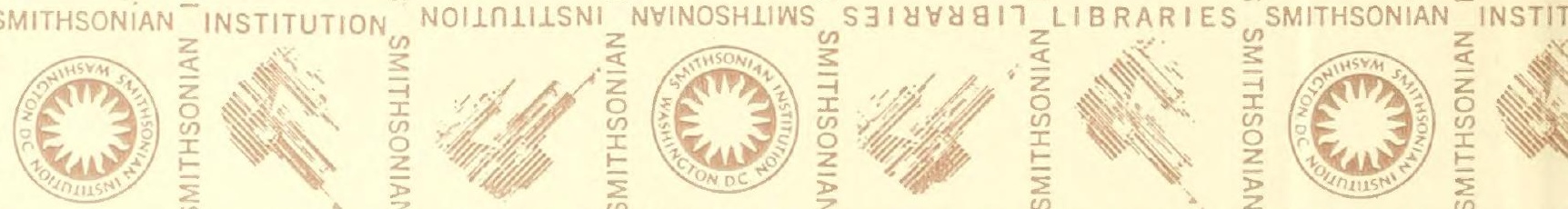
3.

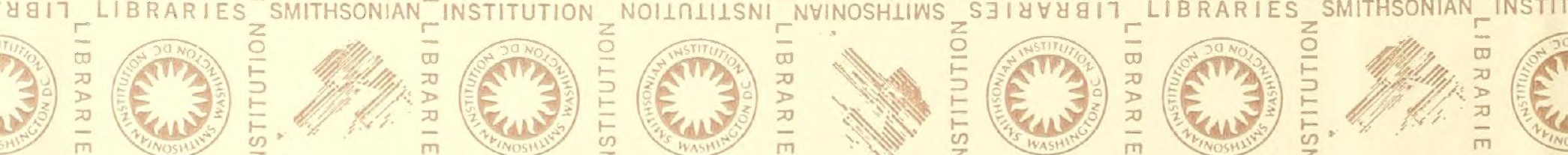

)
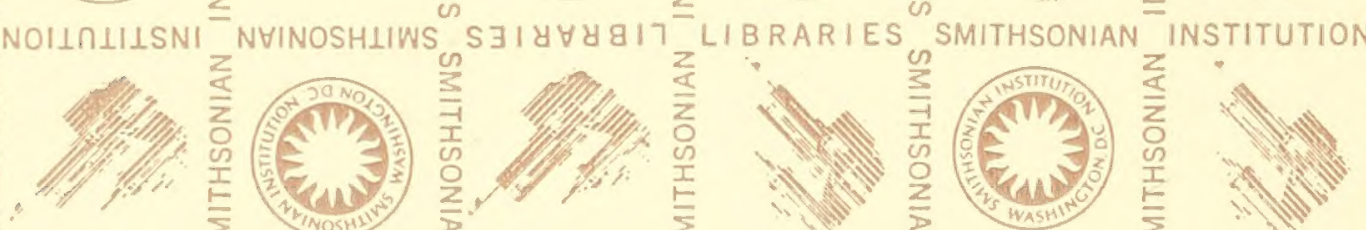

instrit
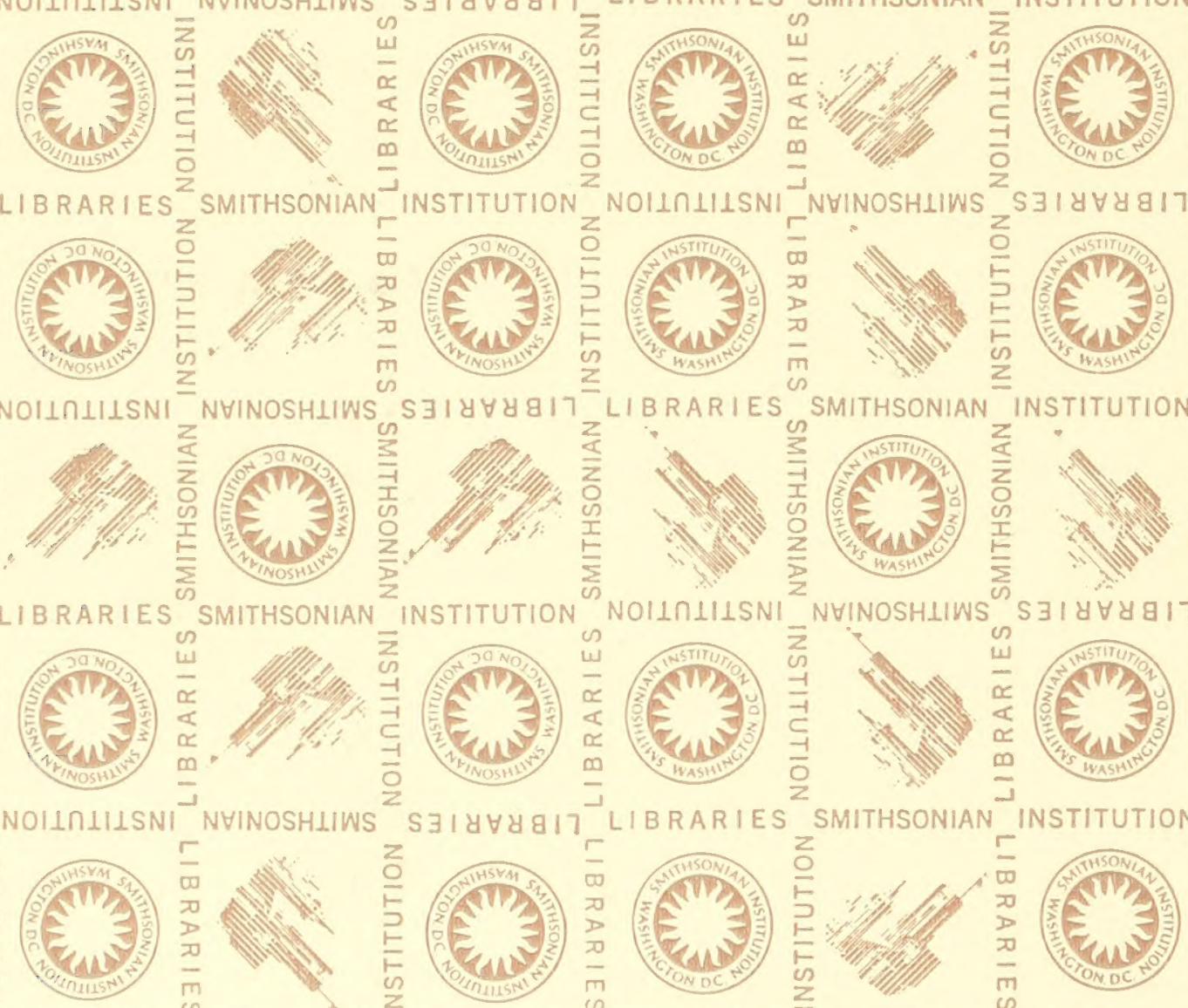

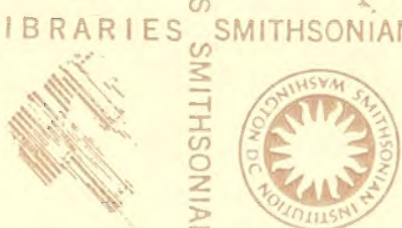
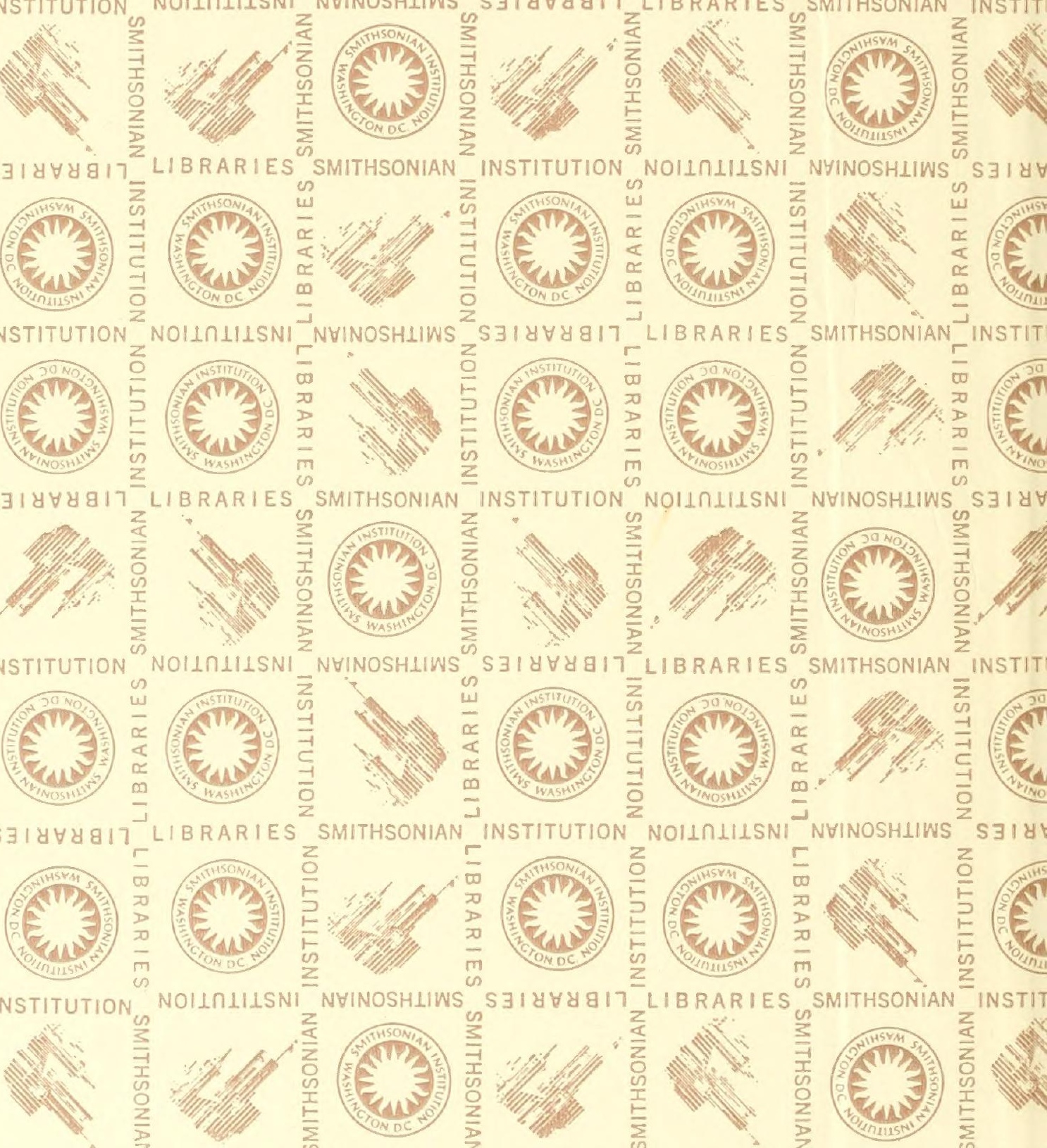




Die

\section{JAPANISCIIEN}

\section{SEEIGEL}

von

Dr. Ludwig Döderlein,

Direlstor des naturhistorischen Museums zu Strassburg i. Els., Privatdocent der Zoologie.

I. Theil.

Familie Cidaridae und Saleniidae.

Mit Tafel I-XI.

Stuttgart.

E. Schweizerbart'sche Verlagshandlung (E. Koch). 
K. Hof buchdruckerei Zu Guttenberg (Carl Grüninger) in Stuttgart 


\section{In halt.}

Familie Cidaridae.

I. Japanische Arten . . . . . . . . . . . . 3 Stereocidaris grandis Dö̀. . . . . . . . . . 3 sceptriferoides n. sp. . . . . . . 5 japonica Dö̀. . . . . . . . . 6

Dorocidaris Reini n. sp. : . . . . . . . 7

Porocidaris gracilis DöD. . . . . . . . . . 8

Goniocidaris biserialis Dön. . . . . . . . 10

, clypeata DöD........... . . 13

mikado DöD. . . 15

II. Recente Arten von nicht japanischer Herkunft . . 16

Dorocidaris canaliculata A. AG. . . . . . . 16

Eucidaris Thouarsii VAL, . . . . . . . 18

galapagensis $\mathrm{n}$. sp. . . . . . . 20

Leiocidaris verticillata LAM.

baculosa LAM. . . . . . . . 23

annulifera LAM. . . . . . . . . 24

imperialis LAM. . . . . . . . . 25

Goniocidaris tubaria LAM. . . . . . . . . 27

Charaktere jugendlicher Cidariden . . . . . . . . . . 27

Wachsthumserscheinungen an den einzelnen Theilen der Cida-

ridenschale

Das Apicalfeld

Das Interambulacralfeld . . . . . . . . . . . 28

Das Ambulacralfeld . . . . . . . . . 30

Das Buccalfeld . . . . . . . . . . . 31

Pedicellarien. . . . . . . . . . . . . . . 32

Primärstacheln . . . . . . . . . . . . . 34

Eintheilung der Cidaridae . . . . . . . . . . . . . 35

Gegenseitige Verbindung der die Schale zusammensetzen-

den Platten bei lebenden und fossilen Formen , , 35

Ambulacralfelder fossiler Cidariden aus der Trias von

St. Cassian
Seite

Kerbung der Hauptwarzen . . . . . . . . . 37

Übersicht der wichtigsten Gruppen von Cidaridae . . . 38

1. Eocidaris aus dem Zechstein . . . . . . . 39

Triassische Formen

2. Mitrocidaris . . . . . . . . . . 39

3. Triadocidaris . . . . . . . . . 39

4. Miocidaris. . . . . . . . . 40

5.

Cidaris-Reihe

6. Plegiocidaris . . . . . . . . . . . . . 40

7. Paracidaris . . . . . . . . . 40

8. Procidaris. . . . . . . . . . . . 41

9. Polycidaris . . . . . . . . . . . 41

10. Orthocidaris ............. . 41

11. Tylocidaris . . . . . . . . . . . 4

12. Dorocidaris . . . . . . . . . . 41

13. Stereocidaris . . . . . . . . . . . 42

14. Eucidaris . . . . . . . . . . . 4 42

Rhabdocidaris-Reihe

15. Rhabdocidaris s. str. . . . . . . . . . . 42

16. Diplocidaris . . . . . . . . . . . . . 43

17. Tetracidaris . . . . . . . . . . . . 43

18. Pleurocidaris. . . . . . . . . . . . . 43

19. Temnocidaris............. . . 43

20. Leiocidaris . . . . . . . . . . . . 43

21. Porocidaris .......... . . 44

22. Goniocidaris . . . . . . . . . . . . 44

Stammesgeschichte der Cidariden . . . . . . . . . 45

Schema der Verwandtschaftsverhältnisse der Cidaridengruppen 48

I. Tabellen zur Vergleichung der einzelnen Exemplare . . 49

II. Tabelle zur Vergleichung der verschiedenen Arten . . . 51

Familie Saleniidae 52

Salenia pacifica DöD. . . . . . . . . . . . 52

Erklärung der Tafeln .............. 53 



\section{Einleitung.}

Die vorliegende Abhandlung sollte nach meiner ursprünglichen Absicht ansschliesslich japanischen Formen von Seeigehn gewidmet sein, von denen mir ein sehr reichlhaltiges Material zur Verfïgung steht. Dasselbe stammt zum grüssten Theil aus den Sammlungen, die ich selbst in den Jahnen 1880 nnd 1881 an verschiedenen Orten der japanischen Küisten anlegte. Eine Übersicht über die dabei erhaltenen Seeigel ist bereits von mir veröftentlicht (Archiv für Naturgesch. Tol. 51 p. 73-112).

Durch das fremalliche Entgegenkommen der Herren Professor Dr. ros Martexs und Dr. Hilgexdorf in Berlin ist es mir möglich, die dem Berliner zoologischen Museum gehörige nicht mubedentende Sammlung ron Seeigeln, die Herr Dr. Hrtgexdorf von Japan zurückgebracht liatte, gleichfalls hier berücksichtigen zu kümen. Ebenso stellte mir Herr Professor Dr. Greefr in Marburg die von Herrn Professor Dr. Rery (Bomn) gesammelten japanischen Echinoidea aufs Zuvorkommendste zur' Verfügung.

Bei der Bearbeitung der Cidaridae, der ersten Familie, die ich vornalm, war ich ïberrascht durch den anffallenden Reichthum an Arten in jener Gegend, von wo bisher iiberhanpt noch kein Cidaride beschrieben worden war; nicht weniger als acht Arten sind den japanischen Küsten eigenthümlich und von mir zum ersten Iale beschrieben. Dieser merwartete Formenreichthum, die theilweise höchst auffallende änssere Gestalt md die grosse Wichtigkeit, die dieser Familie, der ältesten und alterthümlichsten unter den modernen Echinoidea, seit dem Ende der Triasperiode in allen marinen Famen zukommt, veranlassten mich, näher mich mit ihr zu befassen, als es zur blossen Beschreibung der gefundenen Arten nothwendig gewesen wäre.

Besonders fesselte mich eine der gesammelten Arten, Goniocidaris biscrialis, die in mehreren sehr ron einander verschiedenen Altersstadien vorlag. Es liessen sich daran eine Reihe höchst auffallender und charakteristischer Verändermgen der Schale nachweisen, die im Lanfe des Wachsthums allmählig eintreten. Es lag nalse, solche Entwicklungsreihen bei andern Arten von Cidariden zu Yergleichung heranzuziehen. Da aber gerarle ïber diesen Punkt die Literatur nur wenig bietet, nahm ich Anlass, das mir zugängliche Material an nicht japanischen Cidariden darauf hin zu untersuchen, mnd damit den Ralmen, den ich mir ursprünglich fü diese Abhandlung gesteckt hatte, zu überschreiten. Die Exemplare, die ich hiebei benutzte, entstammen zum grüssten Theile den Sammlungen des hiesigen natmhistorischen ILnseums. Einen seln werthrollen Beitrag dazu verdanke ich der Liberalität italienischer Gelehrten, die mir die anf der bekaunten Faln't der Kigl. italienischen Corvette ,Tettor Pisani“ von Herrn CHerchis gemachten Sammlungen von Echinoidea zm Rearbeitmo anvertrauten.

Ist das benutzte Material anch nicht sehr reichlich zu nemen, so schien es mir doch zu geniigen zur Feststellmg mancher Wachsthmmserscheinungen an den einzelnen Theilen der Cidaridenschale. Solche Wrachsthumserscheinungen beziehen sich anch auf eine Anzahl von morphologischen Charakteren, die in der systematik eine mehr oder minder hervorragende Rolle spielen, deren relative Wichtigkeit sich aber wesentlich nu bestimmen lässt ans ihrem Verhalten in verschiedenen Altersuständen. Die genanere Kemntniss ler verschiedenen postembryonalen Entwicklungszustände scheint mir für die Aufliärung der Terwandtschaftsverhältnisse innerlalb engerer Gruppen, wie Familien mol Gatungen, von derselhen Wiclitigkeit zu sein, wie die Kiemtniss des embryonalen Banes zur Anfteckung von Verwandtschaftsbeziehungen entfernten (irades.

Ein besonderes Angemmerk hatte ich auf die Pedicellarien gerichtet; während dieselben nun nuch meiner Erfahrung meist ganz vortreffliche Speciescharaktere abgeben, fand ich mich getailscht in iluer erhoften Verwendbarkeit zur Unterscheidmg natüricher Grupnen innerhalb der Fimilie. 
Zur' Aufklirung der Verwandtschaftsverhältnisse der nenen Arten war es nöthig, neben den recenten auch die tossilen formen zum Vergleich mit herbeizuziehen. Eine interessante Sammlung fossiler Cidariden fand ich im hiesigen geologisch-palïuntologischen Institut, deren Benutzung mir Herr Professor Dr. Benecke aufs Zuvorkommendste gestattete. Mit Hülfe dieses Materials und in Anlehmmg an die vorhandene Literatur labe ich versucht, eine neue Gruppirung der bekannten recenten und fossilen Cidariden rorzunehmen, sowie die Hauptziige der Stammesgeschichte festzustellen.

Als Hauptresultat der Untersuchungen an den fossilen Formen möchte ich ansehen 1) den Nachweis, dass die paläozoische Eocidaris Keyserlingi sich nicht von der Familie der Cidariden tremnen lässt; 2) die Entdeckung einer höchst bemerkenswerthen Struktureigenthümlichkeit bei den vorjurassischen Cidariden; 3) den Nachweis einer der charakteristischsten Gruppen cretacischer Cidariden in den jetzigen japanischen Meeren.

In dem hier vorliegenden ersten Theile der Abhandlung hat ansser der Familie der Cidaridae nur noch die der Salenidae Anfnahme gefunden; die übrigen Familien japanischer Seeigel sollen möglichst bald in einem zweiten Theile folgen.

Es ist mir eine angenehme Pflicht, den obengenannten Herren, die mich durch Zuwendung von Material so wesentlich unterstützten, meinen aufrichtigsten Dank auszusprechen.

Die beigefügten'l'abellen enthalten die wichtigsten Maasse, die den Schlussfolgermngen zu Grunde gelegt sind.

Die Abbildungen sind sämmtlich von mir mit der camera lucida aufgenommen und dann zum grössten Theile yon Herrn Scharfexberger genauer ausgefuilht worden, der mit der grüssten Unverdrossenheit sich die naturgetrene Darstellung der oft sehr schwierigen Objekte angelegen sein liess.

Strassburg i. E., im Juli 1887.

Der Verfasser. 


\title{
Familie Cidaridae.
}

\author{
I. Japanische Arten. \\ Cidaris (Stereocidaris) grandis DöD.
}

'Taf. I Fig. 1-6, 'T'af. II Fig'. 1-11, 'laf. VIII Fig. 2, a--m.

Dorocidaris grandis DöDERLEIN, 1885, Arch. f. Naturg. Bd. 51.

Die Schale (42-61 mm. Durchmesser) ist etwa $1 \frac{1}{2}$ mal so breit als hoch; die obere Hälfte mit dem Apicalfeld ist sehr stark gewölbt; anch um das Mnndfeld ist die Schale nicht eingesunken und dahel fast kugelfürmig. Die ganze Schale und besonders die Genital- und Ocellarplatten sind selnr dick.

I. A. F. ist $3 \frac{1}{2}-4 \frac{1}{4}$ mal so breit als $\mathrm{A}$. F.

Ambulacralfeld ist stark gewellt; an der Peripherie treften anf eine Coronalplatte 17-21 Ambulacralplatten. Die Porenfelder sind sehr vertieft, die Poren eines Paares einander ziemlich genähert und nicht gejocht, die einzelnen Paare durch sehr niedrige Leisten von einander getrennt. Die Breite des Mittelfeldes beträgt etwa die Hälfte von der des A. F. Das Mittelfeld ist dicht gepflastert mit Wärzchen, lie etwa 6 Längsreihen bilden, von denen die randständigen am grössten sind und sehr regelmässig stehen, währenı die immersten mit den kleinsten Wärzchen sehr unregelmässige Reihen bilden.

Im Interambulacralfelde bilden 6 odex 7 Coronalplatten eine Vertikalreilie, von denen die 1 oder 2 obersten auf einer ganz verkimmerten Hauptwarze keinen Stachel tragen. Die Hauptwarzen (an der Peripherie) sind klein und glatt, von einem kleinen, stark vertieften und kreisiunden Hofe umgeben. Der Scrobicularring besteht aus etwa 14 grossen flachen Sekundärwärzchen, denen sich nach aussen kleinere meist dentlich gehöfte Miliarwärzchen anschliessen, die ein dichtes Pflaster bilden und kam die Nähte frei lassen. Die Warzenhöfe sind sowohl ron einander wie von del Porenzone durch weite, von diesen Wärzchen bedeckte Zwischenräume getrennt; selı breit ist anch die mediane Miliarzone. Die obersten Coronalplatten besitzen nux eine ganz rudimentäe flache Hauptwarze mit winzigem Warzenlrof. Die Miliarwärzchen sind in meln olel' weniger dentliche meist horizontale Reihen angeordnet, die durch strichfömige Furchen getrennt sind, welche auf der einen Seite in die Nähte der Ambulacralplättchen, auf der anderen Seite in die entsprechenden Furchen rer benachbarten Coronalplatten verlaufen. Sämmtliche Coronalplatten sind stark gewölbt und fallen gegen die tiefliegenden Nihte ab. Am oberen Rande der Coronalplatten findet sich gem eine eigenthümliche narbenartige V'ertiefung.

Das kreisunde Buccalfeld zeigt etwas mehr als ein. Drittel des Schalendurchmessers.

Das A picalfeld ist etwa halb so breit als der Schalendurchmesser; davon kommt fast die Hälfte auf die Breite des Afterfeltes, das ein Fünfeck nit stark concaren Seiten darstellt; es zeigt einen äusseren Kreis von 10 grossen Afterplatten mit stark vergrösserten Winkelplatten; die imneren Afterplatten sind dagegen winzig; meist nur kömchenförmig. Die Genitalplatten sind fast ron der Grösse des Afterfeldes, schildförmig, kaum höher als breit. Sie stossen aneinander, erscheinen aber durch die mit der Spitze sich berihnenden After- und Ocellarplatten getrennt, da diese weit iber die Ränder der Genitalplatten übergreifen. Die Genitaloffnung liegt etwas näher der Mitte der Platte als dem Aussenrand und ist bei einigen (q) bedeutend grösser als bei anderen (ठ) Exemplaxen. Die Madreporenplatte ist nicht rergrössert. Die Ocellarplatten sind ron mässiger Grösse, herzfömig und etwa so hoch als breit. Das ganze Apicalfeld ist gleichtönuig dicht mit flachen Miliarwärzchen geptlastert, die nu die Jahtlinien fiei lassen; auch sie bilden Reilıen, getrennt durch melı oder weniger dentliche Furchen. 
Stacheln. Die den obersten blinden Platten folgenden Coronalplatten tragen die lingsten Primïrstacheln, die grüsser als der Schalendurchmesser, doch nicht $1 \frac{1}{2}$ mal so gross sind. Gegen das Buccalfeld nelmen sie dann rasclı an Lïnge ab. Die cylindrischen Primärstacheln tragen eine wechselnde Anzahl niedriger Längsleisten, die bald breiter bald schmailer auftreten und im unteren Theile des Stachels in Kürnchen aufgelöst sind. wilhrend sie im oleeren Theile oft sehr rortretende Lamellen bilden. Das obere Ende des Stachels kamn etwas rerbreitert und kelchförmig ansgehöhlt sein, ist mitmer abgeplattet, oder es ist einfach zngespitzt. Die kleineren Primärstacheln sind oft etwas kenlenfürmig, nahe dem Buccalfelde luäufig stark abgeplattet. Die Wärzchen der Scrobicularringe und diejenigen der mteren Schalenhälfte tragen Sekundärstacheln ron mässiger Länge. die als dicke prismatische Tienlen ausgebildet sind (Taf. II Fig. 9, b), während diejenigen der Olerseite sehr flach und breit sind, dabei oft kaum länger als breit, so dass sie das Aussehen ron winzigen Schupen haben (Taf. TIII Fig. 2, 1), die der ron Primärstacheln freien oberen Schalenlälfte ein eigenthümliches Anssehen geben. Die änsseren Sekundirstachehn des A. F. reichen mit der Spitze wenig über die Porenzone hinans.

Von Pedicellarien findet sich

1) eine grosse dickköpfige Form auf fist kugligem Stiel, die kraftige Zälme hat im oberen Theile der Kilappen (Taf. Tilf Fig. 2, a, d, e, k); solche stehen in nicht unbedentender Anzahl anf der ganzen oberen Schalenhïlfte.

2) Eine schlanke Form mit kleinem schwach bewattuetem Kü̈pfehen auf schlankem stiele ron etwa Kopflïnge (Fig. 2, b, f, g), die ïberall auf der Schale zerstrent ist.

3) Eine unbewaffnete Form. mit langem schlankem Kopfe und lijfelfürmigen Klappen auf dümem Stiele ron etwa Kopflänge ( $\mathrm{Fig}$. 2, c, i), die späirlich auf der mteren Schalenhälfte zu finden ist.

4) Eine grossköpfige unbewafthete Form mit banchiger, korbälnlicher centraler Kammer, die oben eine weite Öffnmg zeigt (Fï. 2, h); es gelang nur ein einziges Exemplar dieser eigenthiumlichen Form zu finden, die im Änsseren der ersten Form älmelt.

Diese Art ist von gelblichgraner Farbe, die trockene Schale ist lederbraun mit helleren Warzenhöfen, der Hals der Primbirstacheln mitunter röthlich.

Ein kleineres Exemplar ron $49 \mathrm{~mm}$. Schalendurchmesser unterscheidet sich von den beschriebenen Exemplaren durch folgende P'unkte:

Auf eine Coronalplatte an der Peripherie treften nur 13-14 Ambulacralplatten. Zwischen den beiden Reihen grosser randständiger Wärzchen des ambulacralen Mittelfeldes treten mu' 2 ziemlich regelmässige Reihen sehr viel kleinerer Wäzchen auf. Die Breite der interambulacralen Miliarzone ist betrïchtlich geringer und es sind entsprechend weniger Miliarwärzchen daselbst rorhanden. Die Breite des Afterfeldes beträgt weniger als die Hälfte ron der des Apicalfeldes; die Winkelplatten des Afterfeldes sind noch um ein gutes Stiick ron den Ocellarplatten entfernt: das Afterfeld ist daher auch äusserlich vollständig von den Genitalplatten eingeschlossen; die Ocellarplatten sind breiter als hoch.

Es wiirden daher beim weiteren Wachsthnm folgende Verändermngen an der Schale auftreten:

Die Zahl der Ambulacralplattchen wird grösser, ebenso die Zahl der das ambulacrale Mittelfeld bedeckenden Wärzchen. Die Miliarzone des I. A. F. wird beträchtlich breiter. Die Winkelplatten des Afterfeldes und die Ocellarplatten wachsen allmählig mit den einander zugekehrten Spitzen gegen eininder, bis sie sich berühren und die Genitalplatten wenigstens äusserlich von einander tremen.

Auf schlammigem Grunde der Sagamibai erhielt ich ans etwas über 100 Faden 'Tiefe zwei Exemplare dieser Art; zwei weitere von Herm Professor Rerx gesammelte Exemplare, die ans der gleichen Gegend stammen, rerdanke ich Herrn Professor GreffF in Marburg.

Die vorliegende Art stelıt in jeder Beziehung dem Typus der Gruppe Stcreociduris, der cretacischen O. cretosa Maxt., ausserordentlich nahe (vergl. Paléont. française, T'err. crét. Vol. VII. tab. 1067) und unterscheidet sich von dieser Art nur in nebensächlichen Eigenschaften; die Ähnlichkeit ist so anffallend, dass man bei oberflächlicherem Vergleich an eine Identität der Art denken kümnte; daron kann allerdings num nicht die Rede sein. Die recente Form hat eine kugeligere Schale, die Granulirmng ist dichter, die Zahl der Warzenreihen im A. F. ist etwas geringer, die Genitalplatten sind etwas höher, die Ocellarplatten etwas grösser als bei der Kreideform; das genïgt gerade fïr eine specifische Trennmg; die imnige Verwandtschaft dieser beiden Formen wird aber dnrch so geringfügige Unterschiede um so mehr erhärtet. C. grantis ist der lebende Reprisentant einer rorzinglich markirten Gruppe ron Cidariden, der Gruppe Stcreacidaris, die in der Kreidezeit entstand und dort ihren Höhepunkt erreichte; ror der Entleckung der hier besprochenen japanischen Formen war sie aus späteren Formationen noch nicht bekannt. C. grandis ist der grösste Cidaride. der aus den japanischen Meeren beschiehen ist. 


\section{Cidaris (Stereocidaris) sceptriferoides n. sp.}

'I'af. II Fig. 12-17, 'Taf. VIII Fig. 3, ^-е.

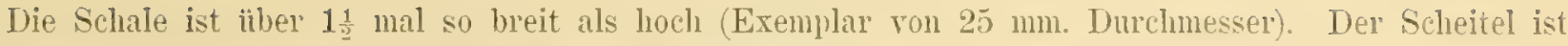
conrex; gegen das Mundfeld ist die Schale etwas eingesenkt.

I. A. F. ist $3 \frac{1}{2}$ mal so breit als A. F.

Ambulacralfeld ist gerrellt; auf eine Coronalplatte an her Peripherie treffen 12 Ambulacralplatten. Die Porenfelder sind etwas rertieft, die Poren eines Paares einander genähert und nicht gejocht, die einzelnen Paare durch niedrige Leisten ron einander getrennt. Die Breite des Mittelfeldes beträgt die Hälfte von der des A. F. Zwischen den randständigen Sekmdärwärzchen zeigen sich noch zwei Reilıen kleiner Miliarwärzchen auf dem Mittelfelde.

Im Interambulacralfelde bilden 5-6 Coronalplatten eine Vertikalreihe, von denen die obersten mur eine rudimentäe Hauptwarze tragen, die stachellos ist oder doch nur eine ganz verkïmmerte Anlage eines Primälstachels zeigt. Die Hauptwarze (an der Peripherie) ist klein mn glatt; der Trarzenhof ron mässiger Grüsse. nalızu kreisrund und stark vertieft. Die Trarzen des Scrobicularringes sind klein und nicht regelmässig; ansserhalb desselben zeigen sich gegen die Mittellinie zu noch etwa zwei Reilhen kleinerer Wärzchen, gegen die Porenzone nul eine Reihe und gegen den oberen Plattemrand eine oder zwei Reihen. Die Warzenhüfe sind vollstïndig ron einander getrennt. Die Nälıte, besonders die Mittelnaht, liegen vertieft nnd zeigen gern einen glatten Rand.

Das Buccalfeld el'eicht nicht ganz die Hälfte des Schalenturchmessers.

Kanm grösser ist das Apicalfeld, von dem das Afterfeld etwa die labbe Breite eimnimmt; letzteres bildet ein Fünfeck mit fast geraden Seiten; es zeigt einen äusseren Ring ron 10 mässig grossen Afterplatten. unter denen die Winkelplatten kaum vergrössert sind. Die immeren Afterplatten sind kleiner, zum Theil nur aus Körnchen bestehend. Die Genitalplatten sind riel kleiner als das Afterfeld, etwa so hoch als breit, und stossen seitlich an einander. das Afterfeld ron den Ocellarplatten tremnend. Die (kleine) Genitalöftinumg liegt im insseren Drittel der Platten; die Madreporemplatte ist etwas vergrössert. Die Ocellarplatten sind ziemlich klein, breiter als hocl. Das ganze Apicalfeld ist gleichmïssig ron zerstrent stelıenden Wärchen berleckt, die aber breite Ränder an đen grösseren Platten frei lassen. Die Nähte liegen tief.

Stacheln. Die obersten Coronalplatten tragen höchstens ganz rudimentäre Primärstacheln; die dann folgenden zeigen die längsten Stacheln, von doppeltem Schalendurchmesser und ron auffallender Dicke; gegen das Buccalfeld hin verkïryen sich die Primärstacheln sehr rasch. Die längsten Stacheln sind nahe der Basis verdickt und verjüngen sich gegen das Ende allmällig; das Ende selbst ist wieder etwas verbreitert und kelchfürmig ausgehühlt. Sie tragen etwa 10-12 grobgesägte Längsleisten. Die kleineren Primärstacheln zeigen kein verbreitertes Ende und viel weniger. Kanten; von den kleinsten sind einige ganz glatt und unbedentend abgeplattet.

Die Sekundårstacheln des Scrobicularringes sind kurz, breit und platt, das obere Ende abgestutzt; die iibrigen kleinen Stacheln sind fast stabförmig und besonders die der Oberseite sehr klein. Die ganze Stachelbedeckung ist auf der Apicalseite ziemlich spärlich.

Von Pedicellarien ist eine dickkönfige Form volhanden auf kurzem diunnem Stiele (Taf. VII Fig. 3, a, c), die in geringer Zahl auf die obere Schalenhälfte beschränkt ist. Eine zweite kleinere seln schlanke Form, die seln schrach bewaffnet ist, und deren dïmner Stiel die doppelte Kopflange erreichen kanm (Taf. TII Fig. 3, b, d, e), ist überaus zallreich besonders auf der unteren Schalenhälfte.

Die Farbe der Schale ist gelblichweiss, die der kleineren Stachehn rein weiss, während die grossen Primirstacheln hellgrau erscheinen mit rosenrothem Hals.

Das einzige mir rorliegende Exemplar dieser Art ron 25 mm. Durchmesser wurde ron Herrn Dr. HiLgendorf bei Japan gesammelt.

Der gewölbte Scheitel, die Neigung zur Terkimmerung der obersten Hauptwarzen, der runde und stark vertiefte Warzenhof, die tiefliegenden Nähte weisen anch dieser japanischen Art iluen Platz unter der Gruppe Stereocidaris an. Die grossen Primärstacheh erimen sehn an die von der cretacischen $C$. sceptrifera, die ron dieser Grupue ja anch kaum zu tremen ist. 


\section{Cidaris (Stereocidaris) japonica DöD.}

Thaf. III Fig. 1-20, 'Taf. VIII Figr. 1, a-ll.

Doracidaris, juponica DöDERLEIN 188a, Archiv f. Maturg. Bd. ōl.

Schale ist etwa doppelt so breit als hoch (bei Exemplaren mit einem Durchmesser von 14.5 -36 mm.). Der' Scheitel ist convex; gegen das MLundfeld ist die Schale stark eingesenkt. Die Schale ist dick, besonders dick sind die Genital- und Ocellarplatten; die Afterplatten greifen unbedentend über den Rand der Genitalplatten.

I. A. F. ist über 3 mal bis fast 4 mal so breit als $A$. F.

Ambulacralfeld ist ganz mbedentend gewellt; auf eine Coronalplatte an der Peripherie treften 8-9 Ambulacralplatten. Die Porenfelder sint wenig vertieft, die Poren eines Paares einander genähert mud nicht gejocht, die einzelnen Paare durch niedrige Leisten von einander getremt. Die Breite des Mittelfeldes beträgt etwa die Hälfte von der des A. F. Zwischen den randständigen Sekundärwärzchen des Mittelfeldes finden sich schon beim kleinsten Exemplare zwei Vertikalreihen ziemlich grosser Miliarwärzchen, imnerhalb deren bei grösseren Exemplaren sich noch zwei weitere Reihen entwickeln kümnen. Horizontahreihen von winzigen Körnchen trennen je zwei der Sekundärärzchen von einander.

Im Interambulacralfelde stehen 6-8 Coronalplatten in einer Vertikalreihe, von denen 1 oder 2 oder bei grösseren Exemplaren gar die 3 obersten nur eine verkümmerte Hanptwarze olme Stachel tragen. Die Hanptwarzen (an dler Peripherie) sind sehr klein, glatt, auf vortretender Basis, der Warzenlof sehr gross, oval und stark rertieft; die Warzenhüfe eines Meridians sind durch eine schmale Brücke getrennt, die nie ganz verschwindet. Der Scrobicularring tritt nicht auffallend hervor. Das mediane Miliarfeld ist bei den kleineren Exemplaren schmal und lässt etwa eine Reihe ron Miliarwärzchen jederseits anftreten; etwas breiter ist es bei grösseren Exemplaren, die jeclerseits zwei, selten meln' Tertikahreihen von Miliarwärzchen zeigen, welche anch in Horizontalreilen angeordnet sind, die durch F゙urchen getremnt werden. Die den Scrobicularwärzchen nächsten Miliarwärzchen sind nicht riel kleiner als jene selbst. Der Scrobicularring grenzt bei kleineren Exemplaren direkt an die Porenzone, bei grösseren entwickelt sich 1, selten 2 Reihen von Miliarwïrzchen dazwischen. Die blinden Coronalplatten zeigen eine ganz rndimentäre Warze mit einem winzigen flachen Warzenhof und sind im ribrigen von nicht sehr dicht stehenden Miliarwärzchen bedeckt, die besonders bei grösseren ExemHaren dentliche durch merkliche Furehen getrennte Horizontalreihen bilden. Die Mittelnaht des I. A. F. ist sehr tief eingeschnitten, bei grösseren Exemplaren manchmal fast furchenfürmig und oft von einem glatten Rande begrenzt.

Das Apicalfeld ist kleiner als die Hälfte des Schalendurchmessers; davon nimmet das Afterfeld weniger als die Hälfte ein, bei grösseren Exemplaren fast mu ein Drittel. Das Afterfeld ist fünfeckig mit leicht concaven Seiten; es zeigt einen änsseren Kreis von 9 bis höchstens 11 Platten, unter denen die Winkelplatten mberlentend vergrössert sind. Ein innerer Plattenkreis kommt nur unvollständig zur Entwicklung, die Platten sind zum Theil auf blosse Kalkkörnchen reducirt, wie solche anch den After momgen.

Die Genitalplatten sind bei jüngeren Exemplaren etwas kleiner, bei älteren etwas grösser als das Afterfeld, etwa so breit als hoch, schildförmig und stossen mit breiten Seiten an einander, das Afterfeld stets Weit von den Ocellarplatten trennend. Die Genitalüfnumg liegt nahe dem Anssenrande; ist sie gross (q), so ist ilne Entfernung davon kleiner als ihr Durchmesser, ist sie klein (d), so erscheint sie weiter entfernt, ohne je der Mitte der Platte sich zu nähern. Die Madreporemplatte ist haum rergrössert. Die kleinen Ocellarflatten sind herzförmig und riel breiter als hoch.

Das Apicalfeld ist ziemlich gleichmissig bedeckt von zerstreut stehenten Milinwälzchen, die nur den Rand der grösseren P'latten frei lassen. Die Nähte sind selı dentlich, bei den kleineren Exemplaren, wozn crerade die stücke ron Tango gehören, sehr tiefliegend, so dass die grösseren Platten sellust stark convex erscheinen mu an den Winkeln sich förmliche Gruben bilden. Bei den grösseren Exemplaren sind die Platten melu aben, die Tähte nicht anfillend eingeschitten.

Ein Exemplar ans der Sagamibai zeigt ein abnorm ansgebildetes Apicalfeld (Taf. III Fig. 12); die Zahl der Genitalplatten beträgt hier nur drei, jede mit einer einzigen grossen Genitalüfinung. Zwei dieser' Platten sind anfallend breit und entsprechen offenbar je zwei normalen Genitalplatten; die Genitalöthinung berithrt bei ilmen den Rand. Die dritte kleinere ist die einfach gebliebene Iadreporenplatte, die ziemlich normal ansgetbildet ist. Die Ocellarplatten sind dagegen in der Fünfzahl vorhanden, die eine der Madreporenplatte gegeniberliegencle ist mgewöhnlich gross, die beiden an die Madreporenplatte grenzenden ron normaler Grösse und die den Doppel-Genitalplatten entonrechenden winzig klein. Das Afterfeld bildet ein gleichseitiges Dreieck mit 11 änsseren Afterplatten; es grenzt an die drei grüsseren Ocellarplatten. Die übrigen Verhälnisse sind die gewöhnlicher Exemplare. 
Stacheln. Im I. A. F. tragen die obersten Coromalplatten keine Primärstacheln. Die darauffolgenten Platten besitzen die längsten Stacheh, die stets länger, aber nie doppelt so lang sind als der Schalenuluchmesser. Die Länge del Primärstacheln nimmt dann gegen das Buccalfeld hin sehr rasch ab. Die grüssten Stacheln sind cylindrisch, ine Obertliche zeigt etwa 10-12 selm niedrige meist ganz in feine Könchen aufgelüste Längsleisten. Bei den von Tango stammenden Exemplaren sind diese Stacheln durchgängig kiurzer und gegen das Ende zu stark verjungt. Ist das Ende selbst niclit abgerieben, so läuft es in mehrere Zacken aus. die bei den Exemplaren von Tango einen etwas verbreiterten Kelch bilden. Die kïrzeren Primärstacheln sind oft drei- oder zweikantig; die dem Buccalfelde benachbarten sind mu selten noch cylindrisch und damn etwas gebogen; meist sind sie aber abgeplattet, die kleinsten spatelfürmig verbreitert und glatt, eine zweischneidige Kilinge billend mit gesiigten Seitenrändern, das Ende oft g'ebogen.

Die Sehundarstachelin sind platt und breit, das Ende abgestutzt, aber etwas schmäler als die Mitte; die des A. F. sind fast linealisch und reichen mit der Spitze nur wenig über die Porenzone hinaus.

Die F arbe der Schale und der Stacheln ist gelblichgrau.

Von Pedicellarien fand sich eine grosse dickköpfige Form mit ziemlich kräftigen Zähnen auf kurzem Stiele (Taf. VIII Fig. 1, b, (l, g), die anf der oberen Hälfte der Schale zerstreut an den Nähten sich findet; eine kleine schlanke Form mit schwachen Zähnchen (Fig. 1, c, e, f) komnt in verschiedener Grösse vor auf kiirzeren orler längeren Stielen, überall auf der Oberfläche der Schale.

In der Sagamibai erhielt ich diese Art in 100-160' Faden 'Tiefe, an der Küste von 'Tango in ca. 40 Faden, in beiden Fällen von schlammigem Grunde. Nach der Zahl der auf eimmal erhaltenen Exemplare zu schliessen lebt die Art daselbst herdenweise.

Wachsthumserscheinungen. Mit zunelmender Grösse (von 14.5-36 mm.) lassen sich an der Schale folgende Veränderungen constatiren: die Zahl der Coronalplatten nimmt sehn langsam zu und zwar sind zuletzt die neu hinzukommenden Platten ohne Primärstacheln. Die Zahl der Miliarwärzchen des A. F. wächst wenig. Die mediane Miliarzone des I. A. F. wird allmählig breiter und lässt mehr Miliarwärzchen zu, zwischen denen Horizontalfuchen dentlich werden. Zwischen dem Scrobicularring und der Porenzone entwickeln sich Miliarwärzchen. Das Buccalfeld wird verhälnissmässig kleiner. Das Afterfeld nimmt an der Grössenzunahme des Apicalfeldes wenig Antheil, so dass auch die Zahl der Afterplatten kaum wächst und dagegen die Höhe der' Genitalplatten rerhältnissmässig bedentend wird. Die Apicalplatten werden flacher mol die Nähte weniger' tief liegend.

Anch diese Art.muss zu der in der Kreide reich vertretenen Gruppe Stereocidaris gestellt werden, der anch die beiden vorher beschriebenen Arten angehöen. Die eigenthümlichen verkümmerten Hauptwarzen auf der Oberseite der dicken Schale, das gewölbte Apicalfeld, sowie die tiefliegenden ITarzenhöfe mit dem kleinen Warzenkopfe, anch die vertieften Nähte und das kleine Afterfeld weisen sie dahin. Etwas fremdartig für diese Gruppe sind höchsteus die grossen oralen Warzenhöfe. Die Primảrstacheln und die Pedicellarien erinnern an Dorocidaris papillata.

Sehr auffallend sind bei dieser Art die kleinen platten zweischmeidigen Primärstacheln in der Nähe des Buccalfeldes, deren Rand gezähnt und deren Ende mitunter gebogen ist, die also einigermassen an die so charakteristischen Porocidaris-Stachehn eximnern. Doch dürfte eine nähere Verwandtschaft mit dieser Gruppe kaum vorhanden sein. wenn eine solche Ansicht auch nicht absolut zurichanweisen wäle.

\section{Cidaris (Dorocidaris) Reini n. sp.}

\section{Taf. IT Fig. 1-7, Taf. TIII Fig. 4, a-d.}

Die Schale ist fast doppelt so breit als hoch, an beiden Polen stark abgeflacht (Durchmesser ron 34 mm.). I. A. $\mathrm{F}$. ist viermal so breit als das $\mathrm{A}$. $\mathrm{F}$.

Ambulacralfeld ist nahezu gerade; auf eine Coronalplatte an der Peripherie treften 12 Ambulacralplatten. Das Porenfelr ist etwas rextieft; die Poren sind klein, die eines Paares ziemlich entfernt ron einander, so dass der Zwischenram zwischen ihnen doppelt so gross ist als eine Porenüthumg; sie sind aber nicht gejocht; die Leisten zwischen den einzelnen Paaren sind undentlich, so dass die ganze Porenzone als fast ebene Fläche erscheint. Die Breite des Mittelfeldes beträigt die Hälfte von der des A. F'; dasselbe trägt jederseits eine randständige Reihe von Sekundärwarzen, denen sich eine innere Reihe sehr viel kleinerer Wärzchen in etwa der doppelten Zahl dicht anscliliesst; das innerste Drittel des Mittelfeldes ist nackt mit sehr dentlicher Mittelnaht. 
Im Interambulacralfelde bilden 6 Coronalplatten eine Vertikalreihe, von denen auch die obersten dentliche Anlagen von Primärstachehn zeigen. Die Hauptwarze (an der Peripherie) ist ron mässiger Grösse mit ghatter' wenig erhobener Basis, der Warzenhof nahezu kreisumd und etwas vertieft. Der Scrobicularring ist mulentich und besteht aus kleinen Wirzchen, die kaum grösser sind als die uibrigen die Coronalplatte ziemlich dicht bedeckenden Miliarwir\%chen; solche bilden etwa zwei unregelmässige Reihen sowohl gegen die Mittelnaht, wie gegen die Porenzone hin. Die Warzenhöfe sind wenigstens an der Peripherie weit ron einandel' getrennt durch die rollständigen Scrobicularringe. Die Horizontalnälıte sind wenig dentlich; die Nittelnaht bildet aber eine etwas vertieft liegende schmale nackte Furche.

Die Breite des Buccalfeldes erreicht etwa $\frac{2}{5}$ des Schalendurchmessers.

Das Apicalfeld ist ebenfalls grösser als der halbe Schalendurclmesser und davon nimmt das Afterfell die Hälfte ein. Dasselbe ist fünfeckig mit etwas concaven Seiten; es zeigt einen äusseren Kreis von 12 grösseren Afterplatten, die durch einen inneren Kireis von etwa ebensoviel kleineren Platten von den den After begrenzenden Kürnchen getrennt sind. Die Genitalplatten sind ungefähr halb so gross als das Afterfeld, viel breiter als hoch und stossen in einem sehr vertieft liegenden Punkte zusammen, in dem sich anch die spitzen Winkelplatten des Afterfeldes mit den Ocellarplatten fast berühren. Die kleine Genitalöthumg ist durch eine Reihe von Miliarwärzchen rom nahen Aussenrande der Platte getremnt. Die Madreporenplatte ist nicht vergrössert. Die Ocellarplatten sind fast dreieckig, viel breiter als hoch; die Nähte zwischen ilmen mrd den Genitalplatten sind tief eingesclnitten und ganz gerade.

Die das Apicalfeld bedeckenden Wärchien sind klein, aber vorspringend, in der Mitte der Genitalplatten winzig, ziemlich gleichmässig zerstreut, lassen aber die Ründer der grösseren Platten frei. Am äusseren Rande rex Genitalplatten bilden sie eine regelmässige Reihe.

Stacheln. Die beiden obersten Primärstacheln jeder Reihe sind am längsten, länger als der Schalendurchmesser; die unteren nehmen rasch an Lünge ab. Die grösseren sind stabförmig von zahlreichen fein gesïgten Längsleisten bedeckt und verjüngen sich gegen das Eude; älnlich sind die kleineren, doch mit plötzlich abgestutztem Ende und fast ganzrandigen Längsleisten. Die klemen stachelchen sind platt, verhältnissmässig lang mol schmal mol gegen das Ende etwas rerjüngt. Die randständigen Stachelchen des A. F. ragen mit der Spitze weit ïber das Porenfeld hinans.

Von Pedicellarien finctet sich eine dickköpfige Form, bei der der oberste Theil der Klappen mit stark gezähntem Rande schnazenähnlich vorragt; sie stehen auf langem schlankem Stiele, der dreimal so lang als das Küpfchen werden kann, und der am oberen Theile einen kurzen Dornenkragen trägt (T'af. VIII Fig. 4, a, c); diese Form findet sich in ziemlicher Anzahl an den Nähten des I. A. F. und des Ap. F., die meisten auf der oheren schalenläilfte.

Eine andere Form mit langen schlanken schwachbezülnten Köpfehen, auf dümnem Stiel, der dreifache Kopflïnge erreichen kam (Fig. t, b, d), findet sich überall, häufig aber nur zwischen den Stacheln der Coronalplatten.

Die Farbe der Schale und der kleineren Stacheln ist ledergelb, die nackten Mittellinien etwas dunkler; die grossen Primärstacheln haben einen grauen Schaft, auf dem etwa 6 mdeutliche Querbänder zu erkemnen sind (auf der Abbildung nicht angerleutet).

Das einzige mir vorliegende Exemplar dieser Art von 34 mm. Schalendurchmesser wurde von Herm Professor Rerx in Enoshima an der Sagamibai elworben und wurde mir von Herru Professor Greeff gïtigst mitgetheilt.

Doruciduris Reine lat in ihrem ganzen Habitus die grösste Ähnlichkeit mit D. papillatu und conaliculut, welchen Arten sie sich auch bei genanerer Vergleichung seln nähert. Die nackte mu etwas vertiefte Mittellinie, besonters des I. A. F., erinnert ansserordentlich an ein ähnliches eigenthimliches Vorkommen bei D. conaliculatu und riickt dadnrch letztere Form den typischen Dorocidaris-Formen näher.

Etwas auffallend ist nur die Beschatfenheit der Porenzone, besonders die bedentende Entfernung der beiden Poren eines Paares ron einander; anch die langen Stiele und die Klappenform der dickküpfigen Pedicellarien finden sich sonst nicht in der Dorocidaris-Gruppe; ähnliche Pedicellarien sind dagegen in der Eucidurisnnd Leiocidaris-Gruppe bekant. Trotzdem diufte diese Art einstweilen noch der Gruppe Dorociduris zugewieven hleiben.

\section{Porocidaris gracilis DöD.}

'Taf. IV Fig. 8-20, 'T'af' VIII Fig. 5, a-e.

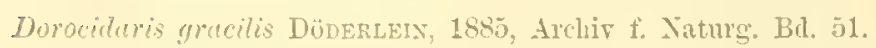

Die kleine schale ist $13 \mathrm{mal}$ so breit als hoch $(7.5-8.5 \mathrm{~mm}$. Sclralendurchmesser) und ist an beiden Polen stark abgeplattet.

I. A. F. ist fast dreimal so hreit als das A. F. 
Ambulacralfeld ist gerade; auf eine Coronalplatte an der Peripherie treffen mu drei Ambulacralplatten. Die Porenfelder sind nicht rertieft, die Poren eines Pares einander seln genảhert und nicht gejocht, die einzelnen Pare sehr schief gestellt und durch dicke Leisten weit von einander getremnt. Das Littelfeld, das etwa zwei Drittel der ganzen Breite des A. F. eimnimnt, zeigt jerlerseits ene randständige Reihe von stark vorspringenden Wärzchen, die sich in die die Porenpare trennenden Leisten fortsetzen; zwischen ihnen bleibt ein glatter, merklich vertiefter Streifen übrig, in deren Tiefe die Mittelnaht verläuft.

Im Interambulacralfeld bilden 6 Coronalplatten eine Vertikalieihe, die sämmtlich Primärstacheln tragen. Die Hauptwarzen sind gross und glatt und springen mit ilurer Basis stark über das Niveau der Schale vor; die elliptischen Warzenhöfe liegen im Niveau der Schale und fliessen fast in ihrer vollen Breite mit den benachbarten Höfen desselben Meridians zusammen; die Scrobicularringe sind beschränkt anf etwa drei Wärzchen, die jeden Warzenhof anf del einen Seite von der Mittellinie, anf der andern von der Porenzone trennen, und die in jedem I. A. F. vier etwas gewellte Vertikallinien bilden, von denen je zwei oberhalb des obersten Warzenhofes jedes Meridians sich in einem Kreisbogen vereinigen. Weitere Wärzchen sind nicht vorhanden anf einer Coromalplatte. Der mittlere Theil des I. A. F. ist nackt und stellt eine glatte ziemlich seichte Furche dar, in deren Grunde die Mittelnaht liegt, welche merkliche Gruben an den Winkeln billet.

Die Breite des Buccalfeldes beträgt mehr als die Hälfte des Schalendurchmessers.

Das Apicalfeld ist nur um $\frac{1}{3}$ weniger breit als der Durchmesser der Schale und davon kommt viel weniger als die Hälfte auf das Afterfeld. Dasselbe zeigt einen äusseren Ring von 8 oder 9 grossen Analplatten, die imeren Analplatten sind wimzig: Die Genitalplatten sind so gross orler grösser als das Afterfeld, polygonal und wenigstens so breit als hoch; sie stossen an einander und trennen das Afterfeld weit von den Ocellarplatten. Die sehr kleine (ठ) oder sehr grosse (q) Genitalüfnung liegt ziemlich genan in der Mitte der Platten. Die Madreporenplatte (nur bei einem Exemplare erkannt) besitzt nur wenige Löcher und ist bedeutend vergrössert. Die Ocellarplatten sind klein, viel breiter als hoch.

Das Apicalfeld ist sehr spärlich mit verschieden grossen Wärzchen versehen, die nul zunächst del Afteröffumg etwas dichter stehen.

Stacheln. Die oberen Primärstacheln sind selur schlank und nahezu dreimal so lang als der Schalendurchmesser; die unteren menden rasch kiuzer. Die grossen Stacheln sind über dem Halse stark angeschtrollen mud hier abgeplattet; ron da verjüngen sie sich allmählig bis zum Ende; sie sind kaum merklich längsgerieft mnd tragen jederseits eine Reihe Zähne oder Dornen, ron ilenen die untersten fast die Länge des Stacheldurchmessers haben, die oberen bis zum Ende seln kurz sind; diese Dornen sind umgeben und längs jeder Reihe mit einander verbunden durch einen dichten Filz von feinen Nadeln, die vielfach mit einander anastomosiren. Nahe dem Bủccalfelde finden sich plattgedrïckte, manchmal leicht gebogene Primärstacheln, deren beide Ränder grob gesägt sind.

Die kleinen Stachelchen bilden schlanke, aber mit Ausnahme der des Apicalfeldes verhältnissmässig lange Stäbchen (Taf. VIII Fig. 5̃, d).

Von.Pedicellarien findet sich in geringer Anzahl mu eine kleine schwach bewaffnete Form auf schlankem Stiele mit verhältnissmässig breitem Kopfe (Taf. VIII Fig. 5, a-c).

Die Farbe der Schale ist ein lichtes Violett, die Warzen und die Stacheln sind rein weiss.

Nur zwei Exemplare (ron 7.5 und 8.5 mm. Durchmesser') erlikelt ich in del Sagamibai aus 160 mul 200 Fadell 'Tliefe.

Die vorliegende Art besitzt eine grosse Anzahl von Charakteren, die als Gemeingut aller jugendlichen Cidariden zu betrachten sind. Vor allem gehüren dahin die Charaktere des A. F., die dicken vorspringenten Hauptwarzen und nicht vertieften Warzenhöfe, die sehr geringe Anzahl von kleinen Wärzchen und deren Vertheilung. Nimmt man dazu noch die winzige Grösse der Schale, so wird es zunächst sehr fraglich scheinen, ob wir es hier mit annähernd erwachsenen Individuen zu thun haben. Es sind nun wesentlich zwei Punkte, die für eine solche Annalme sprechen, nämlich die Anzahl von 6 ausgebildeten Coronalplatten in einer Reilıe, die auffallend gross sein wïde für ein selı jugendliches Individum, und sodann das Torhandensein ron wohlausgebildeten $\delta$ und o Genitalöftnumgen; dies macht es einigermassen walnscheinlich, wenu auch nicht sicher, dass diese Art nicht viel grösser wird, als die vorliegenden Individuen sind. Dazu kommt, dass die Annahme vollständig ansgeschlossen ist, dass es sich hier um Jugendformen einer del ibrigen sieben von Japan bekannt gewordenen Cidariden handle.

Die elliptischen zusammentliessenden Warzenhöfe mu die charakteristische Gestalt der kleineren Primäl'stacheln bestimmten mich hauptsächlich, dieser Art ilu'e Stellung in der Gruppe Porocidaris anzumeisen, welche ja schon neben Formen mit gekerbten Warzen solche mit ungekerbten unfasst; ich finde sodann keinen Chalakter, der gegen diese Zuweisung spräche. Das Apicalfeld erimelt einigermassen an Porocidaris clegans (s. Ac.sssiz, Rep. Chall.-Exp. Ech. tab. 3 fig. 4). Diese Alt ist weitans die kleinste unter den bekannten recenten Cidariden. 


\title{
Goniocidaris biserialis DOD.
}

\author{
Taf. Y Fig. 1-27, Taf. Vill Fig. 8, a-h.
}

Stephanociduris biserialis DöDERLEIN, 1885, Archir f. Naturg. Bd. 51.

A. Exemplare ron 30-34 mm. Schalendurchesser (Exemplare a, b, c der Tabelle). 'I'af. V Fig. 9-14 und 19-27.

Schale ist nicht ganz doppelt so breit als hoch, an beiden Polen vollkommen Hach, sonst gleichmässig gerundet. Die Schale ist düm, besonders düm sind die Platten des Apicalfeldes, das sehr biegsam ist in Folge dessen.

I. A. F. ist $3-3 \frac{1}{4}$ mal so breit als das A. F'.

Ambulacralfeld ist kaum gervellt; auf eine Coronalplatte an der Peripherie treffen 9, löchstens 10 Ambulacralplatten. Die Porenfelder sind nicht vertieft; die Poren sind gross, die eines Paares einander sehr genähert, die einzelnen Paare nahe bei einander durch vorspringende Leisten getremnt. Die Breite des Mittelfeldes betrïgt etwa die Hälfte von der des A. F.; es trägt jederseits eine randständige Reihe grosser flacher Sekundärwarzen mit dentlichem Hofe. Zwischen diesen Reilıen stehen zahlreiche winzige Kï̈nchen, die so angeordnet sind, dass je 4-5 derselben eine Horizontalreihe bilden und diese Reihen dann meist paarweise auf einem Ambulacralplättchen stehen. Zunächst der Mittellinie zeigt jede Horizontalnaht eine scharfe strichfürmige Gribe.

Im Interambulacralfelde bilden 7, höchstens 8 Coromalplatten eine Vertikalreihe. Die Hauptwarze ist klein mo glatt, von einem etwas vertieften. an der Peripherie fast kreisrunden Hofe umgeben, der etwas meln der Porenzone als der Hittelnaht genähert ist. Der Scrobicularing besteht ans 13-15 grossen, flachen, breitgehöften Wäzchen; die Scrobicularwärzchen zweier. benachbarter Höfe berühren sich gerade. Das ziemlich breite mittlere Miliarfeld ist mit winzigen Kömchen bedeckt, die zu 6-10 jederseits der Mittellinie dentliche Horizontalreilen durch die ganze Breite des Miliarfeldes bilden, welche gewöhnlich paarweise durch feine Horizontalfurchen von einander getremnt sind. Gegen die Porenzone zu finden sich eine oder zwei Vertikalreihen kleinerer Wärzchen, ebenfalls durch Horizontalfurchen getremnt, die den Nähten der Ambulacralplatten entsprechen. Die Mittelnaht ist dentlich, aber kamm vertieft, die Horizontalnähte lanfen an beiden Enden in scharfe tiefe Furchen ans, die am medianen Ende anffallender sind als an andern.

Die Breite des Buccalfeldes beträgt etwas melr als den dritten Theil des schalendurchmessers.

Das Apicalfeld ist etwa halb so breit als der Durchmesser der Schale und daron kommt die Hällte auf das Afterfeld. Dasselbe ist fïnfeckig mit stark concaven Seiten; es zeigt einen äusseren Ring: ron 15-16 kleinen Afterplatten, von denen die Winkelplatten sehr beträchtlich in radialer Richtumg verlängert sind und sich weit zwischen die Genitalplatten einschieben, so dass sie an die Ocellarplatten mit einer schmalen Seite stossen. Etwa zwei weitere Ringe von immer kleiner werdenden Afterplatten lassen sich exkennen, ron denen die imnersten durch kleine Kürnchen von der Afteröthming getrennt sind. Die Genitalplatten sind sehr viel kleiner als das Afterfeld, polygonal und etwa so breit als hoch. Die mässig kleinen (ठ) oder grossen (q) Genitalöfnungen liegen nalıezu in der Mitte der Platten. Die Madreporemplatte ist kaum vergrüssert. Die Ocellarplatten sind von mässiger (irösse, breiter als hoch. Bie Platten des Genitalringes sind in ihrer Mitte mit zienlich kleinen Wärzchen gleichmässig bedeckt; ein breiter Rand bleibt glatt. In der Nähe ihres Innenrandes zeigen sümmtliche Afterplatten ein ziemlich grosses Wärzchen, nur die grössten derselben ausserdem noch einige kleinere, anch die Genitalulatten tragen in der Nähe des Innenrandes einige grössere Wärzchen.

Stacheln. Die längsten L'rimärstacheln, an der L'eripherie, sind etwas länger' als der Schalendurchmesser, stabformig und gegen das obere Ende verjüngt. Sie sind entweder glatt mit abgertundeter Spitze oder tragen feingezähnte, gegen das Ende zu dentlicher werdende Lüngsleisten, welche am Ende selbst einen kleinen zackigen Kelch bilden. Die grösseren Stacheln tragen fast alle eine wechselnde, doch immer geringe Anzahl von sehr kräftigen und sehr laugen Dornen, von denen mehrere mit der Basis verwachsen sein kümnen; die dem Apicalfelde nüchsten stachehn sind viel kürzer und die Dornen erscheinen am oberen Ende gehäuft, eine breite Trone bildend (Taf. V Fig. 19). Gegen das Buccalfeld hin werden die Stacheln rasch kürzer und die Dornen verschwinden nach und nach ganz, während die Lüngsleisten noch dentlich sind.

Die Sekundärstacheln sind kurz und dick, etwas abgeplattet und in ihrer ganzen Lünge fast gleich breit. Den kü̈nchen des A. F. und I. A. F' entsprechen winzige Stachelchen (Taf. VIII Fig. 8, g), die den damit bestandenen Flichen ein sammtartiges Ansselıen verleihen (T'af. V Fig. 12).

Von Pedicellarien findet sich die dickköpfige Form mit kurzem Stiel und fast kugeligem Kopfe (T'af. VIII Fig. 8, a, ist ein sehn kleines Exemplar) zerstreut auf den Nähten der oberen Schalenhälfte; daneben kommt eine andere Form vor mit schmälerem Köpfehen von sehr verschiedener Grösse, schwach bewafthet, anf schlankem längerem Stiele (Fig. 8, b, c, e, f), die überall zerstreut ist.

Die Farbe ist ungefäh dunkel lederbram. 
Melurere Exemplare ron 30-34 mm. Schalendurchmesser, die jedenfalls aus der Sagamibai stammten, erhielt ich frisch von Fischern in Enoshima. Die sehr charakteristischen Stacheln dieser Art fand ich einigemale in der Sagamibai in Tiefen von 100-200 Faden, sowie an der Küste von Tango in ca. 40 Faden Tiefe.
B. Exemplare von 20-21 mm. Schalendurchmesser (Exemplare d, e der 'Tabelle).
Taf. V Fig. 15-18.

Zwei Exemplare ron geringerer Grösse (20 und $21 \mathrm{~mm}$. Durchmesser), die ich zugleich mit den eben beschriebenen Exemplaren in Enoshima erhielt, stimmen im ganzen Habitus und in vielen Einzelnheiten so mit diesen ïbereiu, dass sie unbedingt zur selben Art zu rechnen sind.

Die Primärstacheln und Pedicellarien, sowie die Sekundärstacheln, die Gestalt und Dicke der Schale und besonders die dïnnen Apicalplatten, die Hauptwarzen, die grosse Zahl der Analplatten und die Form der Genital- und Ocellarplatten entsprechen denselben Verhältnissen der grossen Exemplare.

In anderen Punkten ist aber ein melr oder weniger verschiedenes Verhalten zu beobachten:

Die Schale ist doppelt so breit als hoch.

Auf 1 Coronalplatte an der Peripherie treffen $7-9$ Ambulacralplatten. Es stelien nur 6 oder 7 Coronalplatten in einer Vertikalreihe. Auf dem A. F. zeigen sich zwischen den beiden äusseren Reihen von Randwärzchen nur etwa zwei Vertikalreilen von kleinen Wärzchen oder Körnchen, die längs der Mittelnaht einen glatten Raud lassen. Ebenso zeigt im I. A. F. die mittlere Miliarzone ausserhalb des Scrobicularringes jederseits nur 1, höchstens 2 umvollkommene Vertikalreihen kleiner Wärzchen, die ebenfalls einen breiten Rand nach der Mittelnaht zu frei lassen; zwischen dem Scrobicularring und der Porenzone sind kaum weitere Wärzchen entwickelt. Von den Furchen auf den Coronalplatten, von den Furchen und Gruben in den Nälıten ist weder im A. F., noch im I. A. F. eine Spur zu finden, wenn anch die Nähte selbst meist sehr leutlich sind.

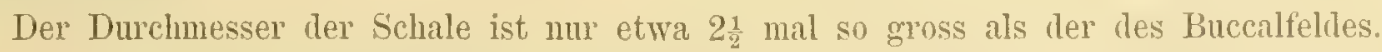

Das Afterfeld ist funfeckig mit fast geraden Seiten und zeigt einen ätsseren Ring von nur 11 bis 12 Afterplatten, unter denen die Winkelplatten kaum vergrössert sind; sie ragen mit einer Spitze nur wenig zwischen die Genitalplatten hinein, und nur vielleicht zwei von ilmen berüluren gerade die Ocellarplatten, so dass die Genitalplatten noch einen fast geschlossenen Kreis bilden, der das Afterfeld von den Ocellarplatten tremnt. Die kleinen Genitalöffnungen liegen zwischen der Mitte und dem Aussenrande der Platten. Auch ist das Apicalfeld viel spärlicher mit Wärzchen bedeckt als bei den grossen Exemplaren.

\section{Exemplar von $6.6 \mathrm{~mm}$. Schalendurchmesser' (Exemplar f der Tabelle). T'af. V Fig. 1-7.}

Die Schale ist über doppelt so breit als loch.

I. A. F. ist viermal so breit als das A. F.; im A. F. kommen auf eine Coronalplatte an der Peripherie 5 Ambulacralplatten. Die Poren sind klein, die Porenpaare schräg gestellt und weit von einander entfernt. Das Mittelfeld trägt nur die beiden randständigen Reihen von Wärzchen; die Verlängerung dieser Wärzchen bilden dicke Leisten, welche je zwei Porenpare von einander trennen, und die auf der anderen Seite in Wärzchen des Scrobicularringes enden; Raum fiur weitere Wïrzclien ist im A. F. nicht vorhanden. Im I. A. F. bilden 5 Coronalplatten eine Vertikalreihe. Die Hauptwarze ist klein, auf stark rortretender Basis, der Warzenhof rund und nicht vertieft. Ein einfacher Kreis von etwa 10 Wärzchen bildet den Scrobicularring; weitere Wärzchen sind nicht vorlanden. Zwischen zwei benachbarten Warzenhöfen eines Meridians bleibt eine schmale Brïcke; längs der Mittellinie ist ein breiter Streifen glatt, ohne Gruben oder Furchen zu zeigen.

Das Buccalfeld ist halb so breit als der Schalendurchmesser. Kaum grösser ist das Apicalfeld, von dem das Afterfeld fast die halbe Breite einnimmt. Dasselbe zeigt einen änsseren Ring von 10 mässig grossen Platten. Die Genitalplatten sind fast so gross als das Analfeld; sie stossen zusammen und tremnen das Afterfeld vollständig von den Ocellarplatten. Eine Genitalöffnmo ist nicht vorhanden. Die Madreporenplatte besitzt wenige Poren. Die Genital- und Ocellarplatten tragen nur seln vereinzelte Wärzchen; die Afterplatten tragen nahe dem Innenrande je ein solches.

Die längsten Primärstacheln über der Peripherie sind fast doppelt so lang, als der Schalendurclmesser; sie sind stabförmig, nach oben rerjüngt, las Ende selbst zu einer zackigen hrone unbedentend rerbreitert; besonders in der oberen Hälfte sind gezïhnte Längsleisten auf der Oberflïche deutlicher. Sonst trïgt jeder Stachel einige kriftige gerade Dornen, die wesentlich zweireihig gestellt sind; gegen das Buccalfeld hin werden die Primärstacheln rasch kleiner, auch glätter, behalten aber sonst denselben Charakter; nur enige zeigen auch von Dornen keine Spur. Zunächst dem Apicalfelde zeigt sich in jedem I. A. F. ein Stachel von ï̈uer $1 \frac{1}{2}$ Schalendurchmesser an Länge, der vollkommen glatt und dornenlos ist und von der Basis zur Spitze sich ganz allmählig verjüngt. 
Die $F_{\text {ar }}$ be ist lederbram. die Nühte rles Apicalfeldes sind heller.

Ein Exemplar in dieser Grösse $(6.6 \mathrm{~mm}$.) erhielt ich in der Sagamibai ans etwa 120 Faden T'iefe.

Der Farbe des Seeigels, sowie der Form der Sekundïr- und Primärstacheln, ïberhanpt dem ganzen Habitus nach kann unter den bekannten japanischen Cidariden nu G. biseriulis in Frage kommen. wem dies eben beschriebene jugendliche Exemplar überhaut einer bekamten Art zuzuweisen ist. Diese Zugehörigkeit wird aber im höchsten Grade wahrscheinlich durch die Beobachtung, dass in allen Punkten, in welchen sich die drei vorliegenden Alterszustände $(6.6 \mathrm{~mm}$. - $20 \mathrm{~mm}$. - $30 \mathrm{~mm}$. Schalendurchmesser) ron einander unterscheiden, die Exemplare von $20 \mathrm{~mm}$. Durchmesser eine Mittelstellung einnelmen zwischen den extremen Altersformen ron $6.6 \mathrm{~mm}$. und $30 \mathrm{~mm}$., welche diese in vollständig befriedigender Weise mit einander rerbindet.

\section{Exemplar ron 3 mm. Schalendurchmesser (Exemplar g der Tabelle).}

Taf. T Fig. 8.

Dies Exemplar, das ich ans ca. 160 Faden Tiefe in der Sagamibai erhielt, steht seinem ganzen Habitus nach der Form von $6.6 \mathrm{~mm}$. so nahe, dass es mit grösster Wahrscheinlichkeit als derselben Art zugehörig zu betrachten ist.

Die Schale ist ibber dopnelt so breit als hoch und besonders die Apicalseite sehr abgetlacht.

Im I. A. F. finden sich schon 4 oder 5 Coronalplatten in einer Tertikalreihe entwickelt; diesen entsprechen aber nur etwa 7 Ambulacralplatten, die im A. F. in einer Reihe vorhanden sind rom Apical- bis zum Buccalfeld, so dass an die untersten Coronalplatten mu eine einzige, an die obersten etwa 2 Ambulacralplatten grenzen. Die Höhe der.Ambulacralplatten ist daher etwa dieselbe wie die der unteren Coronalplatten. Die Ambulacralplatten sind etwa so breit wie hoch; nahezu in der Mitte jeder Platte steht ein einziger, verlaältnissmässig selır langer, aher dünner stabfömiger Stachel, neben welchem ein Ambulacralfüsschen sichtbar wird. das näher dem I. A. F. zu steht. Die Grenzen der Ambulacralplatten sind in der Nähe des Apicalfeldes sehr madentlich. weiter unten werden sie sehr auffallend.

Im I. A. F. trägt jede Coronalplatte einen wohlentwickelten Primärstachel; der oberste ist über doppelt so lang als der Schalendurchmesser, stabförmig, nach oben verjüngt und mit kräftigen Dornen besetzt; nach dem Buccalfelde zu nimmt die Länge dieser Primärstacheln selr rasch ab. die Gestalt bleibt ähnlich. Gegen die Mittellinie des I. A. F. stehen neben jedem Primärstachel etwa 2 oder 3 kleinere Stacheln von der Form und Grüsse der Ambulacralstacheln (die Anfänge des Scrobicularrings). Die Hauptwarze ist durchbohrt und stark über das Nivean der Schale erhoben. Sehr rereinzelt finten sich im I. A. F. anch Pedicellarien mit breiten Käpfchen und diumem Stiele von mässiger Lünge (ron der Form der kleineren Pedicellarien der erwachsenen Individuen).

Das Apicalfeld zeigt 5 grosse Genitalylatten und 5 seln. kleine Ocellarplatten. deren jede eine Pedicellarie trägt; auf den undurchbohrten Genitalplatten stehen je ein oder zwei stabförmige Stachelchen. Vollständig ron den Genitalplatten umschlossen ist das kleine Afterfeld, das ebenfalls einige Stachelchen trägt; nach Wegnahme derselben

Analfeld einer Goniocidaris biserialis von $3 \mathrm{~mm}$. Durehmesser. waren sehr deutlich 7 Afterplatten zu erkennen, aus deren gegenseitiger: Lage nit grosser" Wahrscheinlichkeit zu schliessen ist, dass dieselben durch successire Qnertheilungen einer einzigen urspuinghichen Afterplatte entstanden sind. Eine Afteröfhung ist nicht angerleutet. T'af. T Fig. 8 gibt ron den Afterplatten kein ganz richtiges Bild, da dasselbe vor der Wegnalme der Stacheln gezeichnet wurde, als der Verlauf der Nähte noch nicht mit voller Sicherheit erkamnt werden komte. Vergl. datiir nebenstehenden Holzschnitt.

Ans den hier beschriebenen vier rerschiedenen Altersstufen ron Goniociduris biscrialis (Schalen von ca. $3 \mathrm{~mm} ., 6 \mathrm{~mm}$., $20 \mathrm{~mm}$., $30 \mathrm{~mm}$. Durchmesser) lässt sich nun etwa folgendes Bild ron den allmähligen Verändernngen entwerfen, denen die Schale dieser Art beim allmähligen Wachsen ron $3 \mathrm{~mm}$. bis zu $30 \mathrm{~mm}$. Durchmesser unterliegt:

Die Schale nimmt unbedentend mehr an Höhe als an Breite zu. Die Coronalplatten rermehren sich allmällig vou 4 und 5 auf 8 in einer Vertikalreihe.

Während die ersten Ambulacralplatten etwa ron gleicher Höhe wie die Coronalplatten sind, nehmen die späteren an Höhe nicht zu, indess die Coronalplatten immer höher werden; so dass, während zuerst neben einer Coronalplatte nur eine Ambulacralplatte Platz fand, zuletzt 9 und 10 derselben an eine einzige Coronalplatte grenzen können. Die Porenpare erlualten erst allmällig eine horizontale Stellung: Der mediane Theil des A. F. nimmt besonders an Breite zn, und zwischen den beiden Reilen von Randwarzen entwickeln sich erst ziemlich spät zahlreiche winzige höruchen. Auch auf dem medianen Miliarfelde des I. A. F., das allmählig breiter wird, entwickehn sich erst nach und nach die zahlreichen Kürnchen, die dasselbe schliesslich bedecken. Der 
Scrobicularring, der zuerst nur aus. wenigen gegen die Mittellinie zu gelegenen Wärzchen bestand, vervollstïndigt sich allmählig und tremt die Warzenhöfe weit von einander, die unter das Niveau der Schale sinken. Die Furchen auf den Platten and die Gruben in den Nähten entstelnen erst selı spät.

Das Buccalfeld wird verhältnissmässig kleiner.

Das Afterfeld, das ursprünglich klein ist und vollständig ron den grossen Genitalplatten umschlossen ist, wächst viel rascher an Ausdelnung wie diese, drängt schliesslich die Genitalplatten weit anseinander mit seinen stark sich rerlängernden Winkelplatten, die dann direkt an die Ocellarplatten grenzen. Die Zahl der Afterplatten selbst nimmt selı erheblich zu, so dass, während das Afterfeld zuerst aus einem einzigen Ring von 7 Platten bestand, zuletzt wenigstens 3 Ringe von Afterplatten sich unterscheiden lassen, deren änsserster ans 16 Platten bestehen kann. Die Afteröffnung wird erst im Verlanf dieser Entwicklung sichtbar.

Die Genitalöffnungen entstehen ziemlich spät. Die Ocellarplatten wachsen etwas mehr in die Breite als in die Höhe. Die Miliarwärzchen des Apicalfeldes vermelıren sich allmählig. Die Primärstacheln werden verhältnissmässig kürzer.

Das Auftreten von Gruben an den Winkehn der Platten des A. F. mol I. A. F., verbunden mit dem Vorkommen von grossen Pedicellarien mit kugligem Kopfe bestimmten mich, diese Art der Gruppe Goniocitaris zızustellen. Weitere Gründe dafür waren die höchst verschieden gestalteten Primärstacheln, die mit Dornen versehen sind und Neigung zur Kronenbildung zeigen, sowie die dünue Schale, das biegsame Apicalfeld, der auffallende Scrobicularring und die winzigen Miliarwärzchen, alles Charaktere, die bezeichnend sind fü Goniocidaris.

Dagegen sprach zunächst das Fehlen von glatten wohlbegrenzten Feldern längs der Mittelnaht des A. F. und I. A. F., wenigstens bei den grössten Exemplaren; solche Felder sind aber auch bei G. florigern nicht entwickelt, so dass mir dieser Charakter weniger wichtig erscheint als das Vorhandensein winziger Körnchen im Miliarfelde des I. A. F.; solche finden sich anch bei anderen Goniocidaris-Arten, wenn anch nicht in dieser anffallenden Zahl und Anordnung wie hier.

G. biserialis zeigt auch zu verschiedenen der Goniocidaris-Gruppe fernerstehenden Arten manche Beziehnngen. So erimert das Apicalfeld ausserordentlich an das von Leiocidaris bispinosa (nach A. Agassiz Steplanocidaris), sowoll was die Gestalt und Zahl der Platten betrifft, als durch die bemerkenswerthe Biegsamkeit in Folge der geringen Dicke der Platten.

Ferner finden die auffallenden Horizontalfurchen anf den Coronalplatten ihr Pendant in ähnlichen Terhältnissen innerhalb der wahrscheinlich sehn fern stehenden Dorocidaris-Gruppe, besonders bei Arten ans der Kreide, wie D. perlata und vendocinensis. Viel mehr Ähnlichkeit zeigt aber darin die Gruppe Pleurocidaris, bei der: ausserdem winzige, in Horizontalreihen stehende Kürnchen das Miliarfeld berlecken ganz wie bei G. biscrialis, so bei $P$. vemelosa aus der Kreide, itala und alta aus dem europäischen Tertiär; ganz auffallend stimmt aber damit $P$. canaliculate Duxcax und Staden ans den eocänen Kihirthar-Schichten von Indien iiberein (s. Palaeont. indica, Ser. 14, Vol. I, 3, Taf. 21). Die Sculptur der ganzen Schale ist hier nalezu identisch im A. F. wie im I. A. F., bis auf zwei Punkte: bei $P$. canaliculata fehlen Nahtgruben vollständig, und sodamn sind hier die Poren deutlich gejocht und weit ron einander entfernt. Da aber bei biserialis solche Gruben erst spät auftreten und bei jüngeren Formen von canaliculata die Beschaffenheit der Poren viel ïhnlicher ist der ron biserialis, so halte ich die Möglichkeit für sehr diskntirbar, die Gruppe, der $P$. canaliculata angehürt, als Stammgruppe ron Goniocidaris anzusehen. Der Charakter der Poren, zumal bei Goniocidaris, ist so sclnwer definirbar (sie gelten hier für ungejocht), dass mir dies kein genügender Grund scheint, sie ron einer Gruppe fernzuhalten, zu der sonst so innige Beziehungen zu bestehen scheinen.

\section{Goniocidaris clypeata DöD.}

Taf. VI Fig. 1-19, Taf. VIII Fig. 7, a-f.

Goniocidaris clypeata DöDERLEx, 1885, Arch. f. Naturg. Bd. 51.

Die Schale ist über $1 \frac{1}{2}$ mal so breit als hoch $(15.5 \mathrm{~mm}$. Durchmesser), an beiden Polen Hach.

I. A. F. ist fast dreimal so breit als das A. F.

Ambulacralfeld ist fast gerade; auf eine Coronalplatte an der Peripherie treffen 7 Ambulacralplatten. Die Porenfelder sind kaum vertieft, die Poren eines Paares eimander sehr genähert, die einzelnen Paare durch ziemlich entwickelte Leisten von einander getrennt. Das Mittelfeld nimmt fast drei Viertheile der ganzen Breite des A. F. ein. Es zeigt an beiden Rändern eine Reihe vorspringender Wärzchen, denen sich nach imnen einzelne, eine sehr unregelmässige Reihe bildende kleine Körnchen anschliessen. Die Mittellinie er'scheint etras vertieft mit deutlicher Ifittelnaht.

Im Interambulacralfelde bilden 6 Coronalplatten eine Vertikalreihe. Die Hauptwarze ist ziemlich klein, vorspringend, der Warzenhof rund und stark vertieft. Der Scrobicularring besteht aus etwa 16 kleinen aber 
vorspringenden Wärzchen; er ist vollständig und tremnt die benachbarten Warzenhöfe von einander; lïngs der Horizontalnähte berühren sich die Scrobicularringe, die an der Berührungsstelle aus kleineren Wärzchen hestehen. Gegen die Mittellinie zu schliessen sich dem Scrobicularring etwa zwei selur umregelmässige Reihen winziger Körnchen an, während derselbe die Porenzone berührt, so dass sich dort nur einzelne kleine Kömchen entwickeln kömnen. Lüngs der Mittelnaht bleibt ein nicht sehr breiter Streifen kahl und ist etwas rertieft; die Mittelnaht ist sehr dentlich und bildet an den Winkeln seichte aber immerhin merkliche Gruben.

Der Durclmesser des Buccalfeldes ist kleiner, der des Apicalfeldes grösser als die Hälfte des Schalendurchmessers; das Afterfeld ist bei weitem nicht halb so breit als das Apicalfeld; es bildet ein Fünfeck mit fast geraden Seiten und zeigt einen äusseren Ring ron nem grösseren Afterplättchen, an die sich nach imnen noch wenige seln kleine Plättchen anschliessen. Die Genitalplatten sind kleiner als das Afterfeld, breiter als Loch; sie stossen an einander und tremen das Afterfeld weit von den Ocellarplatten. Eine auffallend grosse Genitalöffnung liegt nalıe dem äusseren Rande, reicht aber bis zur Mitte der Platte. Die Madreporenplatte ist nicht vergrössert. Ocellarplatten sind klein, etwas breiter als loch. Das ganze Apicalfeld ist gleichmässig mit etwas zerstrent stehenden kleinen flachen Wärzchen bedeckt, die einen breiten Rand an den Genitalplatten frei lassell.

Stacheln. Die längsten Primärstacheln stehen an der Peripherie der Schale mo übertreffen den Schalendurchmesser um etwa die Hälfte an Länge. Dieselben sind schlank, stabförmig, nach oben verjüngt und spitz auslaufend, oder mit einer melı oder weniger breiten kelchfürmigen Krone am Ende. Ihre Oberfläche ist mit feingesägten niedrigen Längsleisten bedeckt und trägt (mit Ansnahme der nach unten gerichteten fast glatten Seite) eine grössere Anzahl verschieden langer und dünner oft hakenförmig gebogener Dornen, die häufig stark abgeplattet sind; die längsten Dornen sind wesentlich zweireilig gestellt. Diese Stacheln tragen ansserdem nahe der Basis eine unvollständige kragenförmige Scheibe. Solchen Stacheln folgen gegen das Apicalfeld zu etwas kürzere, sonst aber ähnliche Stacheln, deren Ende zu einer auffallend breiten vertieften Scheibe ungewandelt ist. Die dem Apicalfelde zumächst stehenden bestehen aber nur noch aus einer solchen grossen Scheibe auf einem excentrisch angebrachten Stiele, dessen Länge auf ein Drittel des Scheibendurchmessers reducirt sein kam. Der grössere freie Theil der Scheibe ist bei manchen gegen den Pol, bei anderen gegen đie Peripherie der Schale gerichtet. Diese hüchst merkwïrdigen schildfürmigen Stacheln bilden ein förmliches fast geschlossenes Dach über der Apicalseite des Seeigels. Auf der Buccalseite sind die kürzeren Primärstacheln zunächst noch stabförmig mit kuzen Dornen, die dem Buccalfelde nächsten aber platt mit nahezu oder vollständig glatter Oberfläche mol mit grob gezähnten Seitenrändern; manche der kïrzesten sind leicht gebogen.

Die Sekundärstacheln sind ziemlich kurz, etwas platt, sclmal und in ihrer ganzen Länge gleich breit. Ähnlich sind die winzigen Miliarstacheln.

Von Pedicellarien fand sich eine grössere Form, mit mässig bewafineten Klappen auf ziemlich kurzem Stiele (Taf. VIIJ Fig. 7, a, c), die vereinzelt auf der oberen Hälfte der Schale vorkommt und wohl der dickköpfigen Form entspricht.

Eine zweite schlanke Form, die iiberall zahlreich ist, ist sehr klein mit schmalem Küpfchen und dünnem Stiele, der kaum länger wird als das Küpfchen; die Klappen laufen aus in einen umpaaren anffallend langen und spitzen Zahn am oberen Ende (Fig. 7, b, d, e).

Die Farbe des Seeigels ist ein lichtes Grau.

Ein einziges Exemplar dieser interessanten Art (von 15.5 mm. Durclmesser) erhielt ich in der Sagamibai aus einer 'liefe von ca. 160 Faden am gleichen Orte wie Cidaris japonica und grandis.

Die auffallende Verschiedenartigkeit der Primärstacheln, ihre Gestalt md besonders das Auftreten einer mächtigen Krone an denselben, sodann das nackte Viliarfeld des I. A. F. und das Vorhandensein von seichten Grübchen an den Winkeln der interambulacralen Mittelnaht veranlassten micl, diese Form zur Gruppe von Goniocidaris zu bringen. Die Primärstacheln älmeln theilweise auffallend denen von G. florigera (vergl. A. AGassiz, Challenger-Exped., Echini Tab. I). Bei mehreren Stacheln von G. Aorigcra ist dort ebenfalls die kragenförmige Scheibe angedeutet in der Nähe der Basis des Stachels (Fig. 18 u. 19). Eine Andentung dieser Scheibe zeigt sich anch bei einzelnen Stacheln von G. biserialis (Taf. V Fig. 21 dieses Bandes). Keiner der bekamnten Cidariden zeigt eine solche Verschiedenartigkeit der Primärstacheln (die selbst über lie von G. florigera hinausgeht); die Umgestaltung der Endkrone in eine breite schildförmige Scheibe stelt einzig in der Familie da. Im N. Jahrbuch f. Min., Geol. u. Pal. 1886 (Bd. I. p. 195) habe ich auf die Älmlichkeit dieser schildförmigen Stachehn mit solchen von Cidaris Buchi (syn. Anculociduris) aus der T'rias von St. Cassian aufmerhsam gemacht, die wohl eine ähnliche Stellung an der Schale wie hier eingenommen haben düften; doch entstehen solche Stacheln bei $C$. Buchi nicht durch Verbreiterung einer Endkrone, die in dieser Periode noch gar nicht vorkommt, 
sondern clurch fächerfürmige Ausbreitung des Schaftes, der gegen die Stachelbasis bei manchen Formen gebogen, bei anteren fürmlich geknicht ist. 'I'rotz der grossen Älnlichkeit dieser schildförmigen Stacheln bei den beiden Arten können daher dieselben durchaus nicht auf diese Ähnlichkeit hin in innigere Beziehung zu einander gebracht werden; es sind extreme Endformen von zwei ganz verschiedenen Entwicklungsreilien, die in dieser Beziehung eine äusserliche Ähnlichkeit erreicht laben.

Abgesehen ron den Primärstacheln steht Gr. forigera der vorliegenden Art nicht näher als irgend eine andere Art derselben Gruppe. Was diese Art wesentlich unterscheidet ron den typischen Goniocidaris-Arten. ist der Nangel an Gruben in A. F. und am äusseren Ende der interambulacralen Horizontalnähte; auch ist die nackte Linie in I. A. F. keineswegs scharf begrenzt. Dafïr sind aber die winzigen Könchen auf den Coronalplatten rorhanden, die in auffallendem Gegensatze stehen zu den Wärzchen des Scrobicularringes. Ferner scheinen dieser Art die charakteristischen kugeligen Pedicellarien zu fehlen, die ich übrigens anch an einzelnen Individnen von $G$. tuberia vermisse. Die kleinere Form der vorlandenen Pedicellarien ist eigenthïmlich. Ton den übrigen Charakteren dieser Art wïrde keiner gegen die Vereinigung mit der GoniocidarisGruppe sprechen.

\section{Goniocidaris mikado DöD.}

Taf. VII Fig. 1-6, Taf. VIII Fig. 6, a-f, Fig. 9-18.

Discocidaris milado DöDERLEIs, 1885, Arch. f. Naturg. Bd. 51.

Die Schale (ron $19 \mathrm{~mm}$. Durchmesser) ist kaum $1 \frac{1}{2}$ mal so breit als hoch, an beiden Polen flach.

I. A. F. ist über dreimal so breit als das A. F.

Ambulacralfeld ist ganz umbedeutend gewellt; auf eine Coronalplatte an der Periplerie trefien 8-9 Ambulacralplatten; das Porenfeld ist nicht vertieft; die Poren selbst liegen tief, die eines Paares sind nahe bei einander, die einzelnen Paare durch starke Querleisten ron einander getrennt. Das Mittelfeld ist halb so breit als das A. F., jederseits rom Porenfelde getreunt dnrch eine Reihe rorspringender. Wärzchen; der mittlere Theil ist gleichmässig bedeckt von zerstrent stehenden winzigen Körnchen, die sich anch zwischen die einzelnen Randwarzen einschieben. Die Mittelnaht ist nicht sehr deutlich.

Im In terambulacralfelde bilden 6 Coronalplatten eine Vertikalreihe. Die Hauptrarzen sind klein und glatt, an der Peripherie ron einem mässig grossen, fast kreisrunden und vertieften Hofe umgeben, der gegen die Porenzone sowie gegen die benachbarten Warzenhöfe desselben Meridians gerade Platz lässt zur vollen Entwicklung des Scrobicularringes, während er ron der Jíttellinie weiter entfernt ist. Das mediane Miliarfeld ist rollständig bedeckt von winzigen Kïrnchen, die kaum die Nähte frei lassen; einzelne Kürnchen finden sich auch gegen die Porenzone zu entwickelt. Der Scrobicularring hebt sich sehr scharf al gegen das Miliarfeld, er besteht aus etwa 16 nicht sehr grossen Wärzchen. Die Mittelnaht rerläuft etwas rertieft, an den Winkeln bildet sie kanm merkliche Spuren von Grübchen.

Das Buccalfeld lat fast den halben Schalendurchmesser. Ebenso gross etwa ist das Apicalfeld, ron dessen Breite etwa drei Fünftel auf das Afterfeld kommen. Dasselbe zeigt einen äusseren Ring ron 10 sehr grossen Afterplatten, unter denen die Winkelplatten am grössten sind, welche sich mit einer Seite an die Ocellarplatten anlegen, die Genitalplatten weit von einander tremnend. Ein innerer Ring von kleinen Afterplättchen ist zur. Noth noch entwickelt, an die sich die den After umgebenden Kü̈rnchen anlegen. Die Genitalplatten sind verhältnissmässig sehr klein, etwas breiter als hoch; die grosse Genitalüthung liegt zwischen dem Aussenrande und der Mitte der Platte. Die Madreporenplatte ist nicht rergrössert. Die Ocellarplatten sind fast halb so gross wie die Genitalplatten, nur etwas grösser als die Winkelplatten des Afterfeldes, breiter als hoch. Das Apicalfeld ist gleichmässig bedeckt von zerstrent stehenden, kleinen Körnchen, die den Rand der Platten eben frei lassen. Die grösseren Platten des Apicalfeldes tragen nahe dem Innenrande je 1-3 grössere Wärzchen.

Stacheln. Die längsten Primärstacheln, nahe der Peripherie der Schale, haben etwa doppelten Schalendurchmesser. Dieselben sind schlank, stabfürmig und verjüngen sich allmählig gegen das obere Ende, das bei den grössten sich zu einer winzigen zackigen Krone verbreitert. Die Oberfläche der Stacheln zeight eine Menge kürzerer und längerer stark vorragender Dornen, die meist flach und lappenfürmig ansgebildet sind (Taf. VIII Fig. 12); gegen dlas Stachelende zu treten an deren Stelle zahlreiche niedere aber' spitze Zähnchen. die zu Längsreihen angeordnet sein kömnen. Fünf dem Apicalfelde zunächst stehende Primärstacheln, einer' in jedem I. A. F., sind kïrzer als der Schalendurchmesser, das Ende stark erweitert zu einer sehr grossen aber hüchst zierlichen Tírone, deren nach aussen gerichteter Rand mit sehr tiefen, der nach inneu gerichtete mit feinen Zacken versehen ist.

Sämmtliche grüssere Stacheln zeigen üherdies noch ein ganz auffallendes Xerkmal, indem sie über dem Halse eine breite hragenfürmige Scheibe tragen, ähnlich dem Stichblatte eines Stossdegens, mit feingezacktem. 
Rande. IIanchmal zeigen sich mehrere solcher dicht untereinander liegender Scheiben. Fast alle diese Stacheln sind ausserdem noch bedeckt von einem dichten filzigen Überzug, der aus haarartigen spröden, mit einander vielfach anastomosirenden Kalknảdelchen besteht, und der diesen Stacheln ebenfalls ein ganz eigenthümliches Aussehen gibt. Sammtliche Hervorragungen zeigen sich auf der nach unten gerichteten Stachelseite nur ganz umbedentend entwickelt. Die kleinsten Primärstacheln nahe dem Buccalfelde zeigen eine glatte Unterseite und auf der Oberseite wenige grob gezähnte Längsleistẻn, von denen die beiden äusseren am kräftigsten entwickelt sind.

Die Sekundärstacheln sind klein, schmal, wenig abgeplattet und bis zu Spitze gleich breit. Der Jittelraum des A. F. und I. A. F. ist bedeckt mit winzigen Stachelehen, die länfig zn kugelfömigen Kürnchen reducint sind (T'af. VIII Fig. 6, e).

Ton Pedicellarien findet sich nur eine einzige winzige Form anf kurzem dünnem Stielchen mit kegelförmigem Köpfchen, dessen Klappen schwach bewafinet sind mit Ausnalme eines langen spitzen Zahnes, in den das obere Ende ansläuft; sie finden sich auf der ganzen Schalenoberfläche überall in grosser Menge entwickelt ('T'af. VIII Fig, 6, a-d).

Die Farbe der Schale und der kleineren Stacheln ist rein weiss, die der grösseren Primärstacheln ist licht grau oder grünlich.

Das einzige Exemplar, das mir hier rorliegt, von $19 \mathrm{~mm}$. Schalendurchmesser, erhielt ich in der Sagamibai aus einer 'liefe von 120 Faden; die charakteristischen Primairstacheln fand ich mehrmals in noch griosserer' Tiefe.

Der hier beschriebene Goniocidaris mikado ist die gefalligste und eleganteste Form, die ich von Seejọeln gesehen habe.

Die grosse Terschiedenheit und die Gestalt der Primairstacheln, besonders ilure Neigung zur Bildung von Kronen, die winzigen Köruchen, die das Miliarfeld bedecken und sich scharf abheben von den grösseren Wärzchen des Scrobicularringes, sowie die unlängbare Verwandtschaft mit G. clypeata sind die Grinde, die mich bestimmen, auch diese Art noch in die Grupe ron Goniocidaris zu stellen.

Es fehlen hier die nackten und vertieften Mittellinien der typischen Goniocidaris-Formen ebenso wie sie G. biserialis fehlen; die Winkelgruben sind kaum angedeutet auf der Mittelnaht des I. A. F., und von den ebenso charakteristischen Pedicellarien mit kugligem Köppehen findet sich auch hier keine Spur so wenig wie bei $G$. clypeata.

Die Verwandtschaft mit dieser letzteren Art geht noch hervor aus dem Vorhandensein fast identischer winziger Pedicellarien mit dem anfallenden langen und spitzen Endzalm an den Klappen, sowie aus dem Anftreten der eigenthümlichen Basalkragen an den Primärstacheln, wie er sonst nur noch bei $G$. florigera rorkommt. Bei G. mikado ist aber dieser Kragen zu einer vollständigen breiten Scheibe entwickelt, wälnend inn die beiden anderen Formen mvollständig, nur auf die obere Seite des Stachels beschränkt zeigen.

Die übrigen Charaktere der Coronal- und Ambulacralplatten lassen sich durchaus denen der typischen Croniocidaris-Formen an die Seite stellen.

\title{
II. Recente Cidariden von nicht japanischer Herkunft.
}

\section{Cidaris (Dorocidaris) canaliculata A. AG.}

\author{
'laf. IX Fig. 6, a-p.
}

Goniocillaris canaliculata A. Agassiz, Rerision of the Echini.

A. Agassiz, Report on the (Challenger-) Echinoidea.

Schale (ron 12-29 mm. Durchmesser) ist $1 \frac{1}{2}$ bis fast 2 mal so breit als hoch, an beiden Polen flach.

I. A. F. ist $4-5$ mal so breit als das A. F.

Das Ambulacralfeld ist sehr unbedeutend gewellt; je nach der Grösse der Exemplare grenzen an eine Coronalplatte der Peripherie 4-8 Ambulacralplatten. Porenzone ist kaum vertieft, die Poren sind klein und nicht gejocht; die Pare sind schief gestellt, durch vorspringende Leisten ziemlich weit von einander getrennt. Das Jittelfeld ist ungefähr halb so hreit als das A. F. Die beiden Reihen von Randwarzen liegen bei den kleineren Exemplaren sehr nahe beisammen, bei den grösseren lassen sie zwischen sich gerade Raum für 2 Reilıen kleiner Jiliarwärchen; bei manchen Exemplaren bildet die Mittelnaht eine scharfe tiefe Furche, die bei anderen vollständig fehlen kann. Die Randwäxzchen derselben Reihe sind durch winzige Kömchen von einander getrennt. 
Im Interambulacralfelde bilden 5-7 Coronalplatten eine Vertikalreihe. Die Hauptwarze ist klein, glatt, stark rorspringend, auf erhobener Basis; der Warzenhof ist sehr gross, oval und stark vertieft. Der Scrobicularring, aus ziemlich kleinen Wärzchen bestehend, ungibt den Warzenhof vollständig; längs der Mittelnalit verschmelzen die benachbarten Scrobicularringe zn einer einfachen Warzenreihe, die aber stets die Höfe vollkommen von einander trennt. Der Scrobicularring grenzt bei kleineren Exemplaren direkt an die Porenzone, bei grösseren entwickelt sich noch eine Reihe kleinerer Wärzchen dazwischen. Anch an die Mittelnaht grenzt bei kleinen Exemplaren der Scrobicularring direkt, während er bei grösseren durch 1 bis 2 Reihen von Miliarwärzchen davon getreunt wird, die bei einem Exemplar fast von der Grösse der Wärzehen des Scrobicularringes, bei anderen nu von geringer Grüsse sind. Die Mittelnaht liegt meist in einer scharfen und tiefen Furche; bei einem Exemplar findet sich keine Spur einer solchen Furche, das Miliarfeld ist hier ganz flach und die Mittelnaht kaum zu erkennen.

Das II undfeld hat etwa den laalben Schalendurchmesser, das Apicalfeld ist noch kleiner und etwa die Hälfte seiner Breite fällt auf das Afterfeld. Bei einem ziemlich grossen Exemplar finde ich das Analfeld vollständig eingeschlossen von den Genitalplatten, bei kleineren grenzen drei Ocellarplatten, bei grösseren alle fünf an das Afterfeld. Der äussere Kreis von Afterplatten besteht ans etwa 10, beim grössten Exemplar ans 14 kleinen Plättchen, innerhalb deren sich noch etwa zwei weitere Kreise unterscheiden lassen.

Sämmtliche Platten des Apicalfeldes sind wesentlich in ihrer Jitte mit zerstrent stehenden Miliarwärzchen bedeckt, die Ränder besonders der Genitalplatten sind glatt.

Stacheln. Die längsten Primärstacheln sind ebenso gross bis doppelt so gross als der Schalendurclımesser; es sind dünne cylindrische Stäbe mit abgestutzter Spitze, deren Oberfläche fein gekerbte oder gesägte Längsleisten trägt.

Die Sekundärstacheln sind von mässiger Länge, seln schmal und etwas abgeflacht.

Von Pedicellarien findet sich

1) eine dickköpfige Form auf kurzem Stiele mit stark gezälnnten Klappen in spärlicher Anzahl auf der oberen Schalenhälfte (Taf. IX Fig. 6, a, b, g).

2) Eine zweite kleinere Form mit schlankeren Köpfchen und sehr schwacher Bewaffinng, anf dïnnem Stiele ron ein- bis dreifacher Kopflänge kommt in verschiedener Grüsse anf der ganzen Schale häufig vor (Fig. 6, c, d, f, h, i, l).

3) Selten findet man noch eine dritte Form mit langem schlankem Köpfchen und fast unbewatfneten lüftelförmigen Klappen. die malıe der Basis klaffen; sehr selten ist eine in die gleiche Kategorie gehörige Form mit kleineren und breiteren Küpfchen (Fig. 6, e, k, m).

Die mir vorliegenden Exemplare dieser Art stammen von Patagonien und der Iagellanstrasse.

Diese Art ist, wie ron anderen Antoren, besonders von A. Agsssiz schon gezeigt wurde, ausserordentlich variabel. Sehr veründerlich ist besonders die Grösse der Miliarwärzchen im medianen A. F. und I. A. F., die Breite des interambulacralen Miliarfeldes, das Auftreten oder Fehlen von medianen Furchen, die 'Trennung oder Verbindung des Afterfeldes mit Ocellarplatten, die Grösse der Primärstacheln. An Veränderungen, die direkt mit der Grössenzunahme im Zusammenhange stehen, liessen sich nur constatiren eine geringe Vermelırung der: Coronalplatten und der Ambulacralplatten, eine allmählig stärker werdende ovale Form der Hauptwarzenhöfe, sowie die Ansbildung einer schmalen von Miliarwärzchen bedeckten Mittelzone im A. F. und I. A. F.

Zwischen den Stacheln eines grösseren Exemplars fand sich ein winziges Individum ron etwa 2 ım. Schalendurchmesser (Taf. IX Fig. 6, p), an dem bereits deutlich die Platten des Apicalfeldes, Ambulacral- und Interambulacralfeldes, sowie des Buccalfeldes zu unterscheiden waren. Bei der Präparation wurde leider der Zusammenhang der wenigen Platten des Apicalfeldes zerstört, so dass ich nicht mehr wagen kann, dieselben mit Sicherheit zn deuten.

Das I. A. F. ist katum doppelt so breit als das A. F. Es zeigt nur Arei (oder vier) Coronalplatten in einer Vertikalreihe, die nur je eine einzige kräftige Warze in der Mitte zeigen mit einem Stachel von hüchstens $3 \mathrm{~mm}$. Länge, dessen Oberfläche mit feinen Längsleistchen ausgestattet ist. Jedes Interambulacralfeld endet unten gegen das Buccalfeld mit einer einzigen unparen Platte, die an die beiden das I. A. F. seitlich abschliessenden Ambulacralfelder grenzt.

Die Ambulacralplatten sind auffallend gross; ihre Breite ist melr als die Haifte, ihre Höhe etwa zwei Drittel von der der Interambulacralplatten, so dass den 3 Coronalplatten des I. A. H. eine Tertikalreilhe von 4, höchstens 5 Ambulacralplatten entspricht; dieselben sind gern etwas höher als breit; eine Warze ist nicht zu erkennen; sie sind ron einer einzigen öfhung durchbohrt yon länglichem Umriss, der schief gestelit ist; diese Öffnumg liegt dem buccalen und coronalen Rande der Platten etwas näher als dem merlianen midem apicalen. 
Es ist dentlich zu erkemen, dass die Rinder der an einander stossenden Ambulacral- und Interambulacralplatten über einander greifen vielleicht mit Ausnahme der die Medianlinie der beiden Felder bildenden Ränder.

Das grosse Buccalfeld ist vollständig bedeckt von $10(?)$ Platten, die in einem Kreise angeordnet sind.

Diese Platten sind ron der Grösse der Interambulacralplatten, sie sind aber wie die Ambulacralplatten von einer Öffnumg durchbolnt und erscheinen überhaupt nur als vergrüsserte Ambulacralplatten, da sie auch die ummittelbare Fortsetzung der beiden Plattemeihen des A. F. bilden. Jede der Buccalplatten trägt einen Stachel.

Die Lateme ist von beträchtlicher Grösse, doch ist ihr Zusammenhang nicht wohl erhalten.

Cidaris conaticulata ist von A. Agassiz zu Goniocidaris gestellt worden, wie mir scheint, wesentlich auf Grund der medianen Nahtfurchen im A. F. und I. A. F. Abgesehen aber davon, dass diese medianen Furchen keineswegs constant auftreten imnerhalb dieser Art, möchte ich sie durchaus nicht als gleichwerthig ansehen mit den Gruben. welche z. B. bei Goniocidaris tubaria an den Winkehn der Platten, im I. A. F. auch längs der Porenzone auftreten, und welche bei verschiedenen Arten von Goniocidaris durch nackte, aber kaum rertiefte Flächen längs der Nähte verbunden sein kömnen. Von Winkelgruben ist keine Rede bei C. canaliculata; fehlen die \edianfurchen, so zeigt sich anch keine Spur von Gruben, die ebenso längs der Porenzone nie anftreten. Von anderen, Goniocidaris auszeichnenden Charakteren, wie sie in der Form der Stacheln und der kugeligen Pedicellarien sowie in zahlreichen winzigen Miliarwärzchen zu finden sind, ist bei C. canaliculatu nichts zu sehen. Ähnliche Hauptwarzen und Warzenhöfe kommen auch bei anderen Gruppen vor, so dass daraus auf keine nähere Terwandtschaft gerade mit Goniocidaris geschlossen werden dürfte.

Ich möchte C. canaliculata lieber mit der Dorocidaris-Gruppe vereinigen, der sie durch die Gesammtheit ihrer Charaktere nahe steht. Ovale Warzenhöfe sind mitunter auch hier zu treffen, die grossen Primärstacheln und Pedicellarien sind älnlich; bei einzelnen Formen finden sich auch hier plattgedriichte und gesägte Primärstachehn in der Nähe des Buccalfeldes; es zeigt sich dazu bei manchen Dorocidaris-Arten die Neigung zur Bildung von nackten Medianfurchen im A. F. und I. A. F. (z. B. bei Cidaris Reini).

C. canaliculata wiirde allerdings eine etwas extreme Stellung einnehmen in der Dorocidaris-Gruppe und könnte vielleicht auch als einziger Repräsentant einer besonderen Gruppe angesehen werden. Sie erimert in vieler Beziehung an die Eucidaris-Gruppe, besonders durch das vollkommen flaclie interambulacrale Miliarfeld in den Fällen, wo Medianfurchen nicht zur Entwicklung kommen, und würde sich dam von dieser Gruppe nur wesentlich durch die sehr stark vertieften Warzenhöfe unterscheiden.

Wirklich nahe Beziehungen zu einer der bisher bekannten Arten von Cidariden bietet diese Form jedenfalls nicht dar.

\section{Cidaris (Eucidaris) Thouarsii VAL.}

\section{Taf. IX Fig. 4, a-h.}

Cidaris thonarsii A. Agassiz, Rerision of the Echini (s. daselbst weitere Literatur).

Die Schale (ron 13-51 mm. Durchmesser) ist bei den kleinsten Exemplaren doppelt, bei dem grössten nur $1 \frac{1}{2}$ mal so hoch als breit; beide Pole sind flach; die Schale ist verhältnissmässig dium, ebenso die Apicalplatten.

I. A. F. ist ungefäh 4 mal so breit als das A. F.

Ambulacralfeld ist nur seln wenig wellig; anf eine Coronalplatte an der Peripherie treffen bei den kleinsten Exemplaren 7-8, bei den grössten 11-12 Ambulacralplatten. Porenfeld ist kaum vertieft, die Poren eines Paares sind nicht gejocht, nahe beisammen, die Paare etwas schief gestellt.

Das Mittelfeld hat etwa die halbe Breite des A. F. Die beiden randständigen Reihen von Sekundärwïzchen stehen bei den kleinsten Exemplaren selı nahe beisammen mo lassen zwischen sich nur Raum fur cine einzige Reihe kleiner MIiliarwärzchen; je grösser num die Schale wird, desto weiter rïcken sie auseinander, bis ihre Entferumg von einander bei den grössten Exemplaren fast das Doppelte beträgt rom Durchmesser eines Sekundärwärzchens; dementsprechend vermehren sich die Miliarwärzchen; die ursprüngliche einzige Reihe wird erst umregelmässig, dann entstehen nach und nach 2, 4,6 Reihen kleiner Miliarwärzchen, die bei den grössten Exemplaren ron einem medianen, sehr schmalen, glatten Streifen von einander getrennt sind.

Im Interambulacralfelde finden sich je nach der Grösse Rer Exemplare 5 -10 Coronalplatten in einer Tertikalreihe. Die Hauptwarzen sind glatt, ron mässiger Grüsse, auf rortretender Basis; der Warzenhof ist (lurchans nicht vertieft; bei den kleinsten Exemplaren ist er schon etwas oval; je grösser die Exemplare sind, um so hreiter wird er im Verläitniss zu seiner Höhe. Die benachbarten Hüfe fliessen fast in ihrer ganzen Breite zusammen, bei grösseren Exemplaren stehen längs der Horizontalnaht ein paar winzige Kürnchen. Der Scrobicularring besteht auf beiden Seiten des Hofes ans etwa je 5 Sekundärwärzchen.

Längs der Mittellinie des I. A. F. stossen bei den kleinsten Exemplaren die Scrobicularringe fast znsammen und lassen kaum Raum für sehr vereinzelte kleine Miliarwärzchen; mit zunelmender Grösse entstelt 
allmählig zwischen ihnen ein deutliches Miliarfeld, das immer mehr an Breite zunimmt und zuerst für nur eine, dann für zwei und zuletzt für etwa sechs Reihen von gedrängt stehenden Viliarwärzchen Platz bietet, von denen einzelne dem Scrobicularringe benachbarte ziemlich gross werden, wälrend die der Mittellinie zumächst stehenden winzig sind. Diese Wärzchen bilden deutliche Horizontalreihen. Sämmtliche Theile des Miliarfeldes liegen in dem gleichen Nivean und die Mittehnaht ist löchstens durch einen feinen Strich angedentet. Zwischen der Porenzone und dem Scrobicularring entsteht nu bei den grössten Exemplaren eine Reihe von Miliarwärzchen.

Die Breite des Buccalfeldes beträgt bei kleineren Exemplaren etwas melr, bei clen grössten etwas weniger als die Hälfte des Schalendurchmessers. Der Schalendurchmesser ist bei den kleinsten Exemplaren doppelt, bei den grössten über dreimal so breit als das A picalfeld, wovon bei kleinen Exemplaren weniger, bei grossen bedentend mehr als die Hälfte vom Afterfelde eingenommen wird. Letzteres ist fünfeckig und zeigt einen äusseren Kreis von 9-11 kleinen Afterplatten, innerhalb deren sich noch etwa 2 Kreise immer kleiner werdender Plättchen erkennen lassen. Das Afterfeld ist anfänglich ganz getrennt von den Ocellarplatten, später grenzt es an zwei oder drei derselben. Die Genitalplatten sind immer kleiner als das Afterfeld, bei den grossen Exemplaren ist der Unterschied sehr viel grösser als bei den kleineren. Die Genitalöffnung ist von mässiger Grösse (q) oder klein (ठ) und liegt zwischen der Mitte und dem äusseren Rande der Platte, von letzterem durch wenigstens eine Reihe von Wärzchen getreunt. Madreporenplatte ist kaum rergrössert. Die Ocellarplatten sind mehr als halb so gross wie die Genitalplatten, breiter als hoch, bei den kleinsten Exemplaren über doppelt so breit als hoch.

Das Apicalfeld ist ziemlich gleichmässig bedeckt von sehr kleinen Wärzchen und mitunter yon einem vollständigen Kreis grösserer Wärzchen umgeben. Die Genitalplatten sind durch auffallend kalle Raine von den benachbarten Plättchen getrennt.

Stacheln. Die Primärstacheln sind etwas kiuzer oder länger als der Schalendurchmesser, cylindrisch, selten spindelfömig und damn gegen das Ende verjünt. Das Ende ist gewölnlich abgestuzt und trägt einen centralen Höcker mit radienfürmig davon ausstrahlenden Lamellen. Die Oberfläche des Schaftes zeigt Längsreihen grober Körnchen, die am äussersten Ende Lamellen bilden. Die Sekundärstacheln des Scrobicularringes sind mässig lang, breit und flach, bis zum abgerundeten Ende nicht verschmälert; die des A. F. sind etwas kiirzer aber viel schmäler.

Fon Pedicellarien trifft man

1) eine dickkünfige Form mit mässig starker Bewaffnung spärlich anf den Nähten des I. A. F., mit einem schlanken Stiele von der 3-4fachen Kopflänge; der Stiel zeigt an der Basis des verdünten oberen Endes einen kurzen Spitzenkragen; dieselbe Form anf sehr kurzem Stiel steht auf dem Apicalfelde (Taf. IX Fig. 4, b, e);

2) eine kleine kaum bewaftnete Form mit schlanken Köpfchen findet sich überall anf einem Stiele, der die fünfache Kopflänge erreichen kann; sie ist mitunter ausserordentlich zahlreich im A. F. und I. A. F. (Fig. 4, d, f);

3) eine dritte fast unbervaffnete Form von bedentender Grösse mit löffelförmigen weit klafłenden Klappen anf einem oft mehr als kopflangen Stiele steht überall bisweilen in grösserer Zahl und fehlt nur auf dem Apicalfelde; neben der gewöhnlichen sehr schlanken Form finten sich mitunter selı in die Breite entwickelte plumpe liöpfchen (Fig. 4, a, c).

Farbe. Im trockenen Zustande sind die kleineren, die Schale dicht bedeckenden Stacheln schwärzlich violett, die grossen Primärstacheln erscheinen grau. Die kleineren Primärstacheln lassen dentliche Querbinden erkennen.

Nir liegen Exemplare dieser Art vor von La Paz und von Panama; von letzterem Orte enthalten die Sammlungen des "Vettor Pisani" eine Anzall von Exemplaren.

Mit zunehmender Grösse (von $13-51 \mathrm{~mm}$. Durchmesser) treten an der Schale ron ('iduris thouarsii folgende Veränderungen ein :

Die Schale wird verhältnissmässigg höhel.

Die Zahl der Ambulacralplatten rermehrt sich stark.

Im A. F. rïcken die beiden randständigen Warzenreihen allmilhig immer weiter auseinander und lassen Platz zur Entwickelung von 1-6 Reilıen Miliarwärzchen.

Die Zahl der" Coronalplatten steigt von 5-10 in einer' Vertikalreihe.

Die primären Warzenhöfe werden immer stärkel elliptisch.

Längs der Mittellinie des I. A. F. entsteht ganz allmählich ein immer breiter werlendes ron Wärzchen bedecktes Miliarfeld. 
Der Durchmesser des Buccal- und des Apicalfeldes nimmt verlualtnissmässig langsamer zu als der der Schale, die Genitalylatten wachsen langsamer an Grösse als das Afterfeld. Das letztere schiebt allmählig einige Genitalplatten weit auseinander und grenzt in Folge davon an mehrere der Ocellarplatten.

\section{Cidaris (Eucidaris) galapagensis n. sp.}

Taf. IX Fig. 3, a-d, Taf. I Fig. 1-14.

Die Schale (ron 19-37 mm. Durchmesser) ist etwa doppelt so breit als hoch. Beide Pole sind flach.

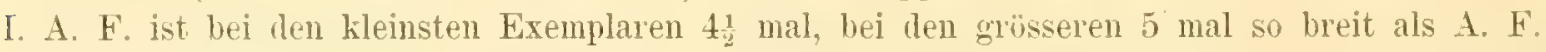

Ambulacralfeld ist nur sehr wenig wellig. Anf eine Coromalplatte an der Peripherie treffen beim kleinsten Exemplar 9, beim grössten 11 Ambulacralplatten. Das Porenfeld ist kaum rertieft, die Poren eines Paares sind nicht gejocht, einander genähert, die Paare etwas schief gestellt. Das Mittelfeld hat bei kleineren Exemplaren die Hälfte, bei grösseren $\frac{2}{5}$ der Breite des A. F. Die randständigen Warzenreilhen des Mittelfeldes bestehen ans grossen dichtstehenden und dadurch verbreiterten Sekundärwarzen, die stark hervorragen; die beiden Reihen stehen auch bei den grössten Exemplaren sehr nahe beisammen und lassen zwischen sich nur Raum für eine einzige, bei kleinen Exemplaren sehr unvollständige Reihe winziger Miliarwärzchen.

Im Interambulacralfelde bilden je nach der Grösse der Exemplare 5-7 Coronalylatten eine Vertikalreihe. Die Hauptwarze ist glatt, von mässiger Grösse, auf etwas vortretender Basis ; der Warzenhof ist nicht vertieft. Er ist schon etwas oval bei kleinen Exemplaren, sehr beträchtlich wird dies bei grossen. Die benachbarten Höfe fliessen fast in ihrer ganzen Breite zusammen; sie sind anf' beiden Seiten von je 4-6 grossen stark vorsuringenden Wärzchen begrenzt. Bei kleineren Exemplaren ist ein medianes Miliarfeld kanm noch entwickelt und trägt nur sehr vereinzelt stehende Miliarwärzchen; bei den grüsseren Exemplaren bleibt ein schmales F'eld zwischen den beiderseitigen Scrobicularringen mit etwa 2 Reihen winziger Miliarwärzchen. Die Mittelnaht ist kaum zı erkemnen. Die Scrobicularringe grenzen direkt an die Porenzone.

Das Buccalfeld ist etwa halb so breit als der Schalendurchmesser, das Apicalfeld hat wenig. mehr als ein Drittel dieser Breite, wovon über die Hälfte auf das Afterfeld kommt. Dasselbe zeigt einen iusseren Kreis von 11-12 kleinen Afterplatten, immerhalb deren sich noch etwa 2 weitere Kreise immer kleiner werdender Plättchen erkennen lassen, deren innerste fast kürnchenfürmig sind. Bei den kleineren Exemplaren ist das Afterfeld fast ganz eingeschlossen ron den Genitalplatten, bei den grüssten grenzen 3 Afterplatten mit einer Seite an Ocellarplatten. Die Genitalplatten sind klein, bei kleineren Exemplaren kaum breiter als hoch, bei grossen viel breiter als hoch. Die Genitalöffnung ist klein (o), nahe der Mitte, oder mittelgross (q), näher dem Aussenrande der Platte liegend. Die Madreporenplatte ist sehr wenig vergrüssert. Die Ocellarplatten sind mehr als halb so gross als die Genitalplatten, riel breiter als hoch. Das Apicalfeld ist ziemlich gleichmässig von mässig grossen zerstrent stehenden Wärzchen berleckt, unter denen die äussersten rergrössert sind und rings un das Apicalfeld einen mitunter ziemlich deutlichen Kreis bilden. Die Nühte sind deutlich, aber bilden keine kahlen Raine zwischen den Platten.

Stacheln. Die längsten Primärstacheln, zwischen Apicalfeld und Peripherie, sind so lang oder etwas länger als der Schalendurchmesser. Sie sind keulen- oder spindelfürmig, in der Hitte des Schaftes bedentend dicker als am Hals, gegen das Ende ofter etwas verjünt. Das Ende ist gewöhnlich abgestutzt und zeigt einen centralen Höcker mit radienfürmig davon auslaufenden Lamellen. Die Oberfläche des Schaftes trägt zahlreiche Längsreihen sehr grober Körner, die gegen das Ende in Lamellen rerlanfen. Weniger keulenformig, mitunter abgeplattet und fast glatt sim die kleineren Primärstacheln. Besonders in der Nähe des Apicalfeldes treten (junge) Primärstacheln anf von der Form der grössten, doch mit nahezu glatter Oherflache.

Bei einem Exemplare finden sich in der Nähe res Buccalfeldes Primärstachehn, deren Schaft, oder wenigstens die obere Hälfte desselben, birnen- und kugelförmig aufgetrieben ist, mit rollständig glatter Oberfläche; das Ende kann bei diesen etwas ansgehöhlt sein (wahrscheinlich monströse Ausbildmig).

Die Sekundärstacheln des Scrobicularringes sind von mạssiger Grösse, breit und platt, mit abgestutztem oberen Ende: die des A. F. simd kïrzer md viel schmäler. Die Miliarstacheln stellen selır kleine Plättchen dar.

Ton Pedicellarien fand sich eine dickköpfige Form, mit mässig bewaftheten Kỉappen auf einem Stiele ron 1-3 facher Ḱopflänge, sehr häufig an den Nähten des I. A. F. (Taf. IX Fig. 3, a, c). Eine andere Form mit kleinem ziemlich schlankem Kopfe, kaum bewaffnet, deren dïmer Stiel die 2-5 fache Kopflänge erreicht, steht in grosser Anzahl auf den Coronalplatten und dem Buccalfelde, und dieselbe Form ron winziger Grösse mit selır kurzem Stiele im A. F. (Fig. 3, b, d).

Farbe. Die Schale und die kleineren Stacheln sind dunkel rothbram bis violett; der Schaft der erwachsenen grossen Stacheln erscheint hellgran. 
TVenige Exemplare diesel bemerkenswerthen Art fanden sich in den Sammlmngen des "Vettor Pisani". Sie' stammen von den Galapagos, ans der Nähe der Floriana- mi Chatham-Insel.

Ein kleines Exemplar, ebendaher, aus $30 \mathrm{~m}$. 'Tiefe, von nur $7 \mathrm{~mm}$. Durchmesser, glanbe ich zu derselben Art stellen zu dürfen (Taf. X Fig. 11-14). Es zeigt folgende Verschiedenheiten von den grüsseren Exemplaren :

An eine Coronalplatte der Peripherie grenzen nur 5 Ambulacralplatten; das Mittelfeld ist halb so breit als das A. F. und zeigt zwischen den beiden an einander stossenden Reihen von Randwarzen keine weiteren Wärzchen.

Im I. A. F. bilden nur 4-5 Coronalplatten eine Reilie. Der Hauptwarzenhof ist nahezu rund; von den Wärzchen des Scrobicularringes treten etwa 4 gegen die Mittellinie hin auf, auf der Seite des Porenfeldes meist nur eines am oberen und eines am unteren Rande der Platte. Für weitere Wärzchen ist kein Platz im I. A. F.

Das Apicalfeld ist lalb so breit als der Schalendurchmesser. Das Afterfeld zeigt 7 grössere Platten in einem äusseren Kreise, an die sich nach imen noch etwa ein hreis kleinerer Afterplättchen anschliesst. Die Genitalplatten stossen sämmtlich an einander und trennen die Ocellarplatten ziemlich weit von dem Afterfelde; sie sind so hoch als breit, ihre äussere Hälfte ist stark eingeschniurt durch die Ocellarplatten, die so breit aber nur halb so hoch sind als die Genitalplatten. Das Apicalfeld wird ron einem Kranz stark rorspringender kleiner Wärzchen umsäumt, einzelne kleinere Wärzchen stehen nur noch am inneren Rande der Genitalplatten und anf den Afterplatten.

Die Primärstacheln sind fast cylindrisch, nur einzelne sind in der Mitte des Schaftes etwas verdickt.

Die Schale und die Stacheln sind im allgemeinen rothbraun; der innere Rand der Ocellarplatten ist gelblich.

An den Exemplaren ron Cidaris galapagensis lassen sich mit zunehmender Grösse (ron 7 mm. bis $37 \mathrm{~mm}$. Schalendurchmesser) folgende Verändermingen constatiren:

Das I. A. F. wird im Vergleich zum A. F. breiter.

Die Zahl der Ambulacralplatten nimmt stark zu.

Das ambulacrale Mittelfeld nimmt weniger an Breite zu als die Porenzonen; es entwickelt zwischen den beiden Reihen von Randwarzen nur sehr langsam eine Reihe von Miliarwärzchen.

Die Zahl der Coronalplatten vermehrt sich langsam.

Die Warzenhöfe werden immer mehr elliptisch.

Die Scrobicularringe vervollständigen sich auf den beiden Seiten der Warzenhöfe.

Es entsteht im I. A. F. sehr allmählig ein schmales medianes Miliarfeld mit wenigen Miliarwärzchen.

Das Apicalfeld vergrössert sich langsam im Vergleich zur ganzen Schale, das Afterfeld verhältnissmässig rascher als das ganze Apicalfeld.

Das ursprünglich weit von den Ocellarplatten getrennte Afterfeld schiebt allmählig mehrere Genitalplatten aus einander und grenzt zuletzt an eimige der Ocellarplatten.

Die Genitalplatten nelmen mehr an Breite als an Höhe zu.

Das Apicalfeld bedeckt sich frühzeitig mit Wärzchen.

Die Primärstacheln verdicken sich ziemlich bald.

Cidaris galapagensis ähnelt der westamerikanischen C. thouarsii so seln, dass ich läugere Zeit schwankend war, ob sich eine specifische Trennung dieser beiden Formen rechtfertigen lasse. Einige Unterschiede scheinen aber constant genug zu sein um eine solche 'Trennung vorzunehmen.

Bei C. thoutarsii entsteht im A. F. und I. A. F. eine allmählig immer breiter werdende von Miliarwärzchen bedeckte mediane Zone, die bei C. galapagensis immer nur selır schmal bleibt, so dass darin grosse Exemplare von C. galapagensis jugendlichen $C$. thouarsii ähneln. Im Apicalfeld fehlen bei $C$. galapayensis die bei $C$. thouarsii entwickelten kahlen Raine an den Nähten der grösseren Platten. Am auffiallendsten ist der Unterschied der keulenförmigen Primärstacheln von C. galapagensis und der stabförmigen Stacheln von C. thouarsii; doch haben jugendliche Formen ron $C$. galapagensis noch stabförmige Stacheln.

Die dickköpfigen Pedicellarien sind bei beiden Formen sehr verschieden; auch scheinen die grossen Pedicellarien mit lüffelförmigen Klappen, die bei $C$. thouarsii häufig sind, ganz bei der neuen Form zu fehlen.

Jedenfalls aber haben wir beide Arten als sehr nahe Verwandte anzusehen, und es diurfte keinen I'unkt geben, durch den sich jugendliche Exemplare von galapagensis, deren Stacheln noch nicht keulenförmig sind, mit Sicherheit von gleich grossen C. thouarsii unterscheiden lassen. Selbst stachellose Exemplare ron ca $20 \mathrm{~mm}$. Durchmesser werden noch kaum sicher zu unterscheiden sein. 
Von allen recenten Cidariden ist $C$. galapagonsis diejenige, die noch am besten den Typus der kenlenfurmigen Stachehn repräsentirt zeigt, welche uns unter den fossilen Formen der Sekundärzeit so läuffig entgegentreten, und die bei den lebenden Formen nur noch bei $L$. imperialis, aber in viel weniger ausgeprägter Weise, rorkommen. Die am meisten kenlenförmig ansgebildeten Stacheln der nenen Art erinnem z. B. sehr an solche von C. florigemma. Daneben kommen noch, wie es aber scheint, nur als monströse Bildungen, bei unserer Art Stachehn ror, die birnfümig sind oder gar in eine dicke Kiugel enden, wie wir sie fossil bei C. clavigeru oder, den vorliegenden etwas unregelmässigen Formen noch ähnlicher, bei $C$. plercacanthu aus der Lreide vorfinden.

\section{Leiocidaris verticillata LAMARK.}

$$
\text { 'Taf'. IX Fig. 8, a-i. }
$$

Pleyllacanthus rerticillata A. Acissiz, Revision of the Echini.

Rhaldocidaris rerticillata DE LORIOL, 1883. C'atal. rais. des Échinodermes de Maurice.

Schale (von $4 \mathrm{~mm}$. und $18.5 \mathrm{~mm}$. Durchmesser) ist etwa doppelt so breit als hoch, an beiden Polen flach. I. A. F. ist bei dem grösseren Exemplare 4 mal so breit als das A. F., bei dem kleinen verhältnissmässig schmäler.

Das Ambulacralfeld ist kaun gewellt; an der Peripherie grenzen bei dem kleinen Exemplar 3 (4), bei dem grösseren 7-8 Ambulacralplatten an eine Coronalplatte. Das Porenfeld ist nicht vertieft; bei dem grösseren Exemplare liegen die Poren eines Paares ziemlich nahe beisammen; eine sie verbindende Furche ist nicht zu erkemen, anch sind die Paare durch keine rortretende Leiste von einander getremnt. Bei dem kleinen Exemplare liegen beide Poren in einer Vertiefung sehr nahe beisammen, sind aber nicht gejocht; die Paare stehen auffallend schief und sind weit ron einander getremnt. Das Nittelfeld zeigt undeutliche Randwärzchen, die bei dem grüsseren Exemplare sehr stark vorspringen und zwischen sich eine breite mediane Zone lassen, die abgesehen von selı vereinzelten kaum sichtbaren Körnchen völlig kahl ist und ziemlich dentlich die Nähte erkemnen lässt.

Im Interambulacralfelde bilden 5 Coronalplatten eine Vertikalreihe, während bei dem kleinen Exemplare nur deren 3, höchstens 4 vorhanden sind. Die Hauptwarze ist gross, auf glatter stark vorspringender Basis, der Warzenhof rund (an der Peripherie) und durchaus nicht vertieft. Die Scrobicnlarringe bestehen aus etwa 12 Wärzchen, sie sind vollständig und berühnen sich an den Horizontalnälıten; ausser diesen Wärzchen sind keine weiteren auf den Coronalplatten entwickelt; längs der interambulacralen Mittelnaht befindet sich ein ziemlich breites nacktes Feld, auf dem nur vereinzelte Körnchen, die Pedicellarien tragen, Platz finden. Diese Mittelzone ist bei dem kleinen Exemplar noch gar nicht vorhanden, und von dem Scrobicularring sind mur einzelne mdeutliche Würzchen auf der medianen Seite des Warzenhofes entwickelt.

Das Afterfeld zeigt einen äusseren Lreis von 10 Platten bei dem grösseren Exemplar, imnerhalb dessen sich noch wenigstens 1 Kreis dentlicher aber viel kleinerer Plätchen findet. Die Genitalplatten (etwa halb so gross als das Afterfeld) sind so hoch als breit und stossen nur an zwei Stellen nahezu aneinander, wälrend drei der Ocellarplatten mit einer schmalen Seite an das Afterfeld grenzen. Die Genitaiöffunng ist etwas nälier der Mitte als dem äusseren Rande der Platte. Die Ocellarplatten sind nicht viel kleiner als die Genitalplatten, viel breiter als hoch.

Bei dem kleineren Exemplare sind nur sechs grosse äussere Afterplatten rorhanden, imnerhalb deren sich noch wenige viel kleinere Plättchen finden. Die Genitalplatten sind fast so gross als das Afterfeld, um das sie einen geschlossenen Ring bilden, und das sie dentlich von den Ocellarplatten tremnen. Die letzteren sind etwa halb so gross als die Genitalplatten und viel breiter als hoch. Ausser einigen Stachelchen und Pedicellarien auf dem äusseren Kand des Apicalfeldes finden sich nur auf den Afterplatten stacheltragende Wärzchen entwickelt. Auch bei dem grösseren Exemplar finden sich sonst nur noch vereinzelte Körnchen auf den Genital- und Ocellarplatten.

Stacheln. Schon bei dem kleinen Exemplar tragen einige der lïngsten Primärstacheln Andentungen der wirtelfürmigen Vorsprünge, die so charakteristisch sind für diese Art.

Die Sekundirstacheln sind sehr platt und breit, in der Ilitte am breitesten.

Von Pedicellarien ist vorhanden

1. eine dickköpfige wohlbewaffnete Form mit vorgestrecktem aberem Ende der KRlappen anf einem Stiele ron ein- bis rierfacher Kopflänge (Taf. IX Fig. 8, c, f); sie stehen zahlreich an den Nähten des I. A. F. und finden sich anch auf dem Apicalfelde; der diumne Stiel ist ansgezeichnet durch einen aus langen Spitzen bestehenden Kragen an der Basis des verdünten Halses;

2. eine viel kleinere schlanke Form, deren Klappen oben ein paar lange spitze Zälne tragen, mit einem dïmnen Stiele von zwei- bis dreifacher Kopflänge; auf der ganzen Schale zahlreich (Fig. 8, d, lr); 
3. eine winzige Form, mit unberraffineten sehr schlanken löffelartigen Klappen ist selten; eine ähnliche. doch bedentend grössère Form fand sich bei dem jungen Exemplar auf dem Apicalfelde (Fig. 8, a, e);

4. von einer winzigen korbartigen Form, unbewaffnet mit auffallend weit geöffneter Centralkammer, fand ich einzelne Klappen auf einem Präparate (Fig. 8, g).

Die beiden mir hier vorliegenden Exemplare sammelte ich bei der Liukiu-Insel Amami Oshima an Milleporenstöckchen, aus etwa 2 Faden Tiefe.

Die Veränderungen, welche beim Wachsthum ron $4-18.5 \mathrm{~mm}$. Schalendurchmesser zu constatiren sind, sind etwa folgende:

Das A. F. wirl im Tergleich zum I. A. F. viel schmäler.

Die Zahl der Ambulacralplättchen vermehrt sich stark.

Die Poren eines Paares rücken weiter auseinander und werden undentlich gejocht; die Paare nehmen allmählig eine horizontale Lage an; es entsteht ein nackter Medianstreifen im Mittelfelde.

Die Coronalplatten nelumen langsam an Zahl zu; die Scrobicularringe vervollständigen sich; längs des interambulacralen Mittelfeldes bildet sich allmählig eine breite nackte Fläche aus.

Die Zahl der Afterplatten vermehrt sich, das Afterfeld wird grösser und drängt die Genitalplatten ans einander, um an einige der Ocellarplatten zu grenzen.

Die Wirtel an den Primärstacheln werden dentlicher und zahlreicher.

\section{Leiocidaris baculosa LAMARK.}

Taf. IX Fig. 10, a-g:

Phyllacanthus baculosa A. Agassiz, Rerision of the Echini.

Rhabdocillaris baculosa DE LORTOL, Cat. rais. des Echinodermes de Haurice.

Schale (ron 32-57 mm. Durchmesser) ist bei kleineren Exemplaren doppelt so breit, bei dem grössten kaum rum ein Drittel breiter als hoch, oben und unten flach; sie ist ziemlich diun und besunders das Apicalfeld besteht ans sehr dümen Platten.

I. A. F. ist $3-4$ mal so breit als das A. F.

Das Ambulacralfeld ist fast gerade; auf eine Coronalplatte an der Peripherie kommen 10-11 Ambulacralplatten. Das Porenfeld ist kaum vertieft; die Poren eines Pares stehen weit auseinander, sind deutlich gejocht, die einzelnen Paare durch niedere Leisten von einander getrennt. Die Breite des Mittelfeldes beträgt bei kleineren Exemplaren $\frac{2}{5}$, bei den grösseren nur $\frac{1}{3}$ von der des A. F. Zwischen den Randwärzchen befindet sich ein ziemlich breiter Raum, der bei den kleineren Exemplaren 2 regelmässige Reihen weit von einander stehender sekr kleiner Wärzchen zeigt, damn drei, bei dem grössten mindestens 4 Reihen, von denen die äusseren neben den Randwärzchen stehen, die imneren unregelmässig dicht neben der Mittellinie.

Im Interambulacralfelde bilden 7-11 Coronalplatten je nach der Grösse der Exemplare eine Tertikalreihe. Die Hauptwarze sitzt auf einer stark vorspringenden, ifter theilweise gekerbten Basis; der Warzenlıof ist nicht vertieft, bei kleineren Exemplaren wenig, bei grossen sehr stark oval. Der Scrobicularring ist bei kleineren Exemplaren manchmal vollständig, aus einem Kreis kleiner, aber immerhin auffallender Wärzchen gebildet; bei anderen besonders den grossen Exemplaren berühren sich die benachbarten Warzenhöfe in ihrer ganzen Breite und fliessen ineinander, so dass der Scrobicularring nur an der Seite entwickelt ist; bei diesen tritt noch ein zweiter Kreis fast gleich grosser Wärzchen hinzu. Geg'en die Porenzone wie gregen die Mredianlinie bleibt bei den kleineren Exemplaren ausserhalb des Scrobicnlarringes ein schmaler von winzigen zerstrent stehenden Miliarwärzchen bedeckter Raum, der bei den grossen Exemplaren gegen die Mittellinie hin bedentend an Breite zunimmt. Die Mediammaht bildet meist eine leicht vertiefte Linie, ist aber mitunter auch ganz undentlich.

Die Breite des Mundfeldes ist nicht grösser als die Hälfte des Schalendurchmessers, die des Apicalfeldes ist selır variabel und schwankt zwischen der Hälfte und einem Drittel des Schalendurchmessers: daron kommt, besonders bei den grossen Exemplaren iiber die Hälfte auf das Afterfeld.

Dasselbe zeigt bei kleineren Exemplaren 11 äussere Afterplatten von geringer Grösse, immerhalb deren sich noch 2 Kreise dentlicher aber immer kleiner werdender Plättchen befinden; an mehreren Stellen durchbriclit das Afterfeld den Genitalring und grenzt mit schmalen Seiten an Ocellarplatten, während sich an anderen Stellen die Genitalplatten gerade noch berühren. Die Genitalplatten sind klein, die Madreporenplatte etwas vergrössert, die Ocellarplatten etwa halb so gross, dreieckig und breiter als hoch. Bei den grossen Exemplaren finden sich bis zu 15 äussere Afterplatten von sehr rerschiedener Grösse, die sämmtliche Genitalplatten weit auseinander geschoben haben und mit breiten, manchmal auffallend breiten Seiten an die Ocellarplatten stossen; 
letztere sind mitunter sehr klein und viel breiter als hoch; die Madreporenplatte ist bedentend vergrössert. Die Grüssenverlältnisse der Apicalplatten variiren übrigens sehr bedentend bei verschiedenen Individuen, ebenso wie die Gestalt der einzelnen Platten.

Von Pedicellarien finden sich bei L. baculosa:

1) Eine dickköpfige Form, deren Klappen sich auszeichnen durch das schmauzenförmig vorspringende obere Ende, das mit kräftigen Zähnen versehen ist; der Stiel hat bis etwa vierfache Kopflånge und trägt an der Basis des Halses einen auffallenden aus langen Spitzen bestehenden Kragen; diese Form ist fast überall zu finden, besonders an den Nähten des I. A. F. (Taf. IX Fig. 10, a, e).

2) Eine Form mit schlankerem kegelförmigen Köpfchen, das die Grösse der vorigen Form erreichen kann, oft auch sehr klein ist; die Klappen sind kamm bewaffnet mit Ausuahme eines kurzen Zälnchens am oberen Ende; der Stiel, ohne Stachelkragen, erreicht oft die fünffache Kopflänge; diese For'n findet sich ïber die ganze Schale verbreitet (Fig. 10, b, d).

3) Eine fast unbewaffnete Form mit schmalen löffelförmigen Kilappen, deren Basis stark anfeeschwollen ist und die etwa die Grösse der beiden anderen Formen erreicht, ist selten zn treften (Fig. 10, c, f).

Die miv vorliegenden Exemplare stammen von Mauritius und dem Rothen Meere; die letzteren fanden sich in den Sammlungen des "Vettor Pisani".

Beim Grösserwerden der Schale (von 33-57 mm. Durchmesser) scheinen bei dieser Art folgende Veränderungen vor sich zu gelıen:

Die Schale wird verhältnissmässig lioher.

Die Porenzone nimmt mehr an Breite zu als das ambulacrale Nittelfeld; dasselbe erhält allmählig eine grössere Anzahl Miliarwärzchen.

Die Zahl der Coronalylatten wichst ziemlich stark.

Die Warzenhöfe werlen immer mehr elliptisch und durchbrechen den Scrobicularring an den Beriilırıngsstellen.

Der Scrobicularring erhält allmälllig noch eine zweite äussere Reilıe fast gleich grosser Wärzchen.

Das interambulacrale Miliarfeld wird bedeutend breiter.

Das Afterfeld wird verhältnissmässig grösser, die Zahl der Afterplatten wird bedentender und die Genitalplatten werlen immer weiter anseinander gedrüngt durch die Afterplatten. Die Ocellarplatten nehmen wenig an Grösse zu; die Madreporenplatte rergrössert sich viel rascher als die übrigen Genitalplatten.

Diese Art ist ausserordentlich variabel, besonders die Stacheln zeigen bei verschiedenen Individuen auffallende Verschiedenheit, ein Punkt, der schon von anderer Seite hinreichend erörtert worden ist.

\section{Leiocidaris annulifera LAMARK.}

$$
\text { Tatt. IX Fig. 10, l, i. }
$$

Phyllacanthus anmulifera A. Agassiz, Revision of the Echini.

A. Agassiz, Rep. ou the Echinoidea of the Challenger-Expedition.

Cidaris amulifera DE LORIOL, Description de trois espèces d'Échinides.

Die Schale eines jugendlichen Exemplares ron $12 \mathrm{~mm}$. Durchmesser ist ïber doppelt so breit als hoch, oben und unten flach.

I. A. F. ist $3 \frac{1}{2}$ mal so breit als das A. F.

Das Ambulacralfeld ist fast gerade; anf eine Coronalplatte an der Peripherie trefien 7 Ambulacralplatten. Das Porenfeld ist nicht vertieft. Die Poren eines Paares stehen nahe beisammen und sind nicht gejocht; die Paare sind etwas schief gestellt und nicht durch Leisten von einander getrennt. Das Mittelfeld ist kaum halb so breit als das A. F. Es zeigt an beiden Rändern eine Reilıe kleiner aber vorspringender Sekundärwärzchen, getrennt durch eine sehr schmale und seichte mediane Furche, die mit Ausnahme winziger zwischen je zwei Randwärzchen einer Seite etwas hineingedrängter Könchen glatt ist.

Im Interambulacralfelde bilden 5 Coronalplatten eine Vertikalreihe. Die Hauptwarze sitzt auf einer stark vorspringenden oft leicht gekerbten Basis, die sich vom Scrobicularkreis an erhebt; letzterer ist fast kreisrund, wenigstens an der Peripherie vollständig und besteht aus etwa 15 kleinen aber auffallenden Wärzchen. Der Scrobicularkreis berüht auf allen Seiten den Rand der Platte und lässt höchstens gegen die Ilerlianlinie zu einen äusserst schmalen glatten Rand frei.

Das II ndfeld ist halb so breit als der Schalendurchmesser, das Apicalfeld mbedentend kleiner; über die Hälfte dayon kommt auf das Afterfeld. Dasselbe ist ein regelmässiges Fünfeck mit einem äusseren Kreis 
von 10 mässig grossen Afterplatten; die Genitalplatten stossen noch eben aneinander; sie sind viel kleiner. als das Apicalfeld, etwa so hoch als breit; halb so gross sind die Ocellarplatten. Die Madreporenplatte ist. kaum vergrüssert; Genitalöffnnngen sind nicht zı erkennen. Die Genital- und Ocellarplatten sind spärlich, das Analfeld dicht mit kleinen Wärzchen bedeckt.

Stacheln. Die längsten Primärstacheh sind etwa um ein Drittel grösser als der Durchmesser der Schale, am dicksten an der Basis des Halses und bis zu dem plötzlich abgestutzten Ende gleichfürmig verjüngt; sie sind von leicht gekerbten Längsleisten bedeckt, die obersten fast glatt. Auffallend sind die in Längs- und Querreilien angeordneten violetten Punkte am glatten Halse der Primärstacheln, die am Schaft des Stachels zn sehr schmalen, gegen das Ende des Schaftes hin immer breiter werdenden Querringen verschmelzen; an einem Stachel finden sich bis 7 Ringe.

Die Sekundärstacheln sind selrr sclmal, bis zur Spitze gleich breit, platt, von dunkel violetter Farbe, bei den Stacheln des Scrobicularringes mit einem breiten hellen Saume rersehen.

Von Pedicellarien wurden ähnliche Formen gefunden, wie sie oben bei $L$. baculosa unter 1) und 2) besclirieben sind.

Das einzige mir vorliegende Exemplar von $12 \mathrm{~mm}$. Durclmesser stammt von Amboina,

Das hier beschriebene Individumm hatte ich zuerst für ein jugendliches Exemplar von $L$. baculosa angesehen, bis mir DE LoRIoL's Abbildung von C. amnelifera zugänglich wurde, die mir über die Identität mit dieser Art keinen Zweifel liess. DE Loriol's Beschreibung der Schale eines Exemplars von $37 \mathrm{~mm}$. Schalendurchmesser stimmt aber so auffallend mit einem etwa gleich grossen Exemplare von $L$. baculosa aus dem Rothen Meere überein, dass in mir Zweifel entstanden, ob es gerechtfertigt ist, die beiden Arten specifisch zu tremen. Anch die Beschaffenheit der Poren, die von DE Lonor znerst als "ungejocht" bezeichnet wurde, hat er selbst später in Übereinstimmung mit den Angaben von AL. AgAssiz doch als gejocht" erklärt. Einen Unterschied zwischen den beiden Arten kann ich nur in der Färbung der Primärstacheln finden; denn selbst die Form der Primärstacheln kamm bei bestimmten Individuen beider Arten identisch sein (vergl. DE LonioL, C. ammulifera in Description de trois espèces d'Échinides tab. 3 und DE LoRIoL, Rh. baculosa in Échinodermes de l'isle de Maurice tab. 2). Nur die Färbung des Schaftes ist verschieden, indem $L$, ammlifera Querbinden zeigt, die L. baculosı fehlen; die eigenthümliche und auffallende Tüpfelung des Stachelhalses dagegen, die sonst nirgends zu beobachten ist, findet sich bei beiden Arten in gleicher Weise. Nachdem aber eine Autorität wie At. Adissiz auf Grund eines reichlichen Materials die Frage nach der möglichen Identität der beiden Arten überhaupt nicht aufwirft, kann ich es nicht wagen bei meinem ganz unzulänglichen Materiale eine solche zu behaupten. Ich kam hier nur constatiren, dass die oben beschriebene jugendliche $L$. cmmiferca nach illren sämmtlichen Charakteren, abgeselien nur von der Färbung der Stacheln, unberingt als ein junges Exemplar von $L$. baculosa gelten künnte, da sie in allen den Punkten, in denen sie sich von grüsseren Exemplaren dieser

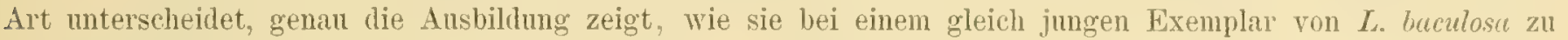
erwarten wäre.

Vollständig übereinstimmend sind auch die Pedicellarien, und es ist sicher ebenfalls nicht olne Bedeutung, dass bei beiden Arten mit ziemlicher Regelmässigkeit sich einige gekerbte Hauptwarzen an der Schale finden.

Hier möchte ich auch noch auf die grosse Ähnlichkeit ron Schleinitzin cremularis Sruber.(1881, Monatsber. Akad. Wiss. Berlin) mit L. anmulifur aufmerksam machen; nach meiner Überzengung sind die Irei Arten baculosa, ammliferc und cremularis anfs immigste mit einander verwandt.

\section{Leiocidaris imperialis LAMARK.}

T'af. IX Fig. 7 , a-f.

Leiocidaris imperialis Désor, 185ّ, Symopsis des Échin. foss.

Phyllacantlus imperiatis Az. Agtassiz, Rerision of the Echini.

dubia AL. Agassiz, ibid.

Rhar dociduris imperiatis DE LORIOL, 1883, Échinid. de I"isle de Maurice. dubia DE LORIOL, ibid.

Schale (von 36 bis $65 \mathrm{~mm}$. Durchmesser) ist bei kleineren Exemplaren fast doppelt, bei grösseren nur $1 \frac{1}{2}$ mal so breit als hoch, an beiden Polen flach, mo von mässiger Dicke.

I. A. F. ist $5 \frac{1}{2}$ bis 6 mal so breit als das A. F.

Das Ambulacralfeld ist stark gewellt; auf eine Coronalplatte an der Peripherie kommen 15-18 Ambulacralplatten. Die Porenzonen sind kaum vertieft, Poren dentlich gejocht. Das A. F. ist bei kleineren Exemplaren etwa $2 \mathrm{mal}$, bei grösseren his fast $3 \mathrm{mal}$ so breit als das Mittelfeld. 'Zwischen den randständigen 
Sekundärwïzchen bleibt ein schmaler Ram übrig, etwa ron der Breite eines Randwärzchens, der rollstimdig bedeckt ist mit viel kleineren Miliarwärzchen, die zwei mehr oder weniger deutliche alternirende Reihen bilden.

Im Interambulacralfelde bilden 5, bei den grösseren Exemplaren 6 Coronalplatten eine Vertikalreihe. Die Hauptwarze ist gross, auf glatter vorspringender Basis; der Warzenlof ist kaum vertieft, an der Peripherie der Schale elliptisch, bei den grösseren Exemplaren etwas mehr als bei kleineren, umgeben von einem ans 14-16 grossen Wärzchen bestehenden Scrobicularring, der die benachbarten Höfe vollständig von einander trennt, längs der Horizontalnaht aber kleinere mit dem benachbarten Kreise alternirende Wärchen zeigt. Der mittlere Interambulacralranm ist stets sehr schmal und bietet Platz für 2 Reihen gedrägt stehender kleiner Miliarwärzchen, zwischen die sich bei grossen Exemplaren noch einige winzige weitere Wärzchen einschieben.

Die Breite des Buccalfeldes ist fast genau die Hälfte des Schalendurchmessers, während die des Apicalfeldes bei kleineren Exemplaren $\frac{2}{5}$, bei grösseren nur $\frac{1}{3}$ dieses Durchmessers zeigt, wovon auf das Afterfeld etwa die Hälfte kommt. Dasselbe ist ein unregelmässiges Fünfeck mit einem äusseren Kreis von 10 mässig grossen Afterplatten, innerhalb deren viel kleinere Plättchen noch wenigstens einen deutlichen Kreis bilden. Die Genitalplatten sind ron ungleicher Grösse, meist viel breiter als hoch und stossen mit den Seiten zusammen, das Afterfeld stets weit von den Ocellarplatten trenuend. Die Madreporenplatte ist bedeutend vergrössert, meist grösser als das Afterfeld; die Genitalöffnung liegt bald näher dem äusseren Rande, bald, wenn sie sehr klein ist, nälıe der Mitte, doch immer durch TVärzchen vom Aussenrande getrennt. Die Ocellarplatten sind wie die Genitalplatten von sehr verschiedener Grösse bei einem Individum, im ganzen aber seh" klein.

Das Apicalfeld ist gleichmässig dicht von kleinen Wärzchen bedeckt; es lässt sich längs des äusseren und des imneren Randes der Genitalplatten, dentlicher bei den jüngeren Exemplaren, eine Reihe merklich grösserer Wärzchen erkennen, denen anch etwas grössere Stacheln entsprechen.

Stacheln. Die längsten Primärstacheln sind fast cylindrisch, in der Mitte kaum dicker als am Ende mit mehr oder weniger deutlichen feinen Längsleisten (rar. dubia), oder sie sind spindelförmig, in der Mitte bedeutend dicker als am Ende mit sehr feiner Längsstrichelung (var. imperialis); das äussere Ende vieler und besonders der kleineren Primärstacheln zeigt auffallende Längsleisten.

Die Sekundarstacheln des Scrobicularringes sind gross, flach und breit mit gerade abgestutztem Ende, die des Ambulacralfeldes sind sehr klein, flach, linealisch. Die Miliarstacheln sind schuppenförmig; meist kaum lïnger als breit.

Von Pedicellarien findet sich

1) eine dickköpfige Form, deren Klappen ausgezeichnet sind durch das schnauzenförmig vorspringende und kräftig bezahnte obere Ende (Taf. IX Fig. 7, b, d); sie findet sich auf etwa kopflangem Stiele spärlich an den Näliten des I. A. F.;

2) eine andere nicht viel kleinere Form, aber mit viel schlankeren Köpfchen, die mässig bezahnt sind, auf kurzem, selten über kopflangem Stiel (Fig. 7, a, e) steht auf dem Buccalfeld;

3) eine Form mit meist sehr langen, ziemlich schlanken Köpfchen und mit löffelfürmigen, kaum bewaffneten Klappen, die in der Nähe der Basis klaffen, ebenfalls mit etwa kopflangem Stiele tritt überall mit Ausnahme des Apicalfeldes zahlreich auf (Fig. 7, c); tritt diese Form spälich auf, danm ist die erste Form häufiger.

Die mir vorliegenden Exemplare der Varietät dubir von $42-65$ mm. Schalendurchmesser stammen von Mauritius, die der Varietat imprialis von $36-55 \mathrm{~mm}$. Durchmesser von Mauritius und den Tongainseln.

Mit der Grössenzunahme der Schale ron 36-65 mm. Durchmesser scheinen folgende Veränderungen einzutreten:

Die Schale wird verhältnissmässig höher, die Porenzonen breiter, die Zahl der Coronalplatten nimmt etwas zu, die Warzenhöfe werden mehr elliptisch, das interambulacrale Mittelfeld wird unbedentend breiter, das Apicalfeld schmäler.

Die beiden Formen $L$. impriatis und dubia werden bisher noch als verschiedene Arten aufgefasst, obwohl schon Az. Agassiz die Identitä beider Arten für möglich hielt und pe Lorıo dieselbe sehr wahrscheinlich machte, indem er nachwies, dass die von AGAssiz gegebenen Unterschiede an der Schale keineswegs constant sind. DE LoRIoc nahm nur desswegen von einer Vereinigung der beiden Arten Umgang, weil ihm nicht Exemplare gleicher Grösse zur Vergleichung vorlagen. Unter meinem Nateriale befindet sich nun ein Exemplar ron $55 \mathrm{~mm}$. Durchmesser, das nach der Form der Primärstacheh zu L. imperialis gehört; dasselbe stimmt num in den Details der Schale mit einem gleich grossen Exemplar, dessen cylindrische Stacheln es zur Form dubia verweisen, dermassen iberein (s. Tabelle), gerade auch in den Punkten, die AL. Agassiz als muterscheidende 
Merkmale angab, dass es mir mmöglich scheint, die beiden zı zwei verschiedenen Arten zu rechnen. Zn einem gleichen Resultat fülnte mich anch die Vergleichung der übrigen Exemplare. Bezïglich der Stacheln, die als einziger Unterschied noch ïbrig bleiben, bestehen ja auch die mannigfaltigsten Übergänge von ausgesprochen spindelförmigen zu ganz cylindrischen Formen an einem Exemplare. Besonders hervorzuheben ist, dass anch hinsichtlich der Pedicellarien kein Unterschied zwischen den beiden Formen besteht.

\section{Goniocidaris tubaria LAMARK.}

T'af. IX Fig. 9, a-e.

Goniocidaris tubaria AL. Aasssiz, Revision of the Echini.

Die Schale (von 22-29.6 mm. Durchmesser) ist mehr als $1 \frac{1}{2}$ mal bis fast doppelt so breit als hoch, an beirlen Polen flach und ziemlich dïnn.

I. A. F. ist bei kleineren Exemplaren etwa 3 mal, bei einem grösseren 4 mal so breit als das A. F.

Auf eine Coronalplatte an der Peripherie kommen 9-10 Ambulacralplättchen.

Im I. A. F. bilden 7-8 Coronalplatten eine Vertikalreihe.

Das interambulacrale Miliarfeld ist bei dem grösseren Exemplar viel breiter als bei den kleineren; die winzigen sich an den Scrobicularring anschliessenden Miliarwärzchen bedecken in Folge davon eine bedeutend breitere Fläche als bei kleineren Exemplaren, während die Breite des nackt bleibenden Mittelstreifens weniger zugenommen lạt.

Die Genitalöffnung ist entweder sehr gross (o) und findet sich in der Mitte der Genitalplatte, oder sie ist klein (ठ) und liegt etwas ausserhalb der Mitte.

Von Pedicellarien fand sich eine dickköpfige Form mit völlig kugeligem Kopfe auf ziemlich kurzem Stiele an den Nähten des Apicalfeldes, A. F. und I. A. F., das Köpfchen häıfig in den Winkelgruben liegend (Fig. 9, a, b); bei einem sonst treftlich erhaltenen Individuum aber fellt diese Form von Pedicellarien vollständig. Eine andere Form hat selı schlanke Köpfchen, manclmal von nahezu derselben Länge, deren Klappen kaum bewaffnet sind mit Ausuahme eines winzigen Endzähnchens; der Stiel hat lıöchstens die doppelte Kopflänge; diese Form steht in sehr verschiedener Grösse über die ganze Schale zerstrent (Fig. 9, c, d).

\section{Charaktere jugendlicher Cidariden.}

Sämmtliche Cidariden sind, wie es scheint, in gewissem jugendlichem Alter, das etwa zwischen 3 und $10 \mathrm{~mm}$. Schalendurchmesser liegt, gleichmässig durch eine Reilhe ron Eigenschaften ausgezeichnet, die beim weiteren Wachsthum je nach den Arten mehr oder weniger bedeutenden, oft sehr charakteristischen Teränderungen unterworfen sein kömnen. Solche jugendlichen Charaktere sind die folgenden:

Die Schale ist wenigstens doppelt so breit als hoch.

Die Zahl der an eine Coronalplatte grenzenden Ambulacralplatten ist eine seln geringe.

Die Ambulacralplatten sind nicht viel breiter als hoch.

Die Porenpare sind weit von einander entfernt, getremnt durch einen horizontalen Ausläufer (Leiste) der Ambulacralwärzchen, und nehmen nur einen selır geringen Theil der Ambulacralplatten in Anspruch.

Die Porenpaare stehen schief.

Die Poren eines Paares stehen nahe beisammen und sind nicht durch eine Furche mit einander verbunden (nicht gejocht).

Das mittlere Ambulacralfeld trägt nur die beiden Reihen von Randwärzchen, die sich längs der Vittellinie fast berühren und keinen Raum gewähren zur Bildung von MIiliarwärzchen.

Die Zahl der Coronalplatten ist eine selır geringe.

Die Coronalplatten sind wenig breiter als hoch.

Die Hauptwarze - ist gross, auf stark vortretender Basis.

Die Warzenhöfe sind rund, nicht vertieft und stehen mit einander in Verbindung.

Die Scrobicularringe bestehen aus einer einfachen Reihe von Wärzchen und sind an den Horizontalnähten unterbrochen.

Die Wärzchen des Scrobicularringes berülnen die Mittellinie und lassen hier keinen Platz zur Entwicklung von Miliarwärzchen; ebenso berïhren sie den ambulacralen Plattenrand.

Das Buccalfeld ist nicht kleiner als die Halfte des Schalendurchmessers; ebenso das Apicalfeld. 
Änssere Analplatten sind in geringer Anzahl rohhanden und ron bedeutender Gröse; sie reichen sehr nalue an die Afterïtinung.

Das kleine Analfeld ist vollständig umschlossen ron den Genitalplatten und weit getrennt von den Ocellarplatten.

Die Genitalplatten sind gross, die Ocellarplatten klein.

Es sind keine Gruben oder Furchen vorhanden an den Nähten, auch liegen die Vertikalnähte nicht vertieft.

Die Afteröffnumg ist dicht ron kleinen Stacheln umgeben.

Das übrige Apicalfeld trägt nur sehr spärliche Wärzchen.

Diese verschiedenen Charaktere kömmen je nach der Art auch in späteren Altersstufen unverändert erlralten werden oder sie sind früher oder später grösseren oder geringeren Veränderungen unterworfen. Die anffallendsten und zur Unterscheidung verschiedener Gruppen imnerhalb der Familie am besten dienlichen Charaktere sind meist erst in fortgeschritteneren Altersstadien deutlich.

\section{Wachsthumserscheinungen an den einzelnen Theilen der Cidaridenschale.}

\section{Das Apicalfeld.}

Das jüngste Stadim eines Apicalfeldes fand ich bei G. biserulis ron $3 \mathrm{~mm}$. Genital-, Ocellar- mnd Analplatten waren bereits gesondert; das Analfeld (nicht grösser als eine Genitalplatte) war von sieben Platten bedeckt, die nach dem Verlauf der Nähte dentlich darauf hinwiesen, dass eine einfache ursprüngliche Analplatte erst in zwei, dann in drei Stücke zerfallen war, deren jedes sich num weiter theilte. Eine Afteröffnung war noch nicht zu erkennen. Die grossen Genitalplatten stossen zusammen und tremnen die kleinen Ocellarplatten weit ron dem Analfelde (Seite 12 und Taf. V Fig. 8). Dies Verhältniss zeigen alle Cidariden ziemlich lange. Im Laufe des Wachsthums kam das Grössenverhältuiss annähernd gewahrt bleiben (z. B. C. japonica), oder es kümen die Ocellarplatten verhältnissmässig gross werden (z. B. C. thouarsii), doch nie grüsser als die Genitalplatten, oder es kam das Analfeld bedeutender an Grösse zmehmen als die Genitalplatten.

Sehr häufig durchbricht in letzterem Falle allmählig das Analfeld den vorher geschlossenen Ring ron Genitalplatten an einer oder mehreren (C. thouarsii) oder an allen 5 Stellen (G. biserialis) und kommt so in direkte Berührung mit den Ocellarplatten, manchmal nur mit deren Spitzen, öfter auch mit breiten Seiten.

Selten ist es, dass die zur Madreporenplatte gewordene Genitalplatte allmällig die anderen bedentent an Grösse übertrifit (L. impcrulis); gewöhnlich ist ein Grössenunterschied kaum merklich.

Die Theilung der Analplatten schreitet immer weiter; bei manchen Arten entsteht nur eine beschränkte Anzahl von Analplatten, bei anderen wird dieselbe sehr bedeutend; am hänfigsten bilden etwa 10 Platten den ämsseren Ring. Diese äussersten an den Genitalring stossenden Analplatten sind stets die grössten und unter ihnen sind die die fünf Winkel bildenden Platten oft grösser als die anderen. Gegen den subcentralen After nimmt die Grüsse der Platten oft selı rasch ab; der After selbst ist immer von winzigen Kürnchen umgeben. Der Verlauf der Nähte zeigt oft noch dentlich, in welcher Weise der Zerfall der Analplatten vor sich ging (Taf. X Fig. 4). Die ursprünglich zusammengehörigen Platten bilden dann lange etwas gebogene keilfürmige Felder, deren Spitzen in der Nähe des Afters liegen, und die durch melırfache Quertheilungen in eine Anzahl Platten zerfallen sind. Stacheltragende Wäzchen entstehen auf dem Apicalfelde znerst rings um die Afteröfnnung, sowie um die später erscheinenden Genitalöffnungen neben wenigen sehr zerstrent stehendeu Wärzchen auf den grösseren Platten. Selır gewöhnlich bildet sich sodam ein Ring ron grösseren Wärzchen aus an itusseren Rande des Apicalfeldes. Dieser Warzenring ist manchmal auch an erwachsenen Individuen noch sehr deutlich zu erkennen. Allmählig erscheinen immer mehr Würzchen auf allen Platten, so dass meist das ganze Apicalfeld gleichmässig ron zerstrenter oder dichter stehenden Wärzchen bedeckt ist. Öfter bleiben die Ränder der grösseren Platten nackt; nur bei wenigen Arten (G. tuburia) erhalten sich grüssere Flächen der Genitalplatten frei von Wärzchen.

\section{Das Interambulacralfeld.}

a) Coronalplatten.

Rei dem ,uingsten beobachteten Stadium (C. canaliculatu von $2 \mathrm{~mm}$. Schalendurchmesser) waren schon 3 Interambulacralplatten in jedem Meridian ausgebildet mit je einer stacheltragenden Hauptwarze. Dieselben waren etwas breiter als hoch: Im Laufe des Wachsthums der Schale treten rom Apicalfelde her immer neue 
Interambulacralplatten auf, und zwar erscheinen dieselben zuerst als winzige Körnchen in dem Winkel, der zwischen der obersten Interambulacralplatte eines Meridians und der anstossenden Genital- und Ocellarplatte gebillet wird. Die Zahl dieser Platten kaun bei gewissen recenten Arten schliesslich bis auf 12 steigen (L. baculos $\ell$ ), während sie wohl bei keiner recenten Art im völlig erwachsenen Zustand geringer als 6 bleibt in einem Meridian. Es gibt fossile Arten mit weniger als 6 und mit mehr als 12 Platten im Maximum. Die 'Zahl der an einem Exemplar beobachteten Coronalplatten hängt daher ebenso selı' von der Art ab, wie von dem Alter, das das Individum erreicht hat. Jede nel hinzukommende Coronalplatte wird etwas höher oder erreicht mindestens die gleiche Höhe wie die rorhergehende der gleichen Reihe. Dem Bucealfelde zunächst laben daher die Platten die geringste, dem Apicalfelde zunächst die bedeutendste Höhe (sofern dieselben schon vollständig ausgebildet sind). Das Höhenwachsthum einer Platte ist ziemlich bald beendet; die Bildung einer nenen Platte erfolgt gewöhnlich erst, wenn die vorhergehende nahezu oder vollständig ihre definitive Höhe erreicht hat. Das Höherwerden der Schale erfolgt durch Bildung neuer Platten; dagegen wachsen die Platten fortwährend noch in der Breite und verursachen dadurch die Zunahme des Umfangs der Schalen. Die am frithesten entstandenen Platten, also die dem Buccalfeld benachbarten, sind dahei stets sehr viel breiter als hoch, während die zuletzt entstandenen manchmal sogar noch etwas höher sind als breit. Je nach den Dimensionen der Schale und der Zahl der Coronalplatten sind die an der Periplerie stehenden wenig bis sehr viel hreiter als loch.

\section{b) Hauptwa a z 11 .}

Die in der Mitte der Coronalplatte entstehende Hauptwarze nimmt zuerst allein die ganze Fläche derselben in Anspruch, wie dies bei sehr kleinen Schalen noch an allen Platten zu beobachten ist. Fruhzeitig zeigt sie sich durchbohrt und ihre Basis erhebt sich zunächst sehr stark über das Nivean der Schale. während die Trarze selbst verhältnissmässig gross ist. Bald entstehen aber an den seitlichen Rändern der Platten kleine Wärzchen, die allmählig einen melı oder weniger vollständigen Ring um die Hauptwarze bilden können, den Scrobicularing, der den primären Warzenhof umgrenzt. In den frihesten Stadien sind bei allen Cidariden diese Wrarzenhöfe kreisrund, liegen im Niveau der Schale und gehen ohne Unterbrechung in die benachbarten Warzenhüfe desselben Meridians über; an diesen Bertihungsstellen zweier Warzenhüfe ist also zuerst deI Scrobicularing stets noch unterbrochen; diese Unterbrechung ist noch bei allen Arten zu constatiren, wenigstens zwischen den zuerst entstandenen Warzenhöfen unmittelbar am Buccalfelde. Später vervollständigt sich sehr häufig der Scrobicularring auch an dieser Stelle und trennt die benachbarten Warzenhöfe. Die WVarzenhöfe sind anch an den neutentstandenen Platten älterer Exemplare stets kreisrund. Sie nehmen entweder nur geringen Antheil am Flächenwachsthum der Platten, dam bleiben sie kreisrund und werden durch kleinere Wärzchen weit von einander getrennt; oder sie nehmen wenigstens am Höhenwachsthum der Platten lebhaften Antheil, dann sind die runden Höfe nur durch schmale Brücken ron einander getrennt; je nach ihrer Betheiligung auch am späteren Breitenwachsthum der Platten werden sie melı oder weniger stark oval und bleiben dann auch gern mit einander in Verbindung. Friher oder später aber betheiligen sich bei allen Arten von Cidariden die primären Warzenhöfe an einem Breitenwachsthum der. Platten; bei solchen Arten, bei denen es am spätesten eintritt, treffen wir noch an der Peripherie kreisrunde Höfe, je nihler dieselben aber dem Buccalfelde stehen, um so melur sind sie oval.

Bei Stercocidaris sowie bei Diplocidaris bleiben auf den zuletzt entstandenen Coronalplatten die Hauptwarzen mit ihren Warzenhöfen ganz rudimentär und nelmen nur einen sehr geringen Theil der Oberfläche der Platten ein, die im übrigen vou kleinen Wärzchen bedeckt sind.

\section{c) Sekundär- und Miliarwärzchen.}

Ton den kleineren Wäzchen, die sich auf einer Coronalplatte bilden, entstehen die ersten am medianen Rande der Platten in sehr geringer Zahl; später bilden sich anch am ambulacralen I'lattenrande einige Träıchen; diese ersten kleineren Wärzchen bilden zu beiden Seiten jeder Hauptwarze schwache Bügen, Anfänge der Scrobicularringe, die mit denen der benachbarten Platte zusammenstossen und so in jedem I. A. F'. riel wellig verlaufende Vertikalreihen ron Sekundärwärzchen bilden, die die Vertikalnähte begleiten. Auf diesem Zustande befinden sich sämmtliche Cidariden einmal in einem bestimmten Alter, und Arten, die nur eine geringe Grösse erreichen, wie $P$. gracilis (Taf. IV Fig. 11) scheinen anf diesem Zustand stehen zu bleiben. Bei vielen Arten entstehen auch später niemals vollständige Scrobicularringe um die Hanptwarzen, sondern es bleiben die Warzenhöfe eines Meridians immer in Verbindung. Neist aber vervollständigen sich an den später entstandenen Platten die Scrobicularringe allmählig immer mehr, indem sie zuerst oberhalb der Hauptwarzen den Kreis schliessen, dann anch unterhalb, so dass die primären Warzenhöfe vollständig unschlossen und von einander durch Wärzchen getrennt sind. Sind die Warzenhüfe gross, so kömnen die sie trennenden Wäzchen längs der Horizontahähte nur kümmerlich entwickelt sein, sind sie klein, so kann hier noch Platz sein zur 
Entwickelung weiterer Wärzchen, die selbst die Scrobicularringe tremen. Wachsen die Coronalplatten in die Breite, ohne dass die primären Warzenhöfe sich auch entsprechend verbreitern, so rïcken die Scrobicularringe, die sich ursprünglich längs der Mediannaht berihhten, hier auseinander und es entsteht zwischen ihnen eine ron Wärzchen, die meist kleiner sind als die der Scrobicularringe, bedeckte Fläche, das interambulacrale Miliarfeld; letzteres ist anfangs sehr schmal, erreicht aber bei vielen Arten ganz allmählig im Verlaufe des Wachsthums eine bedentende Breite. In der Mitte des Miliarfeldes verlänft die Mediannaht; die das Miliarfeld bedeckenden Wärzchen werden meist gegen die Naht zu immer kleiner; sie sind öfters dentlich in Horizontalreihen angeordnet, die selbst durch feine Furchen von einander getremnt sein können. Anch anf der anderen Seite der Platten kann der Scrobicularring sich immer weiter vom ambulacralen Plattenrand entfernen und hier Platz lassen für eine gewölnhlich nur schmal bleibende von kleineren Wärzchen bedechte Fläche.

\section{d) Dickenwachsthum.}

Bei jungen Stadien von Cidariden ist die Oberthäche des I. A. F., überhaupt die ganze Schale, flach; nur die Warzen treten hervor, besonders stark die Basis der Hamptwarze, aber die Warzenhüfe sind nicht eingesunken und die Nällte liegen im Niveau der Schale; diesen Zustand künnen auch erwachsene Formen noch zeigen, besonders diunnschalige Arten (Eucidaris u. a.); bei anderen aber und besonders bei dickschaligen Arten, sinken allmählig die Warzenhöfe unter das Nivean der Schale, und auch gegen die Nähte, besonders gern gegen die Tertikalnähte sinkt die Schale ein, indem diese Stellen im Dickenwachsthrm gegen andere zurickbleiberr.

\section{Das Ambulacralfeld.}

a) Ambulacralplatten.

Bei dem jüngsten Stadium, das zur Beobachtung kam (C. canaliculata), ist die Zahl der Ambulacralylatten haum grösser als die der Interambulacralplatten. Auf drei Interambulacralplatten, die einen Meridian bildeten, kamen z. B. nur vier Ambulacralplatten; dieselben sind kleiner als die Interambulacralplatten, d. h. nur wenig niederer, aber nur etwa halb so breit als diese. Die Zahl der Ambulacralplatten vergrössert sich bei weiterem Wachsthum seln viel rascher als die der Coronalplatten, so dass bei Individuen von etwa 4-8 mm. Durchmesser, wie ich verschiedene vor mir habe, bereits wenigstens drei Ambulacralplatten anf eine Coronalylatte kommen, bei gewissen Arten aber in höherem Alter die Zahl der Ambulacralplatten, die an eine einzige Interambulacralplatte grenzen, bis auf 21 steigen kann ( $C$. grandis). Auch die neuentstandenen Ambulacralplatten rücken rom Apicalfelde her nach; ilh Entstehungsherd liegt, wie bekannt, unter der Mitte des Aussemrandes der Ocellarplatten.

Bei den jüngsten Stadien sind die Ambulacralplatten etwa so hoch als breit, selbst höher als breit; anch bei grösseren Exemplaren sind die zuletzt entstandenen Platten nahe dem Apicalfelde noch verhältnissmässig sehr schmal; je ältere Stadien man antrifft, um so bedentender ist an der Peripherie der Schale, wo jeweilig die breitesten Platten rorkommen, die Breite im Verhältniss zur Höhe, die bei einigen Arten nur zwei- bis dreifach, bei anderen vielfach von der Breite ïbertroffen wird. Im Gegensatze zu den Interambulacralplatten werden bei den Cidariden die Ambulacralplatten alle ungefähr gleich hoch; es nimmt daher die Zahl der eine Interambulacralplatte begrenzenden Ambulacralplatten vom Buccalfelde an bis zum Apicalfelde lin immer melr zu, entsprechend den immer höher werdenden Coronalplatten. Ilre definitive Höhe haben die Ambulacralplatten bald erreicht, wälreud ihr Breitenwachsthum sehr viel länger dauert. Das Breitenwachsthum betrifft sowohl den porentragenden äusseren Theil, besonders bei Arten mit gejochten Poren, als den warzentragenden inneren 'l'heil der Platten je nach der Art in verschiedenem Maasse. Am Dickenwachsthum nimmt die Porenzone weniger Antheil als die Warzenzone und erscheint daher besonders bei dicken Schalen oft seln vertieft.

\section{b) Ambulacraluoren.}

Der ursprünglichste Zustand von Ambulacralporen bei Cidariden, den ich beobachten komnte, fand sich an dem Exemplar von $C$. canaliculata von $2 \mathrm{~mm}$. Durchmesser. Hier sind die verhältnissmässig grossen Ambulacralplatten wenig ausserhalb ilner Mitte von einer einfachen Öffnung durchbohrt; der Umriss dieser Öffnung ist länglich und sehr steilstehend, sein der Medianlinie zugekehrtes Ende viel näher dem Buccalrande als das andere. Eine Einschnürung in der Nitte des Umrisses dentet die spätere Theilung zu einer Doppelpore an (Taf. IX Fig. 6, 1 ).

In etwas weiter vorgerïckten Stadien kommt stets eine Doppelpore in jeder Ambulacralplatte zur Beobachtung. Die beiden Poren eines Paares sind bei jugendlichen Exemplaren einander stets selı' genähert. Je jünger und je kleiner die Exemplare sind, um so steiler stehen die beiden Poren. 
Durch die sich entwickelnde Ambulacralwarze werden die Poren ans der Mitte der Platte nach aussen gedrängt, scheinbar in eine Yertiefung, nämlich in das Thal, das die Ambulacralwarzen zweier benachbarter Platten miteinander bilden ('T'af. IX Fig 8, b; (liese Figur sollte umgelielnt stehen).

Bei weiterem Wachsthum richten sich mun die beiden Poren eines Paares bei vielen Arten so. rlass sie nahezu horizontal stehen; dabei rücken sie ziemlich weit auseinander und können durch eine deutliche Furche miteinander verbunden sein (gejochte Poren); bei vielen anderen Arten bleibt der jugendliche Zustand erhalten, die Stellung der Porenparre ist immer noch etwas schräg, indem die äussere Pore ein wenig höher steht als die innere, sie bleiben einander genähert und zeigen keine Furche, die sie verbindet, ja bei vielen fossilen Formen findet sich ein kleines Wärzchen zwischen ihnen (ungejochte Poren). Nun gibt es aber Übergänge zwischen diesen beiden Extremen, bei denen die Poren horizontal stehen, sogar weit von einander entfernt, ohne eine Furche zwischen sich zeigen (C. Reini); die Furche kamn auch sehr undentlich sein. Der Zwischenraum zwischen beiden Poren ist häufig sehr meben, er kamn Erhöhmgen und Tertiefungen zeigen, die die Poren ebenso weit von den typischen gejochten wie von den ungejochten entfernen ( $G$. biscriatis). Kuz, ich finde es bei verschiedenen recenten Formen wenigstens umöglich mit Sicherheit zu entscheirlen, ob eine "gejochte" oder "ungejochte" Porenform vorliegt. So werthvoll dieser Charakter zweifelsohne ist, er lässt in vielen Fällen röllig im Stich.

In Folge der verhältnissmässig bedentenden Höhe der Ambulacralplatten bei jugendlichen Formen sind bei diesen die einzelnen Porenpaare sehr weit ron einander getrennt, während sie bei älteren Exemplaren viel näher zusammengerïckt erscheinen.

Fast stets sind zwei benachbarte Porempare durch eine melr oder weniger vorspringende Horizontalleiste von einander getrennt, die von der Ambulacralwarze ihren Ausgang nimmt und urspringlich nur eine Verbreiterung derselben darstellte.

\section{c) Ambulacralwärzchen.}

Wie im I. A. F., so entsteht auch im A. F. der Cidariden zunächst auf jeder Platte eine einzige Warze, die Ambulacralwarze, die bei weitem nicht die Grösse der interambulacralen Hauptware zeigt; sie muss sich mit der Doppelpore in die Platte theilen und kann daher anch nicht die Mitte einnehmen, sonctern ist etwas näher gegen den apicalen und medianen Plattenrand gedrängt, während das Porenpar die entgegengesetzte Ecke eimimmt. Die Warze nimmt bald den grösseren Theil der Platte in Anspruch, indem sie nicht nur die grössere mediane Hälfte völlig einnimmt, sondern sich auch längs des oberen und apicalen Plattenrandes verbreitert, bis sie den Rand des Interambulacralfeldes erreicht. Durch diese Verlängerung trennt sie die Porenpare benachbarter Platten von einander, die in der von der Warze nicht eingenommenen Ecke ler Platten wie in einer Vertiefung liegen. Die Verlängerung der Ambulacralwarze aber erreicht ihren Abschluss noch nicht an Rande des I. A. F., sie setzt sich unmittelbar fort in ein nahe diesem Rande stehendes Wärzchen des Scrobicularringes, deren jedes als Enclanschwellung eines solchen Ausläufers der Ambulacralwarzeu erscheint. So steht die Anzahl und Entfernung der lüngs des ambulacralen Randes des I. A. F. zuerst entstehenden Scrobicularwärzchen in direktem Zusammenhang mit der Anzahl und der Höhe der Ambulacralplatten (Taf. IV Fig. 13).

In spateren Stadien, wenn die Ambulacralplatten sich mehr verbreitert haben, erscheint die AmbulacralWarze ziemlich scharf abgesetzt von dem Ausläufer, der als melı oder weniger dentlich vorspringende schmale horizontale Leiste die benachbarten Porenpare von einander trennt. Die Ambulacralwarzen selbst sinc auf die innere Hälfte der Platte beschränkt und bilden die bei Cidariden gewöhnlich ausserordentlich regelmässige Reihe von Randwarzen des ambulacralen Mittelfeldes, die nu bei einzelnen fossilen Formen Neigung zeigt unregelmässig zu werden.

Zuerst berühren sich die beiden Reihen von Randwarzen längs der Mittellinie des A. F., meist riicken sie in späteren Stadien etwas auseinander und geben Raum zur Entwickelung eines medianen von $\|^{\top a ̈ r z c l i e n ~}$ mehr oder weniger dicht bedeckten Feldes, das bald schmal bleibt, bei manchen Arten aber ganz allmïhlig eine bedentende Breite erreichen kann. Die dasselbe bedeckenden Wärchen sind meist kleiner (nur bei einzelnen fossilen Formen grösser z. B. C. pretiosa) als die Randwärzchen und in melı oder weniger regelmäissige Vertikalreihen angeordnet.

\section{Das Buccalfeld.}

Das Buccalfeld fand ich bei dem $2 \mathrm{~mm}$. breiten Exemplar ron C canaliculata vollständig bedeckt von 10 etwa keilfürmigen Platten, die einen Ring um die mit einem kräftigen Kaugerüst versehene MIundüffumg bildeten. Diese Buccalplatten trugen sämmtlich wie die Ambulacralplatten in der Hitte eine einfache etwas schiefstehende Öffnung und daneben eine Stachelwarze. Jede dieser zelın das Buccalfeld bedeckenden Platten erscheint als direkte Fortsetzung je einer der zeln Vertikalreihen von Ambulacralplatten gegen die Jund- 
iiffnung 2u; sie sind ron den Ambulacralplatten selbst nur durclı ilure etwas bedentendere Grösse unterschierlen, und es ist kaum möglich, eine scharfe Grenze zwischen diesen Buccalplatten mod den Ambulacralplatten zu ziehen ('lat. IX Fig. 6, p).

Von Interambulacralplatten grenzen nu fün an das Buccalfeld, indem jedes Interambulacralfeld eine unterste unpare Platte zeigt, die den beiden Reihen von Coronalplatten gleichmässig anzugehören scheint, mid die so verbreitert ist. dass sie an die beiden das Interambulacralfeld begrenzenden Ambulacralfelder stösst. Diese unpaare unterste Platte jedes Interambulacralfeldes geht unzweifelhaft später selbst auf das Buccalfeld über und wird zum Ausgangspunkt für die undurchbohrten Buccalplatten, die gewöhnlich nur eine einfache radiale Reihe bilden, welche, dem Interambulacralfeld entsprechend, sich zwischen die radialen Reihen der durchbohrten Buccalplatten, die Fortsetzugen der Ambulacralfelder, einschieben. Während die Vermelırung: der undurchbohrten Buccalplatten, die im Laufe des Wachsthums vor sich geht, wahrscheinlich erfolgt durch Theilmgen dieser unpaaren Interambulacralplatten, erfolgt die Vermelirung der durchbolrten Buccalplatten dadurch, dass von den Ambulacralfeldern her immer mehr Ambulacralplatten anf das Buccalfeld geschoben werden, so dass dieselbe bei grossen Exemplaren eine ziemlich beträchtliche wird.

\section{Pedicellarien.}

Taf. VIII и. IX.

Von Pedicellarien lassen sich bei den Cidariden drei Hauptformen wohl von einander unterscheiden, die wahrscheinlich bei allen Arten vorkommen, wem auch bei einer Anzahl von Arten eine oder selbst zwei dieser Hauptformen noch nicht beobachtet sind.

A. Grosse dickküpfige Pedicellarien mit banchigen Ǩlappen und einer weiten Centralkammer, deren am oberen Ende der Kilappen gelegene Öffnung von wulstigen Lippen umrahmt ist; diese Lippen und besonders die quer verlaufende Unterlippe (barre bei PERRER*) tragen eine besclıänkte Anzahl meist sehr kräftiger Zähne, die atch noch an einer manchmal vorkommenden median nach unten verlanfenden Fortsetzung: der Unterlippe auftreten können (C. canaliculata).

Die Lippen sind ofters schnanzenförmig vorgestreckt; in diesem Falle lilaffen am oberen Ende die Klappen etwas ( $I_{\text {s }}$ imperialis). Der freie seitliche Rand der Klappen ist meist deutlich gesägt. Diese Pedicellarien zeigen bei einigen zu Goniocidaris gehörigen Arten eine kugelförmige Gestalt.

Sie sitzen oft auf einem kurzen dicken Stiele, der kugelig werden kam (C. grandis); bei anderen ist der Stiel lang, bis zu vierfacher Kopflïnge (C. tribuloides); an der Basis des halsartig verdünnten oberen Theiles trägt er dam mitmiter einen aus kurzen (C. thoursii) oder ans auffallend langen (L. baculosa) Spitzen bestehenden Kragen.

Diese von den meisten Arten bekannten dickköpfigen Pedicellarien finden sich läng's der Nähte auf der oberen Schalenhälfte, selten unterhalb der Peripherie der Schale; anf dem Buccalfelde fehlen sie ganz. Sehr regelmässig stehen sie im Interambulacralfelde, oft gehäuft, gewöhnlich auch einzelne auf dem Apicalfelde, hier oft mit verkürztem Stiele, seltener im Ambulacralfeld.

In der Centralkammer solcher Pedicellarien bemerkte ich bei $C$. grandis ein schlanchförmiges Organ, dessen Mündung mit der stark bezahnten Mündmg der Kammer zusammenfiel; beim Mangel an frischem Naterial war es aber nicht möglich, genaueres über die Beschaffenheit dieser Bildung zu erforschen; doch wäre es denkbar, dass es sich hier um eine Giftdrüse handelt, deren Sekret in die von den scharfen Zälinen erzengte Wunde fliesst, wenn kleine Thiere, die sich auf die Schale niederlassen, von diesen Organen gepackt werden** Thaf. VIII, Fig. 2, e.

B. Schlanke kegelfürmi ge Pedicellarien, meist von geringer Grösse, deren Centralkammer wenig entwickelt ist, die aber stets noch eine querstehende Unterlippe zeigen nahe dem oberen Ende der Kilappen. Mitunter zeigen sich hier einige stärkere Zähnchen, meist fehlen solche und es sind nur die freien Seitenränder der Klappen bis nahe zur Basis fein gesägt. Die obere Spitze der Klappe endet oft in einen mehr oder weniger deutlichen Haken, der bei wenigen Arten $(G$. mikado) zu einer auffallend langen und dünnen Spitze entrickelt sein kamm.

Der Stiel ist immer dünn, manchmal sehr kurz, gewöhnlich lang und damn von 2-5 facher Kopflänge.

Solche schlanke kegelfürmige Pedicellarien sind auf allen Theilen der Schalenoberflache zu treffen, oft von sehr verschiedener Grüsse je nach ihrem Standort. Am grössten und lä̈ufigsten sind sie zwischen den

* s. Perrier, Recherches sur les Pédicellaires etc. in Annales des Sc. natur.; Zoologie. Tome XIII. 1870.

** Über eine ähnliche Ansicht vergl. Stewart, On certain Organs of the Cidaridae in: Trans. Linn. Soc. Zool. Ser. 2. Vol. I. 1877. 
Stacheln del Scrobicularringe; von winziger Grösse sind sie zuweilen im Ambulacralfelde, wo sie manchmal sehr regehmåssig zwischen je zwei Randstachelchen anftreten; sie kommen anch ganz gewölnnlich zwischen den Stacheln des Bucealfeldes ror.

Diese Pedicellarien sind fast bei allen darauf untersuchten Cidariden gefunden worden.

Die unter A. und B. bescliriebenen Formen von Pedicellarien bilden die Pédicellaires armés von PFrrisr.

C. Pedicellarien von selr verschiedener Grösse mit löffelförmigen Klappen. Diese Klappen sind gewöhnlich an der Basis etwas geschwollen und gehen dann meist plötzlich in den schmalen oft sehr verlängerten oberen 'Theil über; sie zeichnen sich aus durch die ganz rudimentäre Centralkammer' und die Abwesenheit einer Querlippe, während am oberen Ende der Rand der Klappe gewölnlich merklich vorgezogen erscheint („löffelförmig"). Sie zeigen nie stäkere Zähnchen am oberen Ende, der freie seitliche Rand der Klappen ist aber" lıäufig fein gesägt oder gezälnt.

Die Klappen bei diesen Pedicellarien klaffen stets, oft fast in ihrer ganzen Länge, zum mindesten aber in der Nähe der Basis.

Sie besitzen einen dünnen Stiel, der selten das Köpfchen an Länge übertrifft. Es gehören zı dieser Form die grössten bei Cidariden bekannten Pedicellarien, sie kommen aber auch in sehr geringer Grösse vor. Auch hier kann bei demselben Individum die Grösse und selbst die Gestalt (C. thouarsii) der zu dieser Form gehörigen Pedicellarien beträchtlich variiren.

Die löffelförmigen Pedicellarien sind gewöhnlich anf die untere Hälfte der Schale beschränkt, stehen anch auf dem Buccalfeld; sie finden sich besonders gern auf den Coronalplatten, und zwar an den Nähten stehend, wenn sie ron bedentender Grösse sind. Manchmal kommen sie auch oberhalb der Peripherie der Schale vor, aber nur in einem einzigen Falle komnte ich diese Pedicellarien auf dem Apicalfelde beobachten (bei einem selır kleinen Exemplar ron $L$. verticillata Taf. IX Fig. 8, a). Diese Form von Pedicellarien ist bisher' kaum bei der Hälfte der bekannten Cidariden-Arten beobachtet, wem anch zu erwarten ist, dass sie gelegentlich bei jeder Art rorkommen kamu. Bei manchen Arten sind sie immer sehr zahlreich (L. imperialis), bei anderen sind sie stets nur seln vereinzelt zu treffen.

Diese dritte Form von Pedicellarien enthält die Pédicellaires inermes von Perrier.

D. Es scheint noch eine vierte Form von Pedicellarien bei den Cidarilen zu greben, von der ich aber bisher nur einige isolirte Klappen gesehen habe, die sich auf Präparaten ganz vereinzelt neben den anderen Formen fanden. Diese "korbförmigen "Klappen zeigen eine seh" weite, banchige Kammer, die am oberen 'Theil in einer sehr grossen Öffnumg mündet; diese Öffnung zeigt einfache dünne und etwas gekerbte Ränder; ron Zähmelung u. dgl. ist keine Spur vorhanden. Solche Pedicellarien erreichen bei C. grandis die Grösse und die äussere Gestalt der dickköpfigen Form (Taf. VIIT Fig. 2, h), sie sind dagegen sehr klein bei L. verticillata (Taf. IX Fig. 8, g); bei anderen Arten kenne ich sie nicht, auch ihren Standort konnte ich nicht entclecken.

Nur mit grosser Vorsicht dürfen Pedicellarien als systematische Merkmale bei den Cidariden beniitzt werden. Die wenig bekannte Form D. kommt dabei gar nicht in Betracht; aber auch die überall häufig vorkommende Form B. eignet sich wenig dazı; sie älnelt sich fast bei allen Arten sehr bedentend, und die Unterschiede sind so geringfïgig, dass es uur wenige Arten sind, bei denen sich einigermassen auffallende und constante Charaktere daran zeigen. Dazu kommt, dass diese Form bei einem und demselben Individuum ausserordentlich variiren kaun, sowohl bezïglich ihrer Gestalt, wie besonders in ihrel Grösse. Ich möchte nur eine lieher gehörige Form bezeichnen, die so aufallend ist, dass sie immer wieder leicht zu erkennen ist; das ist die mit einer langen dünnen hakenfürmigen Endspitze rersehene, wie sie bei $G$. milado und clypeata anftritt (Taf. VIII Fig. 6 u. 7). Die Form B. ist übrigens von der Form A. mu C. nicht immer scharf zu trennen.

Besser zı verwenden ist jedenfalls die löffelartige Form C., die mitunter ziemlich charakteristisch ist, besonders bei Arten, wo sie eine bedeutende Grösse erreicht; doch darf nicht ibersehen werden, dass anclı ihre Gestalt sehr wechselnd sein kann bei einem Individum (C. Thouarsii).

Am geeignetsten für systematische Zwecke ist jedenfalls die dickküpfige Form A. sie ist gewölnlich ron bedeutender Grösse, variirt wenig an einem Individuum, selbst bezüglich ilner Grösse, und ist in ihrer ganzen Bildung ziemlich constant bei einer Art; sie zeigt dazu manche auffallende Eigenthiumlichkeiten, die selr wohl einzelne Arten, manchmal auch Gruppen charakterisiren können:

So sind kugelförmige Köpfchen selır bezeichnend fïr Arten ron Goniocidaris

Auffallend bauchige Köpfchen treten nur bei bestimmten Arten auf (C. Reini, Thouarsii).

Manche Arten sind ausgezeichnet durch die schnauzenformig rorgestreckte Mü̈ndmg der Central-

kammer (imperialis, baculosa, verticillata etc.).

Bei gewissen Arten sind die Klappen auffallend stark bewatinet (C. grandis). 
Bei manchen Arten sind die Stiele sehr kurz (papillata, japonicn, grandis u. a.).

Bei anderen sind sie stets von bedentender Länge (thouarsii, tribuloides, verticillata ete.).

Fiir einige Arten sind lange oder kurze Spitzenkragen des Stieles charakteristisch (verticillata, baculose und ammifera, metularia).

Alser anch bei dieser Form darf nicht übersehen werden, dass eine gewisse Variabilitä innerhalb der Art anftreten kamn, und dass sie sogar bei einzelnen Individuen einmal ganz fehlen hann. So mangelten $z$. B. vortrefflich erhaltenen Exemplaren von Goniocidaris tubaria die für diese Art so üherans charakteristischen kugeligen Pedicellarien mitunter rollkommen. Es ist auffallend, dass selnr ähnliche Formen dieser Pedicellarien bei Arten vorkommen kümen, die nach den übrigen Charakteren sehr wenig Verwandtschaft mit einander beknnden (verticillata und metularia).

In rielen Fällen hat nun ohne Frage die Vergleichung der Pedicellarien nicht geringen Werth für die Systematik; sie geben jedenfalls sehr brauchbare Charaktere zur Unterscheidung ron Arten; so ist einer der wesentlichsten Gründe, die ich fur die innige Verwandtschaft von baculosa und ammelifera anführen kann, die Identitat ihrer Pedicellarien, während andererseits die nicht unerhebliche Verschiedenheit der Pedicellarien von C. thouarsii und yalapagonsis mich in der Überzeugnng bestärkte, dass diese beiden in so vielen Punkten ïbereinstimmenden Arten wirklich specifisch verschieden sind. Zur Charakterisirung von grösseren Gruppen innerhalb der Familie finde ich aber Pedicellarien sehr wenig verwendbar.

\section{Primärstacheln.}

Keulenförmige Primärstacheln, wie sie noch unter den cretacischen Cidariden eine grosse Rolle spielen. verschwinden in späteren Zeiten fast ganz; in der Gegenwart sind solche nur bei Leiocidaris imperialis und Eucidaris galapagensis zu finden; doch ist anch bei diesen die Verdickung des Schaftes nicht sehr bedeutend; nur an einem Exemplar von $C$. galapagensis fanden sich einzelne, offenbar aber abnorm ausgebilitete Stacheln, the in ihrer Gestalt ausserordentlich an die dicken Keulen z. B. von C. pleracanth ans der Kreide erinnern.

Stabförmige Primärstacheln, deren oberes Ende sich verbreitert hat zu einer zackigen Krone, finden sich erst seit der Kŕride (z. B. C. pistillum). Solche Stacheln sind gerade in der Gegenwart wohl vertreten; Neigung zu solcher Bildung findet sich in der Gruppe Stereocidaris und Leiocidaris, besonders charakteristisch sind aber solche Stachehn für die Gruppe Goniocidaris. Sehr stark ist die Ausbreitung der Krone bei G. floriyera, in Form von grossen flachen Schalen zeigt sie sich bei G. mikudo und erreicht ein Extrem bei den schildförmigen Stachehn von $G$. clypeata unter gleichzeitiger ausserordentlicher Verkürzung des Scliaftes.

Stabförmige Primärstacheln mit seitlichen Dornen treten zu allen Zeiten auf; unter den recenten Cidariden ïbertrifft G. biserialis alle anderen durch die Grösse und Dicke der seitlichen Dornen und steht in dieser Beziehnng auch hinter keiner fossilen Art zurïck. Nur in der Gegenwart finden sich Arten, bei denen diese Dornen flach und lappenförmig werden können (florigera, clypeata, besonders aber miliado), und auch nur bei diesen Arten sind die eigenthümlichen kragenförmigen Fortsätze nahe der Basis der Primärstacheln zu beobachten, unvollkommen ansgebildet bei forigera und mikudo, in vollkommener Ansbildung, dem Stichblatt eines Stossdegens rergleichbar, sogar zn zweien oder dreien dicht übereinander, nur bei Gr. mikado.

Nur bei einigen recenten Arten ist die Oberfläche der Primärstacheln von einem dichten Filz anastomosirender Nädelchen bedeckt (mikado, gracilis).

Oberhalb der Peripherie der Schale sind die Primärstacheln am längsten; sie verkiurzen sich gewöhnlich gegen das Apicalfeld zu etwas, sehr stark aber gegen das Buccalfeld zu. Je nach der Stellung an der Schale kömnen die Primärstacheln verschieden gestaltet sein. Nur bei den Arten, bei denen die Stacheln eine Neigmg: zur Kronenbildung an ilırem Ende zeigen, sind die dem Apicalfelde zunächst stehenden gewöhnlich erheblich verschieden in ihrer Gestalt von den übrigen, indem bei ihnen die Krone meist mächtiger hervortritt je näher sie dem Apicalfelde stehen. Bei der Mehrzahl der Cidariden sind es nur die dem Buccalfelde zunächst stehenden Stacheln, die erhebliche Unterschiede gegen die übrigen aufweisen. Allgemein tritt bei ilmen die Kürnelung: der Oberfläche mehr zurïck, so dass sie häufig ganz glatt werden. Bei vielen behalten sie deu runden Querschnitt, bei anderen werden diese Stacheln mehr und mehr abgeplattet, bis sie manchmal flache zweischneidige Klingen bilden, deren beide Seitenränder feiner oder gröber gesïgt oder bedornt sind (Stercocidaris japonica, Porucidaris, Goniociduris). Mitunter sind solche Stacheln anch leicht gebogen.

Die grösste mir bekannte Verschiedenheit der Primärstacheln an einer Schale kommt bei Gr. clypeatı vor. 


\section{Eintheilung der Cidaridae.}

Eine wirklich befriedigende Gruppirung der lebenden und fossilen Cidariden in Gattungen und Untergattungen ist bisher eine ungelöste Aufgabe gewesen und wird es wohl noch lange bleiben. Unter der grossen Schar von Arten, die hieher gehören, sind nur wenige durch so wichtige und constante Merkmale vor den uibrigen ausgezeichnet, dass sie von denselben einigermassen scharf abgesondert werden kömen. Dahin gehören vor allem die fossilen Gattungen Diplocidaris CotTEAU und Tetracidaris DESOR; geringerwerthig, doch immerhin auffallend sind die Charaktere, auf die die Gattungen Temnocidaris Cotтrau und Orthocidaris Cotтedu gegründet sind. Die Versuche aber, in der überwältigenden Menge der übrigen Formen weitere Unterabtheilungen scharf abzugrenzen, wollen alle nicht recht gelingen.

Es ist ja absolut nothwendig, in der sonst ganz unüberselhbaren Zahl von Arten Gruppirungen vorzunelmen, und diese Gruppen auch mit Namen zu belegen. Von Desor, Cotteau, A. Agassiz und anderen, in letzter Zeit von Poser sind für recente und fossile Cidariden eine Reihe von mehr oder weniger brauchbaren Unterabtheilungen aufgestellt worden. Alle diese verschiedenen Gruppen lassen sich aber in keiner Weise scharf von einander tremnen und zeigen so unmerkliche Übergänge in einander, dass es bei zahlreichen Arten nur conventionell sein kann, welcher Gruppe sie beizuzählen sind. Den Kern dieser Gruppen bilden solche Arten, die bestimmte Merkmale in extremer Weise ansgebildet zeigen, Formen, die als Endglieder bestimmter Entricklungsrichtungen anzusehen sind; ilnen reihen sich die Arten an, die sich in diesen Beziehungen indifferenter verhalten und den Anschluss an andere Gruppen vermitteln. Es ist durchaus nicht zu erwarten, dass die Abgrenzung der Gruppen bei zmehmender Kenntniss über diese Familie eine schärfere werde; es ist rielmehr rorauszusehen, dass Gruppen, die jetzt noch sehr gut von anderen abzugrenzen sind, wie Diplociduris, Temocidaris, durch noch zu entleckende Übergangsformen ebenfalls inniger mit den übrigen verknüpft werden. Was allein erstrebt werden kann, ist die Aufstellung von Reihen, die die extremen Formen mit den primitiveren in bestimmte natürliche Beziehungen bringt.

Bei einem derartigen Versuche ist es in vielen Fällen mit grossen Schwierigkeiten verknüpft zu entscheiden, welche Ausbildung eines Merkmals, das bei verschiedenen Arten sich verschieden darstellt, als der primitivere Zustand anzusehen ist und welche Ausbildung als der fortgeschrittenere oder als der extremere Zustand. Zur Entscheidung solcher Fragen halte ich für äusserst wichtig und durch nichts andres zu ersetzen die Kenntniss der postembryonalen Jugendzustände, überhaupt der postembryonalen Entwicklung, zu der iclı in den vorhergehenden Kapiteln einige Beiträge glaubte geben zu können. Der Satz, dass die Ontogenie eine der Hauptsache nach getrene Wiederholung der Phylogenie ist, düfte in hohem Masse auf clie vorilegende Thiergruppe anwendbar sein. Und wenn das Studium embryonaler Zustände die werthvollsten Winke giebt zur Anfdeckung entfernter Verwandtschaftsbeziehungen, so ist das Studium der fortgeschritteneren postembryonalen Entwicklıngszustände geeignet, die phylogenetischen Beziehungen innerhalb kleinerer Gruppen ans Licht zil ziehen.

Stellt es sich z. B. herans, dass der ungejochte Zustand der Ambulacralporen allen jugendlichen Cidariden zukommt, wie ich jetzt glaube annehmen zu dürfen, anch denen, bei welchen später gejochte Poren vorhanden sind, so dürfen wir mit grosser Wahrscheinlichkeit den ungejochten Zustand als den primitiveren ansehen, den phylogenetisch älteren, und annelınen, dass sich ans Formen mit ungejochten Poren solche mit gejochten erst entwickelt haben, was olıne solchen Nachweis keineswegs mit Sicherleit anzunehmen wäre.

Je mehr Merkmale so auf ihre ontogenetische Entwicklung untersucht werden, um so sicherer wird las gegenseitige Verhältniss der zahlreichen Cidaridenformen zu einander zu bestimmen sein.

Bei dem Studium der fossilen Cidariden traf' ich auf' einige plyylogenetisch beachtenswerthe P'mkte, die zınächst noch hier zı erörtem sind.

\section{Gegenseitige Verbindung der die Schale zusammensetzenden Platten bei lebenden und fossilen Formen.}

Taf. IX Fig. 6, p, Taf. X Fig. 15-22, Taf. XI Fig. 1-7.

Bei dem jüngsten mir vorliegenden Stadium einer Cidaridenschale (C. canaliculate ron $2 \mathrm{~mm}$. Durchmesser) greifen sowohl im Ambulacral- wie im Interambulacralfelde benaclbarte Platten mit ihren Rändern etwas übereinander, und zwar bedeckt, wie es scheint, immer der untere Rand einer Platte den oberen Rand der benachbarten desselben Meridians, und ausserdem greift der ambulacrale Rand der Coronalplatten iber die 
anstossenden Ränder der Ambulacralplatten (Taf. IX Fig. 6, p); längs iler Mediannaht scheint ein Übergreifen nicht stattanfinden. Schon in etwas älteren Stadien ist ein solches Übergreifen iberhant nicht mehr wahrzunehmen in Ambulacralteld oder im Interambulacralfeld. Dagegen liegen bei den Cidariden die Platten des Buccalfeldes stets schmpenfürmig ibereinander, und auch im Apicalfeld werden bei dickschaligen Formen die Rimder' der Genitalplatten bedeckt von den benachbarten Ocellar- und Analplatten (z. B. C. grundis, 'Taf. II Fig. 1).

Bei allen triassischen Cidariden dagegen greifen anch noch im erwachsenen Zustande die ambulacralen Rỉnder der Coronalplatten weit über die anstossenden Ränder der Ambulacralplatten (vergl. DöDERLEIx, Eine Eigenthümlichkeit triassischer Echinoiden im N. Jahrl. für Min., Genl. и. Pal. 1887. Vol. 2); die betreftenden Ränder laufen dementsprechend in eine scharfe Schneide aus, die dadurch entsteht, dass die Unterfläche der Platte die Oberflache direkt schneidet ohne Dazwischentreten einer besonderen Randiache ('Taf. XI Fig. 2). Ansserdem trägt jede Ambulacralplatte anf der Oberseite nahe dem schmeidenden Rande eine anffallende Grube (Taf. X Fig. 15, 19), die manchmal furchenformig verlingert ist (Taf. X Fig. 18, 20), und die bei isolirten Ambnlacralfeldern leicht für eine Ambulacralpore gehalten werden kann; in jede dieser Gruben passt je eine der Querleisten, die anf der Unterseite der Coronalplatten nalie dem schneidenden Rande entwickelt sind und denselben gerippt exscheinen lassen (Taf. XT Fig. 1-3). Die aneinanderstossenden Ränder des Ambulacralund Interambulacralfeldes stehen also bei diesen Formen in Gelenkverbindung mit einander und waren offenbar in der Richtung der Querleisten, also tangential, leicht verschiebbar*. Ähnich gebildete Formen funden sich anch noch im Lias. (Bei Ciduris amalthei ans dem mittleren Lias in Schwaben salı ich derartige Ambulacralfelder noch im Zusammenhang mit den entsprechend gerippten Coronalplatten.)

Bei anderen Arten aus dem muteren und mittleren Jura begimnt der gerippte Randtheil sich schärfer gegen die ibrige Unterfliche der Coronalplatten abzusetzen, indem sich eine dentliche Kante dazwischen ausbildet (Taf. XI Fig. 4 \%. 5); damit ist der Anfang zur Bildung einer besonderen ambulacralen Randthache gemacht. Dieselbe ist zuerst noch in einem sehr stumpfen Winkel zm Unterflache geneigt. (Bei manchen Formen setzen sich die Querrippen über die Kante hinïber noch auf die Unterfiache fort; die beiden Theile dex Rippen sind aber etwas gegen einander verschoben.) Bereits im oberen Jura steht, wie es scheint, bei allen Cilariden die Randläche ungefähr senkrecht gegen die Unterflache, ein Verhältniss, das fast sämmtliche recente Seeigel aufweisen (Taf. X Fig. 21, 22. Taf. XT Fig. 6, 7). Auf diese bei Cidariden meist sehr hohe Randfäche sind dann die Rippen beschränkt und reranlassen die bekannte zickzackförmige Knickung dieser Randtäche. Eine entsprechende Randfiche bildet sich in ähnlicher W eise auch an den Ambulacralplatten ans. Je entschiedener eine Randflache sich absetzt gegen die Unterfläche der Coronalplatten, um so geringer wird die Verschiebbarkeit der aneinanderstossenden Platten, die bei den recenten Formen gleich Null ist.

Unter den ältesten Echinoiden aus der palaeozoischen Zeit findet sich eine Anzahl von Formen mit lauter schuppenförmig iibereinandergreifenden Platten (Lepidoccntrus); die sich berührenden Flächen der Platten waren ghatt und gestatteten eine gewisse Beweglichkeit nach allen Richtungen. Bei den triassischen Echinoiden sind übergreifende Ränder auf die Grenze der Ambulacral- und Interambulacralfelder beschränkt und die sich berihluenten Flächen sind hier mit Vorsprïngen und Vertiefungen versehen, die die Verschiebbarkeit der Platten wesentlich anf die tangentiale Richtung beschränken. Nit der wihrend der Juraperiode erfolgten Ausbildung besonderer Randfiachen, auf welche die Vorsprïnge und Vertiefungen beschränkt sind, wird auch die tangentiale Terschiebbarkeit der Platten immer mehr gehemmt, bis sie endlich, wie es scheint, schon seit dem oberen Jura bei allen Echinoidea ganz unmöglich wird (nur die Echinothuridae und einzelne Spatangidae bilden eine Ausnahme).

Nachstehend fügre ich die Beschreibung einiger fossiler Cidariden aus der 'lrias von St. Cassian bei, die den Anlass gaben zu den obigen Erörterungen.

\section{Ambulacralfelder fossiler Cidariden aus der Trias von St. Cassian.}

Cidaris sp. I.

Taf. X Fim. 15-17.

Bruchstïck cines Ambulacralfeldes von $7 \mathrm{~mm}$. Länge und 5,8 mm. Breite. Die vorhandenen 14 Ambulacralplatten jederseits düften etwa einer Coronalplatte entsprochen haben.

Das Mittelfeld trägt jederseits cine Reilıe grosser gehöter Randwazen; die Entfernung der beiden Reihen von einander ist kaun so gross. dass eine der Randwarzen darin Platz fände; der Zwischenraum ist

* Schon Qoenstedt in seiner Petrefaktenkunde, Echiniten, Taf. 67 Fig. 4 n. 6, bildet Coronaltafeln mit den charakteristisehen Querrippen anf der Unterseite ab. 
bedeckt ron zwei Reihen alternirend stehender kleiner MIiliarwärzchen nebst zerstrent stehenden winzigen Körnchen.

Porenpaare stehen fast horizontal; sie sind brillenförmig von einem überall gleichhohen Rande umgeben, daher nicht gejocht. Die Poren sind gross, etwas elliptisch, die eines Paares nahe bei einander. Ausserhalb der Porenpaare verbreitern sich die Ambulacralplatten noch sehr betrïchtlich zur Bildung eines in eine Schneide auslaufenden Randes; diese Verbreiterung trägt neben der äusseren Pore eine auffallende etwa dreiseitige Grube. die leicht für eine dritte Pore gehalten werden kamm; ausserhalb derselben ist der Rand des A. F. glatt. Die Horizontalnähte sind im Bereiche der Porenzone vertieft.

Die untere Seite des A. F, zeigt ein glattes Mittelfeld, während ausserhalb desselben die Porenpare durch stark vorspringende Querleisten von einander getrennt sind.

\title{
Cidaris sp. II. \\ Taf. X Fig. 19.
}

Bruchstück eines Ambulacralfeldes von $7,6 \mathrm{~mm}$. Länge und $5 \mathrm{~mm}$. Breite; die 13 Ambulacralp]ïttchen. die jederseits vorhanden sind, mögen etwa einer Coronalplatte entsprechen.

Das Mittelfeld trägt zwei randständige Reihen von grossen, stark vorspringenden ungehöften Wärzchen, die von einander getrennt sind durch eine Reihe selır kleiner Miliarwärzchen.

Die Porenpaare stehen fast horizontal; die beiden Poren eines Paares sind durch ein Wärzchen getrennt, das fast die Grösse eines Randwärzchens vom Hittelfelde zeigt; die äussere Pore ist etwas in die Länge gezogen und fast dreiseitig. Nach aussen von der änsseren Pore trägt jedes Ambulacralplättchen eine stark elliptische Grube; der äussere Rand des A. F. ist zugeschärft.

\section{Cidaris sp. III. \\ Taf. I Fig. 18.}

Bruchstiick eines Ambulacralfeldes von 6,5 mm. Länge und 4,3 mm. Breite; von den 15 Ambulacralplättchen, die jederseits rorhanden sind, entsprechen etwa 14 einer Coronalplatte.

Das Mittelfeld trägt zwei Reihen grosser Randwarzen, die sich fast berühren, so dass mur sehr vereinzelte Miliarwärzchen dazwischen auftreten können.

Die Porenpare stehen wenig schief; die Poren sind gross, ron gleicher Gestalt, die beiden Poren eines Pares durch ein sehr flaches Wärzchen getrennt. Ausserhalb der äusseren Pore zeigt jedes Ambulacralfeld eine tiefe Querfurche, die fast so breit ist als das ganze Porenfeld. Der Rand des A. F. läuft scharf zu; die Nähte sind ausserhalb des Mittelfeldes vertieft.

\section{Cidaris sp. IV.}

\author{
Taf. 1 Fig. 20.
}

Bruchstück von der einen Hälfte eines Ambulacralfeldes mit 21 Platten.

Das Mittelfeld zeigt eine Reihe grösserer Randwarzen, die gegen die Mittellinie keinen Platz lassen für weitere Wärzchen. Von den vier untersten Ambulacralplättchen entsprechen immer je zwei nur einem Randwärzchen; dasselbe ist stark vergrössert und deutlich durchbohrt.

Die Porenpaare stehen horizontal; die Poren sind gross, elliptisch, zwischen den beiden Poren eines Paares zeigt sich ein merklicher Höcker. Nach aussen von den Porenpaaren findet sich auf jeder Ambulacralplatte eine kräftige Furche, die mindestens doppelt so breit ist als eine Pore. Die Horizontalnähte werden ausserlıalb des Mittelfeldes sehr dentlich.

Vorstehendes Bruchstück ist möglicherweise auf Hemicidaris zu beziehen, noch wahrscheinlicher aber auf die merkwürdige, durch durchbohrte Ambulacralwarzen ansgezeichnete Gruppe von Cidariden, die unten als P'rocidaris zusammengefasst sind.

\section{Kerbung der Hauptwarzen.}

Die Frage, ob die Cidariden mit glatten oder die mit gekerbten Hauptwarzen den ursprünglicheren Zustand darstellen, lässt sich mit Sicherheit nicht beantworten. In der 'Trias ron St. Cassian, der ältesten Fauna, aus der eine grössere Anzahl von Cidariden-Formen vorliegt, kommen meben gekerbten Arten auch glattwarzige vor; letztere sind sogar in der Melirzahl. Ein direkter Zusammenhang aber zwischen diesen glattwarzigen Formen und denen aus der Kreide z. B. ist nicht nachzuweisen. Wilurend der Juraperiode sind 
Formen mit gekerbten Warzen, später dagegen die mit glatten Warzen weitaus in der Überzahl vorlanden, ohne dass die anderen ganz ausgeschlossen wïren.

Ein Übergang von glattwarzigen Formen in gekerbtwarzige ist nirgends nachznweisen. Dagegen ist es sehr wahrscheinlich, dass unabhängig ron einander auf verschiedenen Linien ans Formen mit gekerbten Warzen solche mit ungekerbten allmählig sich herausgebildet haben.

Dahin gehört z. B3. die Reihe cucumifera - propinqua - clavigera. Bei Cidaris cucumifera aus dem Dogger ist die grosse Mehrzahl der Warzen gekerbt; bei propinqua aus dem Malm finden sich nur noch rereinzelte Warzen nahe dem Apicalfelde mit geringen Spuren einer Kerbung; bei clarigera aus der Kreide sind alle Warzen glatt.

Repriisentanten einer aufeinanderfolgenden Reihe sind auch desori - covicalis - marginatr, conomancnsis; Cidaris desori aus dem Dogger hat nur gekerbte Warzen; cervicalis aus dem Malm zeigt nur in der oberen Schalenhalfte gekerbte, in der unteren dagegen glatte Warzen; marginata aus dem Malm und cenomanensis aus der Kreide zeigen nur noch ungekerbte Warzen.

Alle jurassischen Arten der Rhablocidaris-Reihe haben nur gekerbte Warzen; erst von der Kreidezeit an finden sich die ungekerbten Formen.

Die tertiäen Porocidaris-Arten sind gekerbt; die recente purpurata zeigt nur noch einzelne gekerbte Warzen; gracilis ist ungekerbt.

Ich möchte daraus wohl den Schluss ziehen, dass die Kerbung der Hauptwarzen ein Charakter ist, der bei den Cidariden auf verschiedenen von einander unabhängigen Entwicklıngslinien allmählig verloren gegangen ist. Dies erklärt anch das mehr oder weniger regelmässige Auftreten einzelner gekerbter Hauptwarzen bei recenten Arten oder Gruppen, die eigentlich durch glatte Hauptwarzen charakterisirt sind. In der Dorocidaris-Gruppe ist dies bei papillata zu beobachten, für Goniocidaris tubaria wird es von STuder angegeben; besonders aber in der Leiocidaris-Gruppe sind solche Falle bekannt bei den Arten baculosa, ammafera. bispinosa, cremlaris. Diese letztere Gruple kann angesehen werden als eine noch in Umbildung befindliche, bei der" der nenerworbene Charakter, Hauptwarzen ohne Kerbung, noch nicht fest genug eingebirgert ist, so dass Rückschlag auf den älteren gekerbten Zustand noch zienlich häufig vorkommt*

\section{Übersicht der wichtigsten Gruppen von Cidaridae.}

Aus der neueren Literatur, die bei der folgenden Zusammenstellung benutzt wurde, ist wesentlich hervorzuheben:

A. Agassiz, Revision of the Echini. 1872-1874.

A. Agassiz, Report on the [Challenger]-Echinoidea. 1881.

Cоттеau, Échinides régulaires, in: Paléontologie française, Terrains crétacés und Terrains jurassiques.

Cortead, Description des Echinides tertiaires des Isles St. Barthélemy et Anguilla, 1875 in: Kongl. Svenska Vet.--Akad. Handlingar. Vol. 13.

Cotteau, Sur le genre Tetracidaris, in: Bull. Soc. Géol. de France. 3 série, T. I.

Danes, Die Echiniden del vicentinischen und veronesischen 'l'ertiärablagerungen, in: Palaeontographica Bd. 25. 1877

Duncan and Sladen, 'The fossil Echinoidea, in: Nem. Geol. Survey of India.

Laube, Die Fauna der Schichten von St. Cassian, in: Denkschr. Akad. Wissensch. 24. Bd. 1865.

LAUnE, Die Echiniden der österr.-ungar. oberen Tertiärablagermugen, in:-Ablı. k. k. geol. Reichsanstalt. Bd. 5. 1871:

DE Lorion, Échinologie helvétique I, II, III [Jura, Kreide, Tertiär].

De Lorior, Description de trois espèces d'Échinides appartenant à la famille de Cidarides, in: Mém. Soc. sc. nat. de Neufchâtel. T. 5. 1873.

De Lorior, Monographie des Échinides nummulitiques de l'Égypte 1881, in: Mém. Soc. Phys. et d'hist. nat. de Genève. 'T'. 27.

DE Loriou, Eocäne Echiniden aus Egypten und der Lybischen Wüste, in: Palaeontographica Bd. 30. 1883.

De Lonion, Catalogne raisonné des Échinodermes de Maturice, in: Mém. Soc: Phys. et d'hist. nat. de Genève. 'T'. 28. 1883.

Poure, Classification méthodique et Genera des Échinides vivants et fossiles. 1883.

* Anch unter fossilen Formen sind viele derartige Beispiele anzuführen. 
Quenstedt, Petrefactenkunde Deutschlands; Echiniden 1872-75.

STUDER, Übersicht über die „Gazelle"-Echinoiden, in: Monatsber. Akar. Wiss. Berlin 1881.

Thонson, On the Echinoidea of the Porcupine-Expedition, in: Phil. Trans. London 1874.

Wright, Monograph of the British fossil Echinodermata. The cretaceous Echinoidea 186t-82.

The oolitic Echinoidea 1857-1878.

Bei den posttriassischen Cidariden habe ich versucht, mit den zallreichen bereits in die Literatur als Gattungen oder Untergattungen eingeführten Gruppen auszukommen; eine Anzahl dieser aufgestellten Gruppen glaubte ich bei näherer Prüfung eliminiren zu dürfen. Bei den übrigen suchte ich eine möglichst präcise Definition zu geben, die sich mitunter nicht ganz deckt mit der bisherigen, und versuchte sie nach ihren Charakteren und ihrer geologischen Verbreitung in natüliche Bezielungen zu bringen. Die ganze Zusammenstellung kamn nur als eine provisorische angesehen werden. Als brauchbare Gruppen möchte ich unter den Cidariden folgende annelımen:

a) Cidariden mit beweglicher Schale.

\section{Eocidaris DESOR.}

Palaeozoische Cidariden von geringer Grösse, mit schneidendem ambulacralen Rand des I. A. F. Coronalplatten in geringer Anzahl; Hauptwarzen klein, gekerbt; Warzenhöfe elliptisch, etwas vertieft, zusammenfliessend; Scrobicularring nicht auffallend.

Arten: Keyserlingi aus dem Zechstein u. a.

Beschreibung eines Bruchstiickes von

\section{Eocidaris Keyserlingi Geinitz.}

Taf. XI Fig. 8.

Ein gut erhaltenes, anscheinend ziemlich vollständiges Interambulacralfeld liegt vor aus dem mittleren Zechstein bei Pöseneck in 'Thüringen; es besteht ans zwei Verticalreihen von je vier Coronalplatten, zu denen vielleicht noch jederseits eine weitere Platte zu ergänzen ist, um das vollständige Interambulacralfeld zu erhalten. Die Annahme einer grösseren Reihenzahl für das Tnterambulacralfeld ist ganz unwahrscheinlich nach der Wölbung des Stückes; der freie (ambulacrale) Rand der Coronalplatten ist wenig convex [die Platten also nicht hexagonal], so dass das A. F. kaum gewvellt sein konnte; der Rand ist schmeidend wie bei den St. Cassianer Echinoiden, doch scheint die Unterseite nicht gerippt wie bei jenen Formen.

Der ovale Warzenhof ist etwas eingesenkt, die Basis der Hauptwarze stark vorspringend, gekerbt mit kleinem Warzenkopfe. Die Mittelnaht erscheint als eine feine Furche; zwischeu ihr und dem Warzenhof liegen zwei alternirende Reihen ziemlich dichtstehender Würzchen von gleicher Grösse, so dass ein Scrobicularring nicht scharf hervortritt; gegen den ambulacralen Rand hin zeigt sich nur eine Reihe ebenso grosser Würzchen. Die Warzenhöfe fliessen ineinander ïher.

Die Höhe des stark gewölbten Stïckes betrïgt $7 \mathrm{~mm}$., die Breite $5,3 \mathrm{~mm}$.

Dies Stïck zeigt durchaus die Merkmale eines echten Cidariden, und es ist danach kein Grund einzusehen, diese Art unter die Palechinoidea zu versetzen; ïber das Ambulacralfeld ist mir nichts bekannt.

\section{Mikrocidaris.}

? Schale beweglich:

Triassische Cidariden von winziger Grösse, ausgezeichnet durch anfallend dicke und stark hervorragende Hauptwarzen mit verhältnissmässig sehr kleinem nicht vertieftem Warzenhofe; Hanptwarzen sind glatt und durchbohrt; Ambulacralfeld gerade; Poren nicht gejocht.

Arten: pentagona, subpentagona, gerana ans der T'rias von St. Cassian.

\section{Triadocidaris.}

Triassische Ciłariden von mässiger Grösse, mit übereinandergreifenden und in Gelenkverbindung stehenden Rändern des Ambulacral- und Interambulacralfeldes; Hauptwarzen glatt; Warzenhöfe gross, nicht vertieft, rund oder elliptiscl. Poren nicht gejocht.

Arten: venusta, subsimilis, liagora aus der Trias von St. Cassian; ebendaher Suessii mit zusammenfliessenden Warzenhöfen. 


\section{Miocidaris.}

Triassische und jurassische Cidariden von mässiger Grösse und dïnner Schale, mit übereinaudergreifenden in Gelenkverbindung stehenden Rändern des Ambulacral- und Interambulacralfeldes; Hauptwarze klein, gekerbt; Warzenhöfe rund, schwach vertieft; Poren nicht gejocht.

Arten: Klippsteini,? subnobilis ans der 'l'rias ron St. Cassian;

amalthei, arietis 11. i. aus dem Lias und Dogger.

5.

'Triassische Cidariden von mässiger Grösse mit übergreifenden gerippten Rändern des Interambulacralfeldes; Hauptwarze selır grob gekerbt, Poren gejocht (?!).

Arten: subeoronata ans der Trias von St. Cassian.

b) Cidariden mit mbeweglicher Schale, mgejochten Poren und gekerbten Hauptwarzen.

\section{Plegiocidaris Pomet.}

Hauptwarzen sind gekerbt; Coronalplatten in mässiger Zahl, selten verbreitert; Warzenhöfe meist etwas vertieft und getremt; Randwarzen des A. F. ungefähr gleich gross und undurchbohrt.

Nach unten schliesst diese Gruppe unmittelbar an die Miocidaris-Gruppe an, der gegenüber sie modemisirt ist in Folge der Abwesenheit von übereinandergreifenden Platten-Rändern. Den posttriassischen Formen mit ungejochten Poren gegenüber kamn sie als Stammgruppe gelten, aus der sich die andern entwickelt haben mögen, und deren Entwicklungsrichtung sich bereits imnerhalb der Gruppe selbst schon angedentet findet. Sie ist wesentlich jurassisch.

'Typische Arten sind:

Falsani, langrunensis, Desnoyersi, lacviuscula, Desori, alpina ans dem Jura, dissimilis ans der Kreide.

Arten mit sehr zerstreuten Wärzchen und Neigung zur Bildung kahler Flächen:

sublaevis, elegans, microstoma, MLatheyi ans dem Jura, Loryi aus der Kreide.

Arten mit Neigung zur Bildung ungleicher und unregelmässiger ambulacraler Randwarzen (Paracidaris-ähnlich):

Sacmomi, Caumonti, bathonica ans dem Jura.

Arten mit Neigung zur Bildung auffallend dicker Hauptwarzen mit keuleufürmigen Stacheln (Tylocidaris-ähnlich)

cucumifera, propinqua aus dem Jura.

Arten mit Neigung zur Bildung ungekerbter Hauptwarzen (Dorocideris-älmlich):

coronata, cervicalis, monitifera, glandifera aus dem oberen Jura; wohl anch gramulata ans dem indischen 'Tertiär.

\section{Paracidaris POMEL.}

Diese Gruppe geht ganz ummerklich in Plegiociduris über, wo sie durch Arten wie Sacmani u. a. schon angedeutet ist. Sie ist ausgezeichnet durch die Neigung einzelner ambulacraler Randwarzen, auf Kosten der benachbarten bedeutend an Grösse zmzunehmen, so dass auf eine Randwarze mehr als ein Porenpaar treffen kann; diese Neignng zeigt sich zuerst und am auffallendsten in der Nïhe des Buccalfeldes; es ist der erste Schritt zur Bildung zusammengesetzter Ambulacralplatten, wie solche erst in anderen Familien anftreten.

'I'ypische Arten mit breiten Coronalplatten in mässiger Zahl und mit runden Warzenhöfen:

bajoconsis, varusensis, Babeani, Legayi, florigemma, Blumenbachi, vallatus, suevica, Bouchardi aus dem Jura.

Extreme Arten mit zalılreichen Coronalplatten und elliptischen ineinanderfliessenden Warzenhöfen (Polycirtaris-ähnlich):

spinulosa, Poucheti aus dem Jura.

Die Grupe Paracidaris ist unter den hier aufgenommenen wohl die hinfälligste; es ist keineswegs nachgewiesen, ob der Charakter, auf den sie gegründet ist, einigermassen constant ist; das mir zn Gebote stehende Material ist zur Beurtheilung dieser Frage bei weitem nicht ausreichend; jedenfalls zeigen auch andere Cidariden, besonders, wie ich finde, aus der Rhabdocidaris-Reihe, eine ähnliche Neigung (Rhablocidaris Fowleri. Smithi n. a.). 


\section{Procidaris POMEL.}

Entsteht aus der vorigen Gruppe in der Weise, dass die vergrösserten randständigen Ambulacralwärzchen auch durchbohrt werden; Coronalplatten sind breit und zahlreich, die Warzenhöfe elliptisch und in einander fliessend. Ambulacralfeld ist fast gerade.

Arten: Toucasi, spinosa, Edwardsi aus dem Jura.

Es ist möglich, dass als direkter Vorläufer dieser Gruppe jene triassische Cidaridenform anzusehen ist, von der ein Bruchstïck des Ambulacralfeldes abgebildet ist ('Taf. X Fig. 20; vergl. S. 37 unter' Cidaris sp. IV).

\section{Polycidaris Quenstedt.}

Ciduris mit zahlreichen Coronalplatten, die sehr breit werden; Warzenhöfe mehr oder weniger elliptisch und in einander tliessend; Miliarzone sehr breit; Ambulacralfeld gerade.

Arten: multiceps, nonarius, trouvillensis, Blainvillei, Zscholkei aus dem Jura.

Die Gruppe zeigt nahe Beziehungen zu Plcgiocidaris, ist aber vielleicht schon aus deren triassischen Torläufern direkt lerzuleiten; amalthei, arietis, curioni sind schwer davon zu trennen.

c) Cidariden mit unbeweglicher Schale, ungejochten Poren und glatten Hauptwarzen.

\section{Orthocidaris Cotteau.}

Coronalplatten zahlreich und sehr verbreitert; Warzenhöfe sehr klein und rund; Hauptwarze klein und glatt; Ambulacralfeld gerade.

Einzige Art: inermis aus der Kreide.

Diese Gruppe lässt sich vielleicht aus Polycidaris herleiten.

\section{Tylocidaris POMEL.}

Die Hauptwarzen sind sehr gross, kuglig, glatt und nicht durchbohrt. Primärstacheln ausgesprochen kenlen- oder eichelfürmig.

Selrr selten findet man noch eine Spur einer Durchbohrung der Hauptwarzen; das Ambulacralfeld ist kaum gewellt, die beiden Poren eines Paares durch einen deutlichen Vorsprung von einander getremnt.

Arten: clavigera, gibberula, Ranondi, Bowerbanki aus der Kreide.

Tylocidaris ist wohl ohne Zweifel aus der Plegiocidaris-Gruppe hervorgegangen; propinqua aus dem Malm erscheint als direkte Übergangsform; hier erscheinen die Hauptwarzen bereits kuglig und verdickt; die meisten sind noch durchbohrt, aber die dem Buccalfelde zunächst stehenden sind undurchbohrt; ansserden treten neben melir oder weniger deutlich gekerbten Warzen bereits eine Anzahl ungekerbter auf; die Gestalt der Stacheln ist wie bei Tylocidaris. Den typischen Plegiocidaris noch näher steht cucumifera, bei der nur auffallend grosse und kuglige Warzen auftreten, die aber noch alle durchbohrt und gekerbt sind. Seln nahe Verwandte besitzt diese Gruppe auch in der nächsten Gruppe Dorocidaris in den Arten Honorinae aus dem. Jura und vclifera ans der Kreide, bei denen die Durchbohrung der Hauptwarzen noch erhalten blieb.

\section{Dorocidaris A. AgAssiz.}

Schale und Genitalplatten verdickt; Apicalfeld flach; Ocellarplatten ziemlich klein; A. F. dentlich gewellt; Hauptwarzen glatt; Warzenhöfe stark vertieft, kreisrund oder doch mur selten oval, wohl von einander getrennt. Kleinere Wärzchen dicht stehend. Längs der Mittelnaht des I. A. F. ist die Schale stark eingesunken. Primärstacheln lang, stabfürmig, mit gezälnelteu Längsleisten bedeckt, seltener etwas kolbenförmig und grob gekörnelt.

A. Agassiz gibt als besondere Unterschiede an gegenuiber einer anderen Gruppe (Cidaris A. AG. = Eucidaris Pomer), dass ein schmales A. F. vorhanden sei, sowie eine geringe Zahl von Coronalplatten; beim Tergleich von Dorocidaris papillata (dem Typus dieser Gruppe) mit Eucidaris thouarsii z. B. (vergl. 'Tabelle) finde ich aber in diesen Punkten keinen nennenswerthen Unterschied. Ponex findet Horizontalfurchen zwischen den Wärzchen der interambulacralen Miliarzone besonders charakteristisch; solche sind in der That bei manchen fossilen Formen sehr auffallend; sie finclen sich aber ebenso wohl ausgebildet auch bei anderen sehr verschiedenartigen Gruppen (Pleurocidaris) und fehlen dagegen zahlreichen hieher gelïrigen Formen, sind z. B. bei $D$. papillata kaum vorhanden. 
Dagegen besteht zweifelsohne eine Neigung zur Bildung von nackten Gruben oder Furchen längs der Nähte; so zeigen sich bei manchen Arten auffallende Gruben an den Horizontalnähten (marginata, malum, rothomagensis), mitunter auch mehr oder minder ausgeprägte kahle Furchen längs der Vertikalnähte, die aber bei anderen Arten wieder kaum angedeutet sein können, und deren Vorkommen sogar innerlalb derselben Art keinestregs constant ist (canaliculata A. AG.); letatere Art, bei typischen Individuen durch scharfe Vertikalfurchen ansgezeichnet, sollte nach meiner Ansicht hier ihren Platz finden, allerdings als etwas extrem stehende Form.

Es ist sehr wahrscheinlich, dass diese Gruppe aus der Plegiocidaris-Gruppe hervorgegangen ist, von der sie sich mu unterscheidet durch glatte Hauptwarzen. Eine Reihe von Plegiociduris-Arten vermitteln diesen Übergang, indem bei diesen eine mehr oder weniger grosse Anzahl von Hauptwarzen in der oberen Schalenhälfte ungekerbt bleibt (coronata, cervicalis etc.); andererseits finden sich bei echten Dorocidaris-Arten gelegentlich einmal einzelne gekerbte Hauptwarzen (bei der recenten propillata, häufiger noch bei cretacischen Formen, wie ich das an Exemplaren von serrifera und sceptriferc wahrnehmen konnte).

Die Gruppe ist höchst charakteristisch für die Kreidezeit, ist auch recent noch wohl vertreten, fehlt aber anch schon im Jura nicht. Von den Arten sind

Recent: papillata, Bartletti, Blakei, bractecta, canaliculato, hieher vielleicht auch Reini.

Tertiär: Schuabenawi, lacrymula (indisch).

Cretacisch: pretiosa, pyrcnaica; malum, insignis, vesiculosa, cenomanensis, hirudo, serrifera, Forchhammeri, mammillata, Jullieni; mit verbreiterten Coronalplatten und häufig deutlichen Horizontalfurchen auf den Coronalplatten: peromatu, vendocinensis, perlata, pseudopistillum, rothomagensis. Jurassisch: Morierei, marginata, millepunctata.

Durchaus Tylocidaris ähnlich, aber der duchbohrten Hauptwarzen wegen zu Dorocilaris zu rechnen sind: velifera aus der Kreide und Honorinae aus dem Jura.

\section{Stereocidaris POMEL.}

Stellt unzweifellaft eine von Dorocidaris ausgegangene extreme Gruppe dar, die durch zahlreiche Übergangsformen noch aufs innigste mit Dorocidaris verbunden ist. Sie ist ansgezeichnet durch sehr dicke Schale mit selrr solidem Apicalfeld, das auffallend convex ist; Ocellarplatten und Afterfeld sind sehr klein; die obersten Coronalplatten zeigen eine ganz verkïmmerte Hauptwarze ohne Primärstacheln; die sonstigen Eigenschaften sind wie bei typischen Dorocidaris-Arten, und es zeigen sich wie bei diesen gern Gruben an den Nỉhten (grandis, subvesiculosa, cretosa, serrata).

Die Gruppe erscheint erst in der Kreide und ist dafür höchst charakteristisch, findet sich auch noch recent in den japanischen Meeren.

Arten:

grandis, japonica, sceptriferoides recent aus den japanischen Meeren;

subvesiculosa, cretosa, Merceyi, Carteri, serrata, sceptrifera, atropha aus der Kreide (Dorocidaris insignis, hirudo, vesiculosa schliessen sich diesen aufs innigste an).

\section{Eucidaris PomeL (= Cidaris s. str. A. AgAssiz).}

Schale diun, ebenso Apicalfeld; Ocellarplatten sehr gross; Hauptwarze glatt; Warzenhüfe nicht vertieft, gross, elliptisch und zusammenfliessend; A. F. sehr wenig gewellt; Poren nicht gejocht; längs der Nähte zeigt die Schale keinerlei Einsenkung; Nähte sind gewöhnlich kaum zu erkennen, höchstens durch feine scharfe Striche angedentet. Primärstacheln stab- oder keulenförmig mit gekörnelter Obertlïche und von mässiger Länge.

Arten:

metularia, tribuloides, Thouarsii, galapagensis sind recent.

'Tertiär sind: melitensis, Loveni (vielleicht beide besser zu Dorocidaris).

Durch Lardy aus der Kreide ist diese Gruppe vielleicht mit Dorocidaris zu verbinden.

d) Cidariden mit mbeweglicher Schale, gejochten Poren und gekerbten Warzen.

\section{Rhabdocidaris DESOR.}

Schale ziemlich diinn, oben flach; Apicalfeld dünn und hinfällig; A. F. gerade oder wenig gewellt; Poren gejocht; Hauptwarzen kläftig gekerbt; Warzenhöfe rund oder elliptisch, etwas vertieft; Miliarfeld des I. A. F. mit zerstrenten, ungleich grossen Wärzchen bedeckt. Erreicht gewöhnlich eine beträchtliche Grösse. 
Arten mit sclmäleren Coronalplatten in meist geringer Zahl:

copeoides, guttata, orbignana, Cartieri, caprimontana, nobilis aus dem Jura.

Arten mit stark verbreiterten Coronalplatten in meist bedeutender Zahl:

Foveri, Smithi, moraldina, major, horrida, Rhodani, Gauthieri, maxima aus dem Jura.

tuberosa, Tournali aus der Kreide.

mespilum, Zitteli, sindensis (indisch) aus dem Tertiär.

Zn dieser Gruppe steht möglicherweise subcoronata ans der Trias von St. Cassian in sehr naher Beziehung; doch ist bei dieser Art, wie bei allen gleichzeitigen, noch keine ambulacrale Randfläche an den Coronalplatten ausgebildet; eine solche scheint sich erst imnerhalb der Gruppe Rhabdocidaris zn entwickeln (vergl. Rh. horrida Taf. XI Fig. 4, 5). Die hieher gehörigen Arten sind meist von bedeutender Grösse mit sehr langen stabförmigen oder fächerförmigen Stacheln versehen.

\section{Diplocidaris DESOR.}

Rhabdocidaris älnnlich, doch mit alternirend unter einander stehenden Porenpaaren, so dass in jeder Porenzone vier Vertikalreihen von Poren vorhanden sind; das Ambulacralfeld ist meist stark gewellt, das Apicalfeld solide und gewölbt; Hauptwarzen gekerbt; die obersten Coronalplatten mit verkümmerter Hauptwarze.

Arten: Dumortieri, Gauthieri, gigantea, Etalloni, miranda aus dem Jura.

\section{Tetracidaris COTTEAU.}

Poren sind Diplocidaris älnlich; eine auffallend grosse Anzahl von sehr verbreiterten Coronalplatten, die in jedem I. A. F. vier Vertikalreilien bilden und nur zunächst dem Apicalfelde auf die beiden sonst vorhandenen Vertikalreilıen reducirt sind. Hamptwarzen gekerbt.

Einzige Art: Reynesi ans der Kreide.

e) Cidariden mit unbeweglicher Schale, gejochten Poren und glatten Warzen.

\section{Pleurocidaris POMEL}

Mit den Charakteren von Rhabdocidaris, aus der die Gruppe vermuthlich hervorgegangen ist; sie unterscheidet sich davon durch die glatten Hauptwarzen, sowie durch die winzigen gleich grossen Körnchen auf dem interambulacralen Miliarfelde, die in dentliche Horizontalreihen angeordnet sind, welche durch feine Horizontalfurchen getrennt werden.

Hieher die Arten:

sanctae crucis, Ponyannei [mit einzelnen gekerbten Warzen], venulosa, subvenulosa aus der Kreide. alta, itala, Adamsi, mezzoana (?), pseudojurassica, canaliculata Duxcan und SLaden (indisch) ans dem Tertiair.

Hieher gehört wohl anch die recente Sharreri At. Agassiz aus Westindien, die ron Agassiz zu Porocidaris gestellt wird.

\section{Temnocidaris COTTEAU}

Dies sind Pleurocidaris, die ausser den Querfurchen noch Gruben anf den Coronalylatten zeigen: ähnliche Gruben finden sich auch auf dem Ambnlacralfelde.

Arten: maynifica, Baylei, danica aus der Kreide.

\section{Leiocidaris DESOR.}

Es sind Thabdocidaris älnnliche Formen mit glatten Hanptwarzen, deren Warzenhöfe elliptisch, znsammenfliessend und nicht vertieft sind.

Arten mit dünner Schale und sehr dünnem Apicalfelde:

baculosa, anmulifera, crenularis, bispinosa, verticillata sind recent.

Arten mit dickerer Schale und soliderem Apicalfelde:

imperialis (syn. dubia), gigantec recent.

[salvionsis aus der Kreide mit vergrösserten Ambulacralwarzen gehört vielleicht in die Nähe.]

Die nahe Verwandtschaft mit Rhabdocidaris zeigt sich schon darin, dass gerade in dieser Gruppe gekerbte Hauptwarzen noch ziemlich regelmässig gefunden werden und zwar meist an den dem Apicalfelde 
zunächst stehenden Warzen (bei baculosa, ammlifera, cremelaris, bispinosa); Struden luat auf diese Beobachtung hin fü cromlaris eine besondere Gattung Schleinitzia gegriunlet.

Dem sehr diunnen Apicalfelde, dis einige Arten dieser Gruppe auszeichnet, ist von A. Agassiz ein besonderer. Werth beigelegt worden, und dasselbe ist als wesentlichster charakter der von ihm gegrïndeten Gattung Stephanocilaris hervorgehoben worden, zu der jedoch nu bispinosa gerechnet wird.

Die Poren sind nicht melı bei allen hieher gehörigen Arten so deutlich gejocht, wie bei Rhablociduris; bei manchen ist die charakteristische. Verbindungsfurche zwischen den beiden Poren eines Paares kaum zu erkennen (amulifera, verticillata), so dass solche Formen bei ausschliesslicher Berïcksichtigung dieses Charakters sich kaum von Gruppen mit ungejochten Poren trennen lassen.

Ar. Agassiz hat fiir diese Grupue den Branor'schen Namen Plyllacanthus wieder angewendet, doch ihn in ganz anderem Sinne gefasst als Brand, indem ex ihn vollstindig synonym verwendet mit dem älteren Leiocidaris. Die an sich nicht artenreiche Gruppe noch zu trennen, wie Poyel es thut, mm anch den AgassizBrand'schen Namen zu erhalten und daneben auch noch Stephanocidaris zu verwenden, erscheint mir doch zu viel.

(f) Cidariden zweifelhafter Stellung mit unbeweglicher Schale, meist molentlich gejochten Poren und meist glatten Warzen.]

\section{Porocidaris DESOR.}

Ambulacralfeld wenig gewellt; Poren nur manchmal dentlich gejocht; Warzenböfe gross und tlach, elliptisch, zusammenfliessend; Hanptwarzen glatt oder gekerbt. Primärstacheln zunächst dem Buccalfelde flach, oft etwas gebogen, mit kriftig gezảhnten Seitenrändern.

Arten: icronensis (- Schmidcti), anomala (indisch) ans dem T'ertiär; auch Clevei gehört vielleicht hieher. purpurato, deyans, gracilis recent.

Diese Gruple hat nu einen sehr lockeren Zusammenhalt; das einzige Merkmal, das allen Formen zukommt, bestelıt in den elliptischen zusammenfliessenden Warzenhöfen und den eigenthümlichen flachen, grobgesägten Primärstacheh in der Nähe des Buccalfeldes. Ähnliche Stacheln kommen aber auch anderweitig ror, so bei $C$. japonica, wo sie ebenfalls sogar gebogen sind wie ofters bei Porocidaris, ebenso bei Goniocidaris clypeata.

Der bei den tertiuren Formen so charakteristische Kreis ron Löchern im Warzenhof ist bei den recenten Arten nicht vorhanden. Die tertiären Arten haben gekerbte Hauptwarzen, ebenso elcgans; bei purpurata sind die meisten Warzen glatt, bei der kleinen gracilis waren überhaupt keine gekerbten Warzen zu beobachten.

Von Al. Agassiz wurde anch die recente Shareri mit glatten Warzen hieher gezählt, die nach meiner Ansicht besser bei Plurocidaris unter"ubringen ist.

Wenig Übereinstimmung herxscht anch in der Beschaffenleit der Poren; dieselben sind nur bei den tertiären Arten entschieden gejocht; nach W. THompson sind sie bei mrpurata "nahe beisammenstehend" und offenbar, wie bei den anderen recenten Arten, nicht dentlich gejocht.

\section{Goniocidaris DESOR}

Schale ziemlich dïn, besonders anch die Apicalplatten; Apicalfeld flach; Ambulacialfeld fast gerade; Poren eines Pares einander genälıert; Hauptwarzen glatt; Warzenhöfe nahezu rund, wohlgetrennt, etwas vertieft; Scrobicularring anffallend, aus einè Reihe grösserer Wärzchen bestehend; der übrige Theil der Coronalplatten wie der mittlere Theil des ambulacralen Mittelfeldes von winzigen Kö̈nchen bedeckt, die längs der Nähte kahle Felder lassen können; an den Winkeln der P'latten gewöhnlich meh oder weniger deutliche Gruben; die grossen Pedicellarien meist mit kugligem Iöpfchen. Primärstacheln sind roi sehr verschiedener Gestalt, stark bedornt und zum Theil areniont.

Hieher die recenten Arten:

tubaria, geramoides, biserialis,

und mit Basalkragen an den Jrimärstacheln:

florigrra, clypuratr, mikado.

Auch diese Gruppe ist keineswegs scharf begrenzt. Die nackte Zickzacklinie längs der Mittelnähte, die für die am längsten bekannten Arten tubaria mol geranoides, die Typen der Gruppe, so bezeichnend sind, findet sich bei den ubrigen Arten nicht. Die Winkelgruben sind sehr verschieden ansgebildet; bei tubaria md geranoides sehr auffallend treten sie bei clypeata etwas zurick und felklen bei mikado anscheinend ganz; bei biscrialis sind sie an grösseren Exemplaren wohl ausgeprägt, während sie an jüngeren noch fellen.

Die charakteristischen kugelförmigen Pedicellarien, die sonst nirgends bei Cidariden vorkommen, kömen einzelnen Individuen von tubaria ganz fehlen und sind bei clypeata und mikado noch gar nicht beobachtet. 
Ziemlich constant ist der Charakter der Primärstacheln, die stets stabfürmig und kräftig bedornt sind; bei allen Arten treten gekrönte Stacheln auf, die aber auch manchen Individnen ganz fehlen können; die Verschiedenartigkeit der Primärstacheln an einem Individuum ist in dieser Gruppe grösser als bei den ïbrigen Cidariden. Alles zusammengenommen dürfte diese Gruppe eine natürliche sein.

Die recente canaliculata A. AG. möchte ich aus dieser Gruppe entfernen und Dorocidaris anreihen, welcher Gruppe sie sich auch ihrem ganzen Habitus nach gut anschliesst. Der einzige Charakter, auf Grund dessen sie von A. Agassiz zn Goniocidaris gestellt sein dürte, scheint die tiefe Furche lïngs der Mittelnähte zu sein; dieselbe ist bei canaliculata nicht einmal constant und erscheint anch bei Arten von Dorocidaris angedentet. Ausserdem tritt aber bei den typischen Goniocidaris-Arten, bei tubaria und geranoides, gar keine vertiefte Furche auf; es bleibt bei diesen nur ein breiter Zickzackstreifen längs der Mittelnähte nackt. Gerade die bezeichnendsten Merkmale von Goniociduris aber, die winzigen Körnchen im Viliarfelde, die Winkelgruben, die kingeligen Pedicellarien und die gekrönten und bedornten Primärstacheln treten bei canaliculata A. AG. nicht auf.

Der.Anschluss an eine andere Gruppe ist für Goniocidaris mit Sicherheit nicht zu entscheiden. Es gibt manche fossile Arten, bei denen sich älnliche Winkelgruben vorfinden, so Polycidaris multiccps und nonarius, ferner Dorocidaris subvesiculosa und rothomagcnsis. Es wäre nicht ummöglich, dass die Goniocidaris-Gruppe von dünnschaligeren Dorocidaris-Formen abstammt.

Doch möchte ich sie lieber auf Plcurocidteris zurückführen, in welcher Gruppe eine tertiäre Art aus

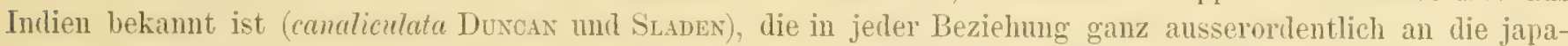
nische Goniocidaris biserialis erimnert und nur durch den Mangel der Winkelgruben und die dentlich gejochten Poren davon zu unterscheiden ist. Noch melır gleichen sich jüngere Exemplare der beiden Arten, denen bei G. biserialis noch die Winkelgruben fehlen, während jüngere canaliculata kaum noch gejochte Poren besitzen.

Diese Anffassung würde anch die verschiedenen nahen Beziehmngen erklären, die zwischen Goniocidaris und Leiocidaris nnzweifelhaft existiren, da auch Leiocidaris nahe verwanlt ist mit Plcurocidaris: Goniocidaris biserialis hat dasselbe grosse, biegsame, mit zahlreichen Afterplatten bedeckte Apicalfeld wie Lciocidaris (Stcphonocidaris) bispinosa; ebenso erinnern die Primärstacheln dieser und rerwandter Arten sehr an die ron Gromiocidaris.

\section{Stammesgeschichte der Cidariden.}

Der Ursprung der Cidariden muss in der palliozoischen Zeit gesnclıt werden. Eine Art ans dem Zechstein, Eocidaris Keyscrlingi, ist mit grosser Wahrscheinlichkeit bereits als echter Cidaride anfzufassen.

Nur spärliche Reste sind ans der älteren Trias bekannt, Stacheln und vereinzelte Asseln.

In der oberen Trias, in den St. Cassianer Schichten tritt zum ersten Male eine reiche Cidariden-Fanna auf; einer grossen Mamnigfaltigkeit von Stacheln entspricht auch eine auffallende Menge selur verschiedenartiger Schalenformen. Manche der St. Cassianer Arten zeichnen sich durch die winzige Grösse ilhrer Schalen aus; neben ilmen treten aber anch noch andere Arten auf, die an Grösse mittelgrossen recenten Formen nicht nachstelen.

Der auffallendste Charakter der triassischen Cidariden ist in der eigenthümlichen Verbindung der Ambulacralplatten mit den Interambulacralplatten zu sehen; die sich berülırenden Ränder der Ambulacral- und Interambulacralfelder laufen in breite Schneiden aus, clie weit über einander übergreifen und durch einander entsprechende Querleisten und Furchen in Gelenkverbindung mit einander stehen, so dass eine ansgiebige Verschiebung der sich berührenden Platten in taugentialer Richtung ermöglicht ist. Erst während der Juraperiode bilden sich allmählig besondere Randflächen an dieser Stelle aus, die die Beweglichkeit der Platten hemmen, bis eine solche wenigstens vom oberen Jura an ganz ummöglich wirl mit dem Auftreten hoher senkrecht zur. Oberfläche der Platte stehender Randflïchen. Solche feste Schalen haben sich leicht in vollem Znsammenlang erhalten, während zusammenhängende Ambulacral- und Interambulacralplatten der älteren beweglichen Schalen grosse Seltenheiten sind.

Vom Begimn der Juraperiode an lassen sich zwei Reihen von Cidariden ziemlich scharf ron einander tremnen, solche mit ungejochten Poren (Cidaris-Reihe) mi solche mit gejochten Poren (7habdocidaris-Reihe). Erst unter den jüngsten Formen finden sich häufiger Arten, deren Zuweisung zu einer dieser beiden Reihen Schwierigkeiten macht (in dex Goniocidaris-, Porocidaris-, Leiocidaris-Gruppe). Nach der individuellen Entwicklung zu schliessen, ist die ungejochte Form der Poren der urspringlichere Znstand; die bisher bekumnt gewordenen Ambulacralfelder von Cidariden aus der Trias zeigen sïmmtlich sehr ansgesprochen die ungejochte Porenform, doch ist vielleicht anzunehmen, dass schon C. subcoronata von St. Cassian der Ihabdocidaris-Reihe angehört hat, obwohl davon noch kein Ambulacralfeld vorliegt. 
Während der Juraperiode hatte die weit überwiegende Nehrzahl der Cidariden beider Hanptreihen gekerbte Hauptwarzen; Formen mit glatten Hauptwarzen sind in dieser Zeit ganz verschwindend; umgekehrt treten ron der Kreidezeit an die Formen mit glatten Hanptwarzen ganz in den Vordergrund, die gekerbten Formen dagegen durchaus zurick. Unter den recenten Arten existirt nur eime einzige, bei der die Mehrzahl der Warzen gekerbt sind, während sich allerdings Spuren ron Kerbung noch bei einer Anzahl anderer recenter Arten nachweisen lassen. Doch darf auch nicht übersehen werden; dass sich glattwarzige Formen, sogar in der Mehrzahl. schon in der St. Cassianer 'Trias finden.

Bei Beginn der Juraperiode treten in der Cidaris-Reilse zwei nicht scharf von einander gesonderte Gruppen neben einander anf, die wohl in die Trias zuruckreichen: die Plegiocidaris-Gruppe mit wenigen kanm verbreiterten Coronalplatten, und die Polycidaris-Gruppe mit zahlreicheren Coronalplatten von auffallender Breite und mit kleinem Warzenhofe.

Die Polycidaris-Gruppe ist ziemlich artenarm und erlischt bald; sie besitzt vielleicht in der Kreide noch einen direkten Abkömmling, Orthocidaris mit selr zahlreichen Coronalplatten und winzigen glatten Hanptwarzen.

Ansserordentlich viel reicher ist die andere Gruppe, Plegiocidaris, im Jura vertreten; sie entwickelt sich nach sehr verschiedenen Richtungen und kann als Stammgruppe der iibrigen Zweige der Cidaris-Reihe betrachtet werden, die innerhalb der Plegiocidaris-Gruppe schon vorbereitet werden.

Eine Richtung zeichmet sich dadurch aus, dass die sonst sehr regelmässigen Randwarzen des Ambulacralfeldes unregelmässig werden (Sacmani u. a.); indem sich nun einzelne der Randwarzen bedentend auf Kosten der benachbarten vergrösserm, entstelt die Gruppe Paracidaris, und wenn solche Randwarzen sogar wie die interambulacralen Hauptwarzen durchbohrt werden, die Gruppe Procidaris. [Letztere Gruppe hat vielleicht schon in der Trias existirt s. 'J'af. X Fig. 20.]

Bei einer anderen Richtung werden die Hauptwarzen ungewöhnlich gross und vorspringend; sie tragen auffallend dicke Stacheln (cucumifera u. a.); die Hauptwarzen verlieren die Kerbung (Honorinae) und in der Kreide endlich auch die Durchbohrung (Gruppe Tylocidaris).

Die Hauptrichtung kemnzeichnet sich dadurch, dass besonders im oberen Jura neben gekerbten Hauptwarzen anch ungekerbte an einer Schale auftreten (cervicalis u. a.); so entsteht allmählig die DorocidarisGruppe, indem alle gekerbten Warzen durch ungekerbte ersetzt werden; schon im Jura vorhanden, spielt diese Gruppe von der Kreide an eine ganz hervorragende Rolle unter den Cidariden und ist auch recent noch wohl vertreten.

Viele Formen ron Dorociduris zeichnen sich durch besonders dicke Schalen aus; in innigem Zusammenhange mit solchen stehen Formen mit sehr solidem und gewölbtem Apicalfeld, die die Eigenthümlichkeii zeigen, dass anf den obersten Coronalplatten sich keine Primärstachehn entwickeln; diese für die Kreiđe lö̈chst charakteristische Gruppe (Stercocidaris) kommt auch noch lebend in den japanischen Neeren vor.

Tielleicht auch von Dorociduris stammen die dünnschaligeren Euciduris-Formen mit grossen zusammenfliessenden und flachen Warzenhöfen, die in geringen Tiefen unserer wärmeren Meere leben.

In der anderen Hanptreihe, der Rhabdocidaris-Reihe mit gejochten Poren, ist Ihabdocidaris s. str. im Jura durch eine Anzahl von grossen Arten vertreten, kommt spärlich in der Kreide vor und findet sich selust noch im T'ertiär (R. Zitteli); in Jura zweigt sich eine merkwürdige Gruppe ab, die loöchst anffallend besonders dadurch ansgezeichnet ist, dass je zwei anfeinanderfolgende Porenpaare sich alternirend stellen und daher vier Vertikalreihen von Poren in einer Porenzone auftreten (Diplocidaris); vielleicht als cretacische Nachkommen kann eine noch merkwürdigere Form angesehen werden, bei der eine ganz auffallende Anzahl von Coronalplatten in vier statt in den normalen zwei Vertikalreihen für jedes Interambnlacralfeld vorhanden sind (Tetracidaris).

Von den eigentlichen Rhubdocidaris wesentlich nur durch glatte Hanptwarzen unterschieden sind die recenten dümnschaligen Leiocidcris, während grobgesägte Primärstacheln in der Nähe des Buccalfeldes die seit dem Tertiär vorhandene Porocidaris-Gruppe anszeichnet, bei der ebenfalls glatte Hauptwarzen vorkommen kömnen.

In der Kreide tremnt sich von dem Rhabdocidaris-Stamme eine Richtmog, die ausser durch glatte Hanptwarzen noch dadurch ausgezeichnet ist, dass die Miliarwärzchen auf den breiten Coronalplatten ron gleichmïssiger winziger Grösse werden und duch feine Qnerfurchen in Horizontalreihen getrennt sind (PleurocidarisGruppe); kommen dazu noch Gruben anf den Coronalplatten, so entsteht die Temnociduris-Gruppe, die auf die Kreide beschrinkt ist. Plewocidaris selbst ist noch tertïr und wahrscheinlich anch recent (P. Sharreri).

Vermuthlich ron tertiären Plourocidaris abznleiten ist endlich die recente Goniocidaris-Gruppe, ausgezeichnet durch Gruben in den Winkeln der Platten und durch eigenthümliche reich bedornte und gekrönte Stachehn von ausserordentlich verschiedenartiger Gestalt, die den hieher gehörigen Arten ein ungemein zierliches Ausselien verleihen.

Anf nebenstehender Stammtafel habe ich versucht, die Verwandtschaftsverhältnisse der verschiedenen Cidariden-Gruppen und ihre geologische Verbreitung schematisch darzustellen. Zum Verständniss dieser Tafel 
ist zu bemerken, dass die auf derselben aufgeführten Species nur als Repräsentanten der engeren Gruppen anzusehen sind, denen sie angehören, so dass danach z. B. als der cretacische Vorfahr von Cidaris grandis nicht gerade $C$. cretosa anzuselien ist, sondern überhaupt eine Form, die zu der cretosa-Gruppe gehört.

Die den Species- (und Gattungs-) Namen vorangesetzten Zahlen entsprechen den hier folgenden Nummern der Hauptgruppen von Cidariden, denen die betreffenden Arten zuzuweisen sind:
1. Eocitlaris.
12. Dorocidaris.
2. Mitirocidaris.
13. Stereocidaris.
3. Triadocidaris.
14. Eucidaris.
4. Miocidaris.
15. Rhabdociduris.
5).
16. Diplocidaris.
6. Plegiocidaris.
17. Tetraciduris.
7. Paracidaris.
18. Pleurocidaris.
8. Procidaris.
19. Temnocidaris.
1. Polycidaris.
20. Leiociduris.
10. Orthocidaris.
21. Porocidaris.
11. Tylocidaris.
22. Goniocidaris. 


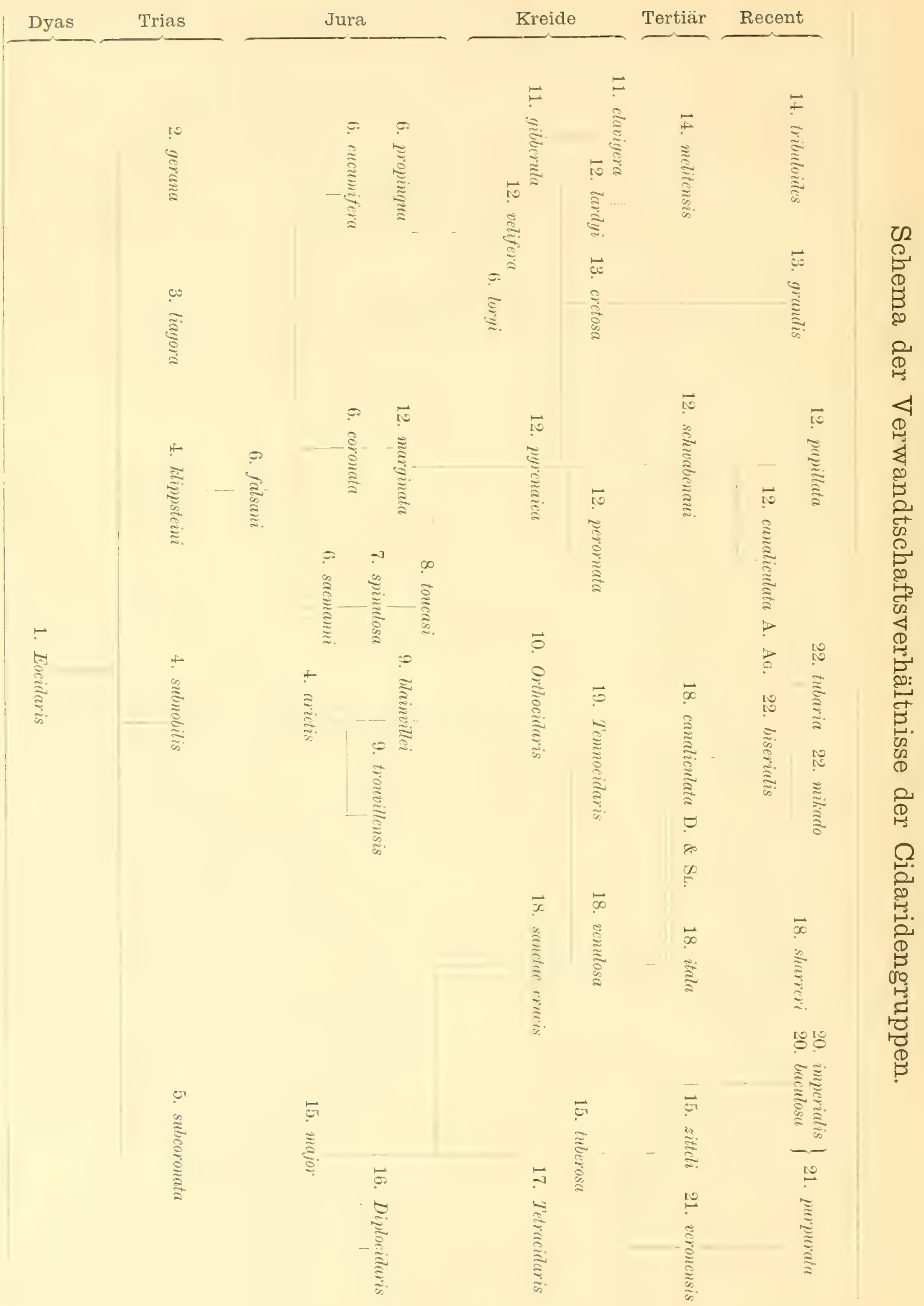




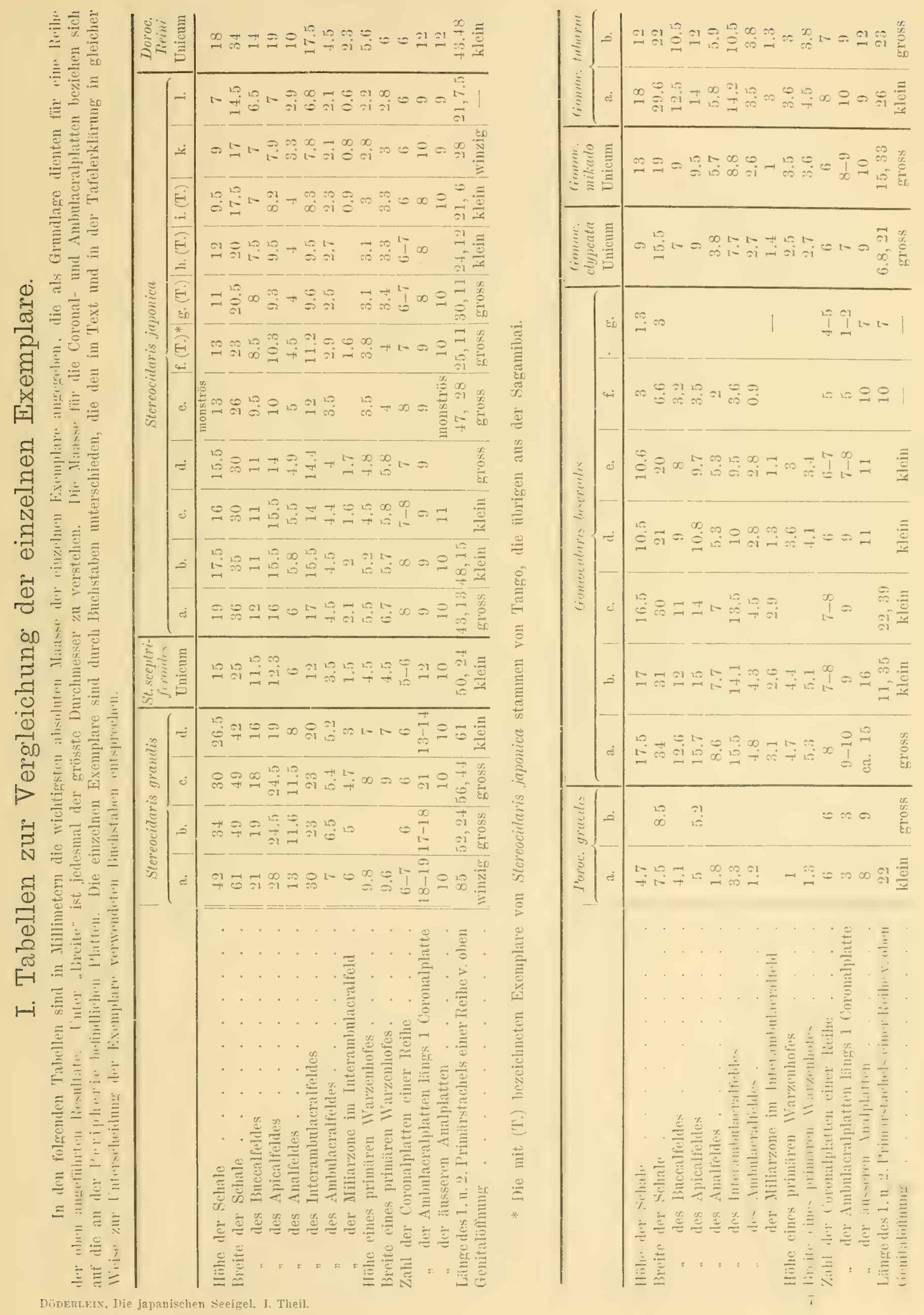




\begin{tabular}{|c|c|c|c|c|c|c|c|c|c|c|c|}
\hline & \multicolumn{4}{|c|}{ Dorocidaris papillata } & \multicolumn{7}{|c|}{ Dorocidaris canaliculata } \\
\hline & a. & b. & c. & d. & a. & b. & c. & d. & e. & f. & g. \\
\hline Höhe der Schale . . . . . . . & 33 & 26 & 16 & 13.5 & 17 & 14 & 12.5 & 10 & 7 & 7 & \\
\hline Breite der Schale. . . . . . & 49 & 42 & 25 & 24 & 29 & 24 & 21 & 16 & 13 & 12 & ca. 2 \\
\hline$" \quad$ des Buccalfeldes . . . . & 18 & 15 & 11 & 11 & 12 & 10 & 11 & 8 & 7 & & \\
\hline$"$ des Apicalfeldes. . & 22 & 19 & 11 & 12.5 & 11 & 9 & 10.5 & 7.8 & 6 & 5.6 & \\
\hline " des Analfeldes . . . . & 11.5 & 11 & 6 & 6.2 & 6.4 & & 5 & 4.2 & 3.3 & 3.2 & \\
\hline .. des Interambulacralfeldes . & 23 & 21 & 11 & 10.5 & 14 & 11.5 & 10.2 & 8 & 7 & 6.5 & \\
\hline " des Ambulacralfeldes . & 5 & 4 & 2.6 & 3 & 3 & 2.8 & 2.8 & 1.9 & 1.7 & 1.3 & \\
\hline$"$ der Miliarzone im I. A. F. & 3.1 & & & 1.3 & 0.8 & 1.3 & 1.4 & 0.5 & - & 一 & \\
\hline Höhe eines primären Warzenhofes & 7.8 & & 5 & 4.5 & 5 & 3.2 & 3 & 3 & & & \\
\hline Breite eines primären Warzenhofes. & 9 & & 5.4 & 4.6 & 6.7 & 4.8 & 4 & 3.5 & & & \\
\hline Zahl der Coronalplatten einer Reihe. & $7(8)$ & $7 \mid$ & 6 & $5-6$ & 7 & 7 & $6-7$ & $5-6$ & 5 & $5-6$ & $3-4$ \\
\hline$"$ der Amb.-Platten liings 1 Coronalpl. & 11 & $11-12$ & 8 & 11 & $7-8$ & 6 & $5-6$ & $5-6$ & 5 & $4-5$ & $1-2$ \\
\hline " der insseren Analplatten. . . & 11 & & 10 & 10 & 14 & & 10 & 10 & 10 & & \\
\hline Länge der grössten Primärstacheln & & 84 & & & 45 & 23 & 26 & 23 & 23 & 21 & 3 \\
\hline Genitalöffnung . . . . . . . . & klein & & & klein & gross & & klein & winzig & & & \\
\hline
\end{tabular}

\begin{tabular}{|c|c|c|c|c|c|c|c|c|c|c|c|c|c|c|}
\hline & \multicolumn{6}{|c|}{ Eucidaris galapagensis } & \multicolumn{8}{|c|}{ Eucidaris Thouarsii } \\
\hline & a. & b. & c. & d. & e. & f. & a. & b. & c. & d. & e. & f. & g. & h. \\
\hline Höhe der Schale . . . . . . & 20 & 15 & 11.5 & 10.5 & 9 & 3.5 & 34 & 25 & 20 & 17.5 & 15 & 12 & 10 & 6.7 \\
\hline Breite der Schale. . . . . . & 37 & 29 & 24.5 & $21 \mid$ & 19 & 7 & 51 & 451 & $\mid 37$ | & 32 & 27.5 & 22 & 18 & 13 \\
\hline „ des Buccalfeldes . . & 18 & 13.5 & 11.5 & $|10.5|$ & 9 & 4 & 22 & 22 & 20 & 16 & 13.5 & 12 & 10 & 7 \\
\hline des Apicalfeldes. . & 13 & 11.3 & 8.5 & 9 & 7.4 & 3.6 & 16 & 18 & 14 & 11.5 & 10.5 & 9 & 8 & 6 \\
\hline . des Analfeldes . . . . & 7 & & 4.8 & & 4 & 1.8 & 9.5 & & 8.5 & & 5.7 & 4.7 & 3.8 & 2.7 \\
\hline$"$ des Interambulacralfeldes. & 18 & 14 & 11.5 & 10 & 9 & 3.5 & 24 & 22 & 18 & 16 & 14 & 10.5 & 9.5 & 7 \\
\hline$"$ des Ambulacralfeldes . . & 3.6 & 3 & 2.7 & 2.3 & 2 & 0.8 & 5.5 & 5 & 4 & 3.8 & 3.5 & 2.4 & 2.3 & 1.9 \\
\hline , der Miliarzone im I. A. F. & 1 & 0.5 & 0.3 & 0.2 & 0 & 0 & 3.4 & 2.4 & 2 & 1 & 0.7 & 0.5 & 0.3 & 0 \\
\hline Höhe eines primären Warzenhofes & 6 & & 4 & 3.5 & 3.7 & & 6 & 5.8 & 5.5 & 4.7 & 3.5 & 3.2 & 3.1 & 2.4 \\
\hline Breite eines primären Warzenhofes. & 8 & & 5 & 4.3 & 4.1 & & 9 & 8.8 & 7.2 & 6.5 & 5.5 & 4 & 4.1 & 2.8 \\
\hline Zahl der Coronalplatten einer Reihe. & 7 & $6-7$ & 6 & $5-6$ & $5-6$ & $4-5$ & 10 & 8 & $7-8$ & 7 & 7 & $6-7$ & 6 & $5-6$ \\
\hline$"$ der Amb.-Platten längs 1 Coronalpl. & 11 & 11 & $10-11$ & $9-10$ & 9 & 5 & $10-11$ & 12 & 11 & 11 & 9 & 9 & 8 & $7-8$ \\
\hline " der äusseren Analplatten. . & 11 & & 12 & & 12 & 7 & 9 & & 11 & & 10 & 11 & 9 & 9 \\
\hline Länge der grössten Primärstacheln & $38(6.5)^{*}$ & $38(6.6)$ & $22(5)$ & $26(5)$ & $17(6)$ & $7(1)$ & 39 & & 33 & & 31 & 32 & 19 & 17 \\
\hline Genitalöffnung . . . . . . . & klein & & klein & & winzig & -1 & gross & & klein & & & klein & klein & klein \\
\hline
\end{tabular}

* Die eingeklammerten Zahlen bezeichnen die Dicke dieser Stacheln.

\begin{tabular}{|c|c|c|c|c|c|c|c|c|c|c|c|c|c|}
\hline & \multicolumn{2}{|c|}{$\begin{array}{l}\text { Leio- } \\
\text { cidaris } \\
\text { verti- } \\
\text { cillata }\end{array}$} & \multicolumn{4}{|c|}{ Leiocidaris baculosa } & \multirow[t]{2}{*}{$\begin{array}{l}L \text {. } \\
\text { an- } \\
\text { muli- } \\
\text { fera }\end{array}$} & \multicolumn{6}{|c|}{ Leiocidaris imperialis } \\
\hline & a. & b. & a. & b. & c. & d. & & a. & b. & $c^{*} *$ & d. & e. & $f_{0} *$ \\
\hline Höhe der Schale . . . . & 10 & 1.9 & 44 & 40 & 16 & 19 & 5.5 & 39 & 37 & 36 & 25 & 25 & 19 \\
\hline Breite der Schale. . . & 18.5 & \pm & 57 & 55 & 33 & 32 & 12 & 65 & 55 & 55 & 46 & 42 & 36 \\
\hline " des Buccalfeldes . . & 10.6 & & 28 & 23 & 14 & 15.5 & 5.5 & 33 & 27.5 & 27 & 24.5 & 21.5 & 18 \\
\hline des Apicalfeldes . . & 9 & & 25 & 20.6 & 12.5 & 15.5 & 5.2 & 22.5 & 20 & 19 & 18.5 & 17 & 14 \\
\hline des Analfeldes . . & 5 & & 15 & 13.4 & & 8.6 & 2.8 & 12 & 9.5 & 10 & 9.5 & 8.8 & 8 \\
\hline des Interambulacralfeldes & 10 & & 28 & 27 & 17 & 16 & 5.3 & 33 & 27.5 & 28 & 23 & 21.5 & 19 \\
\hline " des Ambulacrilfeldes . . & 2.6 & & 7.5 & 7 & 4 & 5 & 1.5 & 6.1 & 4.8 & 4.6 & 4.6 & 3.8 & 3.5 \\
\hline$"$ der Miliarzone im I. A. F. & & & 5 & 3.4 & 0.9 & 1.1 & 0.3 & 2 & 1.7 & 1.4 & 1.3 & 1 & 0.7 \\
\hline Höhe eines primären Warzenhofes & & & 6.5 & 6.2 & 5.5 & 5 & & & 9.5 & & & 7.5 & 6 \\
\hline Breite eines primairen WVarzenhofes. & & & 10 & 9.6 & 6.8 & 6.7 & & & 12 & & & 8.2 & 8 \\
\hline Zahl der Coronalplatten einer Reihe. & 5 & $3-4$ & 11 & 10 & 8 & 7 & $5-6$ & $5-6$ & 6 & $5-6$ & $5-6$ & 5 & 5 \\
\hline " der Amb.-Plattenlängs 1 Coronalpl. & $7-8$ & $3-4 \mid$ & 10 & $10-11$ & 10 & 10 & 7 & 18 & 17 & $17-18$ & 16 & 16 & $15-17$ \\
\hline .. der iusseren Analplatten. . . & 10 & 6 & 15 & 15 & & 11 & 10 & 10 & 10 & 10 & 10 & 10 & 10 \\
\hline Linnge der grössten Primärstacleeln & 19 & 5.5 & 50 & 67 & 56 & 31 & 19 & $76(7)^{* *}$ & $71(7.3)$ & $70(9.5)$ & $54(5.7)$ & $59(5)$ & $48(8)$ \\
\hline Genitalöffnung . . . . . . . & klein & -1 & mässig & klein & & klein & - & mässig & mässig & mässig & mässig & klein & mässig \\
\hline
\end{tabular}




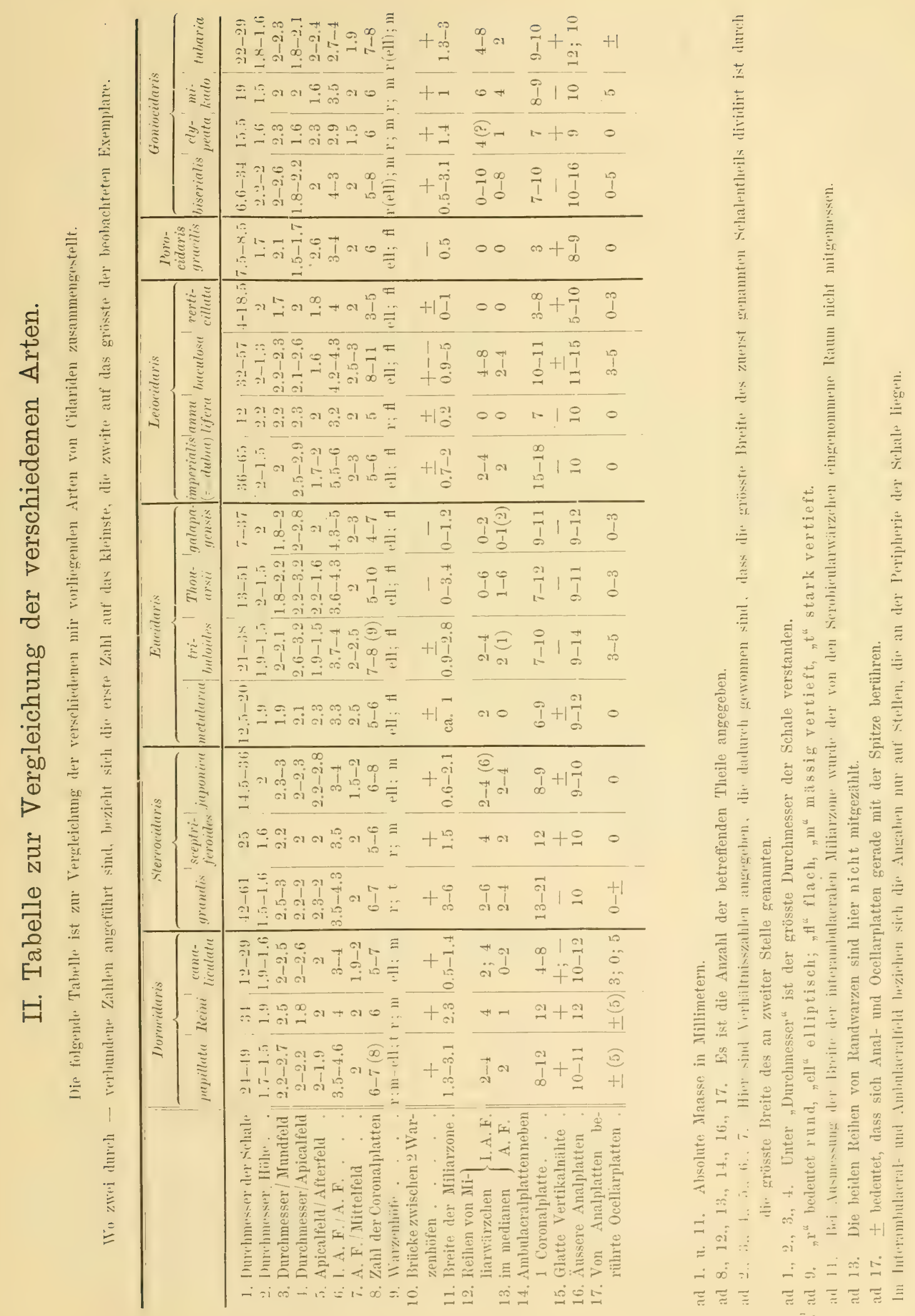




\title{
Familie Saleniidae.
}

\author{
Salenia pacifica DöD.
}

Taf. XI Fig. 9-28.

Salenia pacifica DöDerleis, Arch. f. Taturg. 51. Bd.

Die Schale ist $1 \frac{1}{1}$ mal so breit als hoch.

In Interambulacralfeld bilden 7, höchstens 8 Coronalplatten eine Verticalreihe, im A mbulacralfeld sind etwa 14 Ambulacralplatten in einer Verticalreihe rorhanden. Die Poren sind sehr klein, die einzelnen Paare weit vou einander entfernt und sehr schräg gestellt. In Mittelfelde stehen zwei Reihen ron Sekundärwärzchen, die gegen das Buccalfeld hin an Grösse zunehmen und undentlich gekerbt sind; unmittelbar am Ambulacralfelde entspricht eine dieser Ambulacralwärzchen je zwei Porenpaaren.

Die Hauptwarzen im Interambulacralfelde sind ziemlich gross, kuglig, undurchbohrt, aber gekerbt; gegen das Apicalfeld wie gegen das Buccalfeld nehmen sie bedentend an Grösse ab; in der Nähe des Buccalfeldes sind die Hauptwarzen im I. A. F. und die Ambulacralwarzen etwa von gleicher Grösse. Die Hauptwarzen sind umgeben von einem unregelmässigen Kreis weniger sehr kleiner Sekundarwarzen.

Das Buccalfeld ist von Kalkplättchen bedeckt und trägt 5 Paare von dicken Ambulacralfiisschen, deren jedes ron einigen winzigen Pedicellarien begleitet ist; der bnccale Rand der Schale ist etwas gekerbt; hier tritt an jeder Seite der Ambulacralfelder eine kurze etwa vierlappige Kieme hervor (Taf. XI Fig. 133).

Das grosse Apicalfeld ragt sehr stark hervor. Die Nähte der Platten sind ansserordentlich undentlich, ebenso die winzigen Genitalöfnungen, die die Mitte der Genitalplatten eimnehmen. Die Platten sind gleichmässig dicht bedeckt mit groben Papillen, die radiär anf jeder Platte angeordnet erscheinen, vou den Genitalporen als Centren ansgehend; zwischen den Papillen finden sich zahlreiche winzige Pedicellarien (Hig. 12).

Das Analfeld ist begrenzt von zwei Genitalplatten, der Submalplatte und der dieser gegenüberliegenden Ocellarplatte; der Rand dieser Platten, besonders der Subanalplatte, erhebt sich wallälmlich gegen das Analfeld (Taf. XI Fig. 12). Das Analfeld ist bedeckt von kuzen beweglichen Stachelchen, die an der Spitze knopffömig rerdickt sind; etwa 8 derselben, die am äusseren Rande einen Ring bilden, fallen durch ihre bedeutende Grösse aut?.

Stacheln. Die lingsten Primärstachehn dürften etwa dreimal so lang als der Schalendurchmesser gewesen sein; dieselben sind borstentörmig, mit dichten Wirteln von kieinen Zähnchen bedeckt; sie sind sehr düm nahe dem Apicalfelde; anf der Buccalseite werden sie allmählig kurz und abgeplattet mit stark gesïgtem Rande; ihmen gleichen vollkommen die Stacheln des Ambulacralfeldes auf der Buccalseite.

Die Sekundïrstacheln älmeln denen anderer Salenia-Arten, sind aber selr stark gekrümmt.

Ton Pedicellarien fund sich eine winzige Form überall zerstrent, rlie sich in nichts wesentlichem muterscheidet von den ophicephalen I'edicellarien der Echiniden und verwandter Familien; die halbkreisfürmigen Bögen an dèr Basis sind sehr niedrig und selten dentlich zu erkemnen (Taf. XI Fig. 25-28).

Die Sphaeridia sind mahezu kugelförmig; je eines oder zwei finden sich in jedem Ambulacralfelde nahe dem buccalen Rande (T'af. XI Fig. 13 r. 24).

Farbe. Der Schaft der Primärstacheln ist rein weiss; alles übrige ist mit einem Netze von purpurfarbenem Pigment ibberzogen, wie bei S. varispina.

Ein einziges Exemplar ron $8,5 \mathrm{~mm}$. Schalendurchmesser erhielt ich ans einer Tiefe ron 120 Faden in der Sagamibai. Dasselbe trug auf der Buccalseite drei Exemplare einer parasitischen Schnecke, der Gattung Stylifer zugehörig, umgeben von zahlreicheu Eiern, die von diesen Thieren abgesetzt waren; die Schale dieser Stylifer war weisslich und ausserordentlich diimm und zerbrechlich (Fig. 10). 
Es ist möglich, dass diese japanische Form von Salenia identisch ist mit der Salenia hastigera A. A . $_{\text {, }}$ der sie in vielen Punkten ähnelt*; doch scheint mir das Apicalfeld viel gröber granulirt zu sein bei der vorliegenden Art und ausserdem wird der auffallenden Stacheln, die das Analfeld der japanischen Art bedecken, keine Erwähnung gethan bei S. hastigera.

Einer scharfen Trennung der Saleniidae von den Cidaridae, die neuerdings von DunCaN und StaDEN** stark befürwortet wurde, muss ich durchaus beistimmen. Zu den übrigen Punkten, die eine nähere Verwandtschaft der beiden Familien ausschliessen, kann ich noch die fundamentale Verschịedenheit in der Form der Pedicellarien hinzufügen, die bei den Saleniidae Echiniden-ähnlich sind.

\title{
Erklärung der Tafeln.
}

\author{
Tafel I. \\ Stereocidaris grandis.
}

Figur 1, 2, 3. Ansicht ron oben, von mnten und von der Seite in natülicher Grüsse. (Ex. b***)

4. 'Theil des Apicalfeldes. $\times \frac{5}{3}$. (Ex. c.)

5. Coronalplatte und Ambulacralfeld an der Peripherie der Schale. $\times \frac{5}{3}$. (Ex. c.)

6. Mit Stacheln bedeckte Partie auf der unteren Schalenhälfte. $X \frac{5}{3} . \quad$ (Ex. b.)

\section{Tafel II.}

\section{Figur 1-11. Stereocidaris grandis.}

Figur 1-3. Ansicht der Schale in natïrlicher Grösse, von oben, von unten und von der Seite. (Ex. a.)

4. Coronalplatte und Ambulacralfeld an der Peripherie deṛ Schale. X 2. (Ex. a.)

5. Zwei Ambulacralplatten. $\times 5 .(\mathbf{E x}$. a.)

6. Primärstacheln in etwas mehr als natïrlicher Grösse. (Ex. a.) a) einer del grössten Stacheln mit der Ansicht des Endkelches; b) kleinerer Stachel; c) Theil del Oberfläche dieses Stachels. vergr.

7. Primärstacheln in etwas mehr als naturlicher Grösse. a) mit abgeplattetem Ende; b) regenerirter Stachel; c) mit stark verbreitertem Ende; d) Theil der Oberfläche dieses Stachels. vergr. e) aus der Nähe des Buccalfeldes. X 2. (Ex. b.)

8. Kleinste Primärstacheln aus der Nähe des Buccalfeldes. $X 2$. a) cylindrische Form; b) abgeplattete Form. (Ex. b.)

9. Sekundärstacheln. $\times 4$. a) des Ambulacralfeldes; b) des Scrobicularringes. (Ex. b.)

10. Primärstacheln in etwas mehr als natirlicher Grösse. (Ex. c.)

". 11. Zwei Ambulacralplatten. $\chi 5$. (Ex. c.)

$$
\text { Figur 12-17. Stercocidaris sceptriferoides. }
$$

Figur 12. Ansicht ron oben in natïrlicher Grösse.

13. Ansiclit von der Seite, ebenso.

n 14. Apicalfeld. $\times \frac{5}{3}$.

.. 15. Coronalplatte und Ambulacralfeld. $>3$.

- 16. Zwei Ambulacralplatten. X9.

" 17. Primärstacheln; a) einer der grössten. $\times 1{ }^{3} ;$ b) einer der kleinen aus der Näle des Buccalfelites. $\times 3$

* A. Agassiz, Report on the [Challenger-] Echinoidea.

** Duxcas und Stadex, On some Points in the Jorplology and Classification of the Saleniidae Ar., in Ann. and Irag. of Nat. Hist. 1887.

*** Bei dieser wie bei den folgenden Tafelerklärungen beilentet Ex. b, Ex. c u. s. w. Exemplar b, c u. s. w. der Tabelle I. 


\section{Tafel III.}

Stereocidaris japonica.

Figur 1. Ansicht von oben in natürlicher Grösse. (Ex. f.)

. 2. Ausicht von unten, ebenso. (Ex. e.)

. 3. Ansicht von oben, ebenso. (Ex. i.)

" 4. Mit Stacheln bedeckte Partie von der Peripherie der Schale. $\times 2 \frac{1}{2}$. (Ex. f.)

. 5. Schale von unten, natürliche Grösse. (Ex. c.)

. 6. Dieselbe von oben.

. 7. Dieselbe von der Seite.

" 8. Dieselbe aufgebrochen, um die Dicke der Platten zu zeigen.

" 9. Zwei Coronalplatten, deren eine blind ist, mit einem Theile des Ambulacralfeldes. $X$ 3. (Ex. c.)

10. Apicalfeld. $\times 2$. (Ex. a.)

. 11. Apicalfeld. $\times 2$. (Ex. g.)

.. 12. Monströses Apicalfeld. $X 2 . \quad($ Ex. e.)

.. 13. Grösster Primärstachel. $\times 2$. Obere und untere Ansicht. (Ex. e.)

. 14. Grösster Primärstachel. $\chi 2$. (Ex, f.) Daneben ein Theil der Oberfläche. vergr.

. 15. Kleinerer Primärstachel. X 2.

. 16. Einer der kleinsten Primärstacheln, gebogen von fast rundem Querschnitt. $X 2$.

. 17. Primärstachel aus der Nähe des Buccalfeldes, flach, mit wenig gesägten Rändern.

, 18. Primärstachel aus der Nähe des Buccalfeldes, flach, mit stark gesägten Rändern und gebogener Spitze. $\times 4$.

. 19. Sekundärstachel von einem Scrobicularringe. $X 6$.

"20. Sekundärstachel vom Ambulacralfelde. $\times 6$.

\section{Tafel IV.}

Figur 1-7. Dorocidaris Reini.

Figur 1. Ansicht von oben in natürlicher Grösse.

"2. Ansicht von der Seite, ebenso.

"3. Apicalfeld. $\times \frac{5}{4}$.

" 4. Coronalplatte mit Ambulacralfeld. $\times 3$.

"5. Zwei Ambulacralplatten. $\times 6$.

" 6. Grösster Primärstachel $X \frac{5}{3}$. Daneben ein Theil der Oberfläche. vergr.

7. Primärstachel ans der Nähe des Buccalfeldes. $\times 2 \frac{1}{2}$.

\section{Figur 8-20. Porocidaris gracilis.}

Figur 8. Ansicht von oben. $\times 2$. (Ex. b.)

, 9. Ansicht von unten. $\times 2$. (Ex. b.)

"10. Ansicht von der Seite in natürlicher Grösse. (Ex. a.)

"11. Schale von oben. $\times 5$. (Ex. a.)

"12. Apicalfeld. $\times 5 .(\mathrm{Ex}, \mathrm{b}$.

- 13. Interambulacral- und Ambuliacralfeld. $\times 4$. (Ex. a.)

. 14. Zwei Ambulacralplatten. X 7 .

. 15. Theil des Buccalfeldes mit den benachbarten Schalenpartieen. $\times 5$. (Ex. a.)

. 16. Einer der grössten Primärstacheln. $X 4$. b) unterster Theil des Schaftes; c) oberer Theil des S'chaftes. vergr.

. 17. Kleinerer Primärstachel. $\times 4$.

18, 19, 20. Kleinste P'rimärstacheln. $\times 6$. 


\section{$-55-$ \\ Tafel V. \\ Goniocidarisbiserialis.}

Figur 1-7. Exemplar von $6.6 \mathrm{~mm}$. Schalendurchnesser. (Ex. f.)

Figur 1. 1. 2. Ansicht von oben und von der Seite. $X 3$.

"3. Apicalfeld und Theil der Schale. $\times 6$.

, 4. Zwei Ambulacralplatten. X 9.

. 5. Grosser ausgebildeter Primärstachel. $\times 5$.

"6. Primärstachel mit glatter Oberfläche zunächst dem Apicalfelde. $X 5$.

" 7. Kleiner Primärstachel ans der Nähe des Buccalfeldes. $X 5$.

Figur 8. Apicalfeld eines Exemplares von 3 mm. Schalendurchmesser. Vergl. Holzschmitt pag. 12.

Figur 9-14. Grosse Exemplare von 30-34 mm. Schalendurchmesser.

Figur 9. Ansicht von oben in natürlicher Grösse. (Ex. c.) Die Stacheln sind reich mit Bryozoęn, Spongien u. dgl. bedeckt.

, 10. Apicalfeld. $\times 2$. (Ex. b.)

" 11. Schale von der Seite, natürliche Grösse. (Ex. b.)

. 12. Mit Stacheln bedeckte Partie der Schale. X 2. (Ex. c.)

, 13. Coronalplatte und Ambulacralfeld. $X$ 2. (Ex. b.)

. 14. Zwei Ambulacralplatten. X 0. (Ex. b.)

Figur 15-18. Exemplare mittlerer Grösse von 20-21 mm. Schalendurchmesser.

Figur 15. Aufgebrochene Schale, um die Dicke der Platten zu zeigen. $\times 2 \frac{1}{2}$. (Ex. d.)

, 16. Apicalfeld. $\times 3 . \quad($ Ex. d. $)$

" 17. Coronalplatte und Ambulacralfeld. $\times 3 . \quad$ (Ex. d.)

" 18. Zwei Ambulacralplatten. X 6. (Ex. d.)

Figur 19-27. Primärstacheln der grösseren Exemplare. $X 2$.

Figur 19. Ans der Nähe des Apicalfeldes. (Ex. b.)

. 20. Bruchstück mit sehr starken Dornen; isolirt gefunden.

21. a) Oberseite, b) Unterseite. (Ex. c.)

"22-25. Von der oberen Schalenhälfte.

, 26, 27. Aus der Nähe des Buccalfeldes.

\section{Tafel VI. \\ Goniocidaris clypeata.}

Figur $1-3$. Ansicht von oben, von unten und von der Seite. $\times 2$.

$"$ 4. Apicalseite nach Wegnahme eines der schildförmigen Stacheln. $X 3$.

, 5. Apicalfeld. $\times 2$.

, 6. Coronalplatten und Ambulacralfeld. $\times 4$.

7. Zwei Ambulacralplatten. $\times 9$.

๑ 8, 9. Kleinste Primärstacheln aus der Nähe des Buccalfelds. $\times 4$.

$"$ 10-17. Verschiedene Formen von Primärstacheln. $\times 2 \frac{1}{2}$. Die stabförmigen ohne Endscheibe sind ron der unteren Schalenhälfte; je grösser die Endscheibe im Verhältniss zur Länge des Schafts ist, um so näher stehen sie dem Apicalfelde.

ᄁ 18-19. Schildförmiger Primärstachel ans der Nähe des Apicalfeldes von der Seite und von unten. $X 4$.

\section{Tafel VII.}

\section{Goniocidaris mikado.}

Figur 1-3. Ansicht von oben, von unten und von der Seite, in natürlicher Grösse.

4. Theil des Apicalfeldes nebst einem Primärstachel mit stark ausgebildeter Endkrone und Basalkragen. $\times 4$.

"5. Mit Stacheln bedeckte Partie der Schale. $\times 4$.

"6. Theilweise von Stacheln gereinigte Partie der Schale. $X t$. 


\section{Tafel VIII.}

Figur 1. Stereocidaris japoniea.
a) 7 wei Ambulacralplatten. $X 6$.
b) Dickküpfige Form von P'edicellarien. $\times 20$.
c) Kleine schlanke Form. $\times 20$.
d) Einzelne Klappe der dickköpfigen Form. $\times 50$.
e, f) Einzelne Klapyen (ler schlanken Form. $\times 50$.
g) Stiel der dickküpfigen Form. X
h) Kalkkörper der Ambulacralfüsschen. $X$ õo.

Figur 2. Stereocidaris grandis.
a) Dickküpfige Form der Pedicellarien. $\times 20$.
b) Schlanke Form. $\times 20$.
c) Grosse lüftelartige Form. $\times 20$.
(1, e) Einzelne Klappen der dickköpfigen Form. X 50.
f, g') Einzelne Išlappen der schlanken Form. X 50.
1i) Einzelne IKlappe der grossen korbartigen form. $X 50$.
i) Einzelne Klappe der grossen löfelartigen Form. $\times 50$.
k) Kngliger Stiel rer dickhöpfigen Form. 50.
l) Schuppenförmiger Miliarstachel von der Apicalseite. $\times 20$.
m) Kalkkürper der Ambulacralfüsschen. $\times 50$.

Figur 3. Stereocidaris sceptriferoides.
a) Dickküpige Form der Pedicellarien.
b) Schlanke Form. $\times 20$.
c) Klappe der dickköptigen Form. $\times 50$.
d, e) Ǩlappen der schlanken F'orm. 50.

Figur 4. Dorocillaris Reini.
a) Dickküpfige Form der Pedicellarien.
b) Schlanke Form. \20.
c) Klappe der dickküpfigen Form. $X 50$.
(d) Klappe der schlanken Form. $\times 50$.

Figur 5. Porocidaris gracilis.
a) Pedicellarie. $\times 20$.
b, c) Einzelne Klapuen derselben. $\times 80$.
d) Sckundïrstachel. $\times 20$.
e) Talkkiorner der Ambulacralfiisschen. $\times 80$.

Figur 6. Goniocidaris miliado.
a) Einzige Form der Pedicellarien. $\times 20$.
b, c, d) Einzelne Klappen. $\times 80$.
e) Miliarstacheln. $\times 20$.
1') Kalkkörper der Ambulacralfüsschen. $\times 80$.

Figur 7. Goniocidaris clypeata.

a) Dickköpfige Form der Pedicellarien. $\times 20$.

b) Schllanke Form. $\times 20$.

(" Klappe der dickküptigen Form. \ 80 .

(d, e) Klappen der schlanken Form. $\times 80$.

f) Kalkkürper der Ambulacralfüsschen. $X 80$.

Figur 8. Goniocidaris biserialis.
a) Dickküpfige Form der Pedicellarien. $\times 20$.
b, c), schlanke form. $\times 20$.
d) Inlappe der dickköpfigen Form. $\times 50$.
e, f) Klappen der schlanken f'orm. $X 50$.
g) Miliarstachel. > 20.
h) Kalkkürper der Ambulacralfüisschen. $X 50$. 
Figur 9-18. Goniocidaris miliado.

Figur 9. Apicalfeld. $\times 2$.

- 10. Zwei Ambulacralplatten. X 7 .

" 11. Primärstachel aus der Nähe des Apicalfeldes nebst Ansicht der Endkrone von oben. $X 2 \frac{1}{2}$.

, 12. Primärstachel. $\times 2 \frac{1}{2}$. Daneben einzelne gelappte Seitendornen. vergr.

- 13, 14. Grosse Primärstacleeln. X $2 \frac{1}{2}$.

"15. Regenerirter Primärstachel mit nicht filziger Oberfläche. $\times 2 \frac{1}{2}$.

" 16-18. Kleine Primärstacheln aus der Nähe des Bnccalfeldes. $\times 2 \frac{1}{2}$.

\section{Tafel IX.}

Figmr 1. Eucidaris metularia.

a) Dickköpfige Form der Pedicellarien mit langem Dornenkranz am Schafte. $\times 20$.

b, c) Schlanke Form. $\times 20$.

d) Löffelartige Form. $\times 20$.

e) Einzelne Klappe der dickköpfigen Form. X 50 .

f) Klappe der schlanken Form. $\times 50$.

g) Klappe der löfelartigen Form. $X 50$.

Figur 2. Eucidaris tribuloides.
a) Dickköpfige Form der Pedicellarien.
b) Schlanke Form. $\times 20$.
c) Löffelartige Form. $\times 20$.
d) Klappe der dickköpfigen Form. $X 50$.
e) Klappe der schlanken Form. $\times 50$.

Figur 3. Eucidaris galapagensis.
a) Dickköpfige Form der Pedicellarien. $\times 20$.
b) Schlanke Form. $\times 20$.
c) Klappe der dickküpfigen Form. $\times 50$.
d) Klappe der schlanken Form. $\times 50$.

Figur 4. Encidaris thouarsii.
a, c) Löffelartige Formen der Pedicellarien. $\times 20$.
b) Dickköpfige Form mit schwachem Domenkranz am Schafte. $X 20$.
d) Schlanke Form. $\times 20$.
e) Klappe der dickköpfigen Form. $\times 50$.
f) Klappe der schlanken Form. $X 50$.
g) Zwei Ambulacralplatten eines Exemplars von 13 mm. Durchmesser. $\times$ 7. (Ex. h.)
h) Zwei Ambulacralplatten eines Exemplars von $45 \mathrm{~mm}$. Durchmesser. $X$ 7. (Ex. b.)

Figur 5. Dorocidaris papillata.
a) Dickköpfige Form der Pedicellarien.
b) Löffelartige Form. $\times 20$.
c) Schlanke Form. $\times 20$.
(d) Zwei Ambulacralplatten eines Exemplars von $25 \mathrm{~mm}$. Durchmesser. $\times 7$. (Ex. c.)
e) Ebenso von 24 mun. Durchmesser. $\times 7$. (Ex. d.)
f) Ebenso von $49 \mathrm{~mm}$. Durchmesser. $\times 7$. (Ex. a.)

Figur 6. Dorocidaris canaliculata.
a, b) Dickhöpfige Form der Pedicellarien. $\times 20$.
c, d) Schlanke Form. $\cdot>20$.
e) Löffelartige Form. $\times 20$.
f, h, i, l) Klappen der schlinken Form. X 50.
g) Klappe der dickköpfigen Form. $\times 50$.
$\mathrm{k}, \mathrm{m})$ Klappen der löfelartigen Form. $\times 50$.
n) Zwei Ambulacralplatten eines Exemplares vou $13 \mathrm{~mm}$. Durchmesser. \ 9. (Ex. f.)
o) Zwei Ambulacralplatten eines Exemplares von $29 \mathrm{~mm}$. Durchmesser. $\times$ 7. (Lx. a.)
p) Zusammengehörige Stiicke der Schale eines Exemplares von etwa 2 mm. Durchmesser. A. Am- bulacralplatten; J. Interambulacralplatten; $J^{\prime}$. Unpaare Interambulacralplatte, die wahrschein- lich auf das Buccalfeld ïbergeht; B. durchbohrte Buccalplatten. X 20. (Ex.g.)




\section{- 5க}

Figu 7. Leiocidaris imperialis.

a) Schlanke form von Pedicellarien. $\times 20$.

b) Dickköpfige Form. $\times 20$.

c) Löffelartige Form. $\times 20$.

(l) Klappe der dickköpfigen Form. $\times 50$.

e) Klappe der schlanken Form. X 50.

f) Zwei Ambulacralplatten eines Exemplares von 55 mm. Durchmesser. \ 7. (Ex. b.)

Figur 8. Leiocidaris verticillata.

a) Obere Ansicht eines Exemplars von 4 mm. Durchmesser (Ex. b) mit geleinigtem Apicalfeld.

×. (Auf einer der Genitalplatten findet sich eine grosse löffelartige Form ron Pedicellarien.)

b) Eine Coronalplatte und Theil des Ambulacralfeldes von demselben Exemplar. (Ex. b.) Diese Figur sollte eine umgekelurte stelling haben.

() Dickköpfige Form von Pedicellarien mit langem Dornenkianz am Schafte. $\times 20$.

(i) Schlanke Form. $\times 20$.

e) Lüffelartige Form. $\times 20$.

f) Klappe der dickköpfigen Form. $\times 50$.

g) Klappe einer korbartigen Form. X 50.

1. Klappe der schlanken Form. $\times 50$.

i) Zwei Ambulacralplatten eines Exemplars von 18.5 mm. Duxchmesser $\times 9$ (Ex. a), deren Poren nicht gejocht sind.

Figur 9. Goniocidaris tubariu.

a) Dickköpfige Form der Pedicellarien. $\times 20$.

h Klappe derselben. $\times 50$.

(*) Schlanke Form. $\times 20$.

(1) Klapne derselben. $\times 50$.

«) Zwei Ambulacralplatten eines Exemplars von 22 mm. Durchnesser. X 7. (Ex. b.)

Figur 10. a-g) Leiocidaris baculosa; h und i) L. annulifera.

a) Dickköpfige Form von Pedicellarien mit langem Domenkranz am Schafte. \ 20.

b) Schlanke Form. $\times 20$.

c) Löffelartige Form. $\times 20$.

d) Klappe der schlanken Form. $\times 50$.

e) Klappe der dickköpfigen Form. $\times 50$.

f) Klappe der löfelartigen Form. $\times 50$.

g) Zwei Ambulacralplatten eines Exemplars von 55 mm. Durchmesser. $\searrow$ 5. (Ex. b.)

h) Zwei Ambulacralplatten eines L. anmulifera von $12 \mathrm{~mm}$. Durchmesser. \ 12.

i) Ansicht eines Theils der Schale desselben Exemplars von $L$, amulifera. , 6 .

\section{Tafel X.}

Figur 1-14. Eucidaris galapagensis.

Figur 1, 2. Ansicht ron oben und von unten, in natïrlicher Grösse. (Ex. b.)

3. Ausicht von der Seite. $\times 1 \frac{1}{3}$. (Ex. e.)

.. 4. Apicalfeld. $\times 2$. (Ex. a.)

"5. Partie der Schale. $\times 2 \frac{1}{2}$. (Ex. a.)

.. (i. Zwei Ambulacralplatten. $\times$ 7. (Ex. a.)

. 7. Primärstachel. $\times 2 \frac{1}{3}$. (Ex. e.)

." 8. 9, 10. Monströse Primärstacheln ron der Unterseite der Schale. $\times 3 . \quad$ (Ex. b.)

"11. Ansicht des kleinsten Exemplars ron oben. \3. (Ex. f.)

" 12. Apicalfeld desselben Exemplars. $\times 7$.

"13. Partie der Schale desselben Exemplars. $\times 7$.

"14. Zwei Ambulacralplatten desselben Exemplars. $\times 10$.

Figm 15-20. Ambulacralfelder triassischer Echinich. (s. Seite 36.)

Figur 15. Obere Ansicht des Ambulacralfeldes ron Cidaris sp. I ron St. Cassian. $X 6$.

"16. Dasselbe von der Seite.

"17. Ein 'Tleil desselben ron unten. 
Figur 18. Obere Ansicht des Ambulacralfeldes von Cidaris sp. III von St. Cassian. $\times 6$.

" 19. Obere Ansicht des Ambulacralfeldes von Cidaris sp. II von St. Cassian. $X 6$.

"20. Obere Ansicht der einen Hälfte eines Ambulacralfeldes von Cidaris sp. IV von St. Cassian. 6.

"21. Obere Ansicht des Ambulacralfeldes der recenten Eucidaris thouarsii. $\times 6$.

"22. Dasselbe von der Seite.

\section{Tafel XI.}

Figur 1. Untere Ansicht einer Coronalplatte von Cidaris liagora aus der Trias von St. Cassian.

"2. Dieselbe von der Seite.

"3. Untere Ansicht einer Coronalplatte von Cidaris subsimitis ans der Trias von St. Cassian.

" 4. Untere Ansicht einer Coronalplatte von Rhabdocidaris anglosuevica Opp. (syn. horrida Mst.) aus dem Dogger von Ehningen.

5. Dieselbe von der Seite.

"6. Untere Ansicht einer Coronalplatte von der recenten Eucidaris thouarsii.

7. Dieselbe von der Seite.

n 8. Interambulacralfeld eines Exemplars von Eocidaris keyserlingii GEIN. aus dem Zechstein von Pöseneck in Thüringen. $\times 6$.

Figur 9-28. Salenia pacifica.

Figur 9, 10, 11. Ansicht von oben, von unten und von der Seite $\times 5$; auf der Unterseite sind 3 Exemplare von Stylifer angeheftet.

"12. Subanale Platte und ein Theil des Afterfeldes mit Stacheln. $\times 10$.

. 13. Theil des Buccalfeldes; die anstossende Schalenpartie zeigt ausser einigen Stacheln und Ambulacralfüsschen ein Sphäridium und die gelappten Kiemen. $\times 12$.

14. Theil eines der grössten Primärstacheln. $\times 8$.

15-17. Kleinere Primärstacheln. $\times 8$.

" 18. Einer der kleinsten Primärstacheln. $\times 10$.

" 19-22. Verschiedene Secundärstacheln. $\times 10$.

"23. Rosette und Kalkkörper" der Ambulacralfüsschen. $\times 150$.

"24. Sphäridium. $\times 40$.

25. Pedicellarie. $X 40$.

" 26-28. Einzelne Klappen der Pedicellarien von verschiedenen Seiten. $\times 150$ 



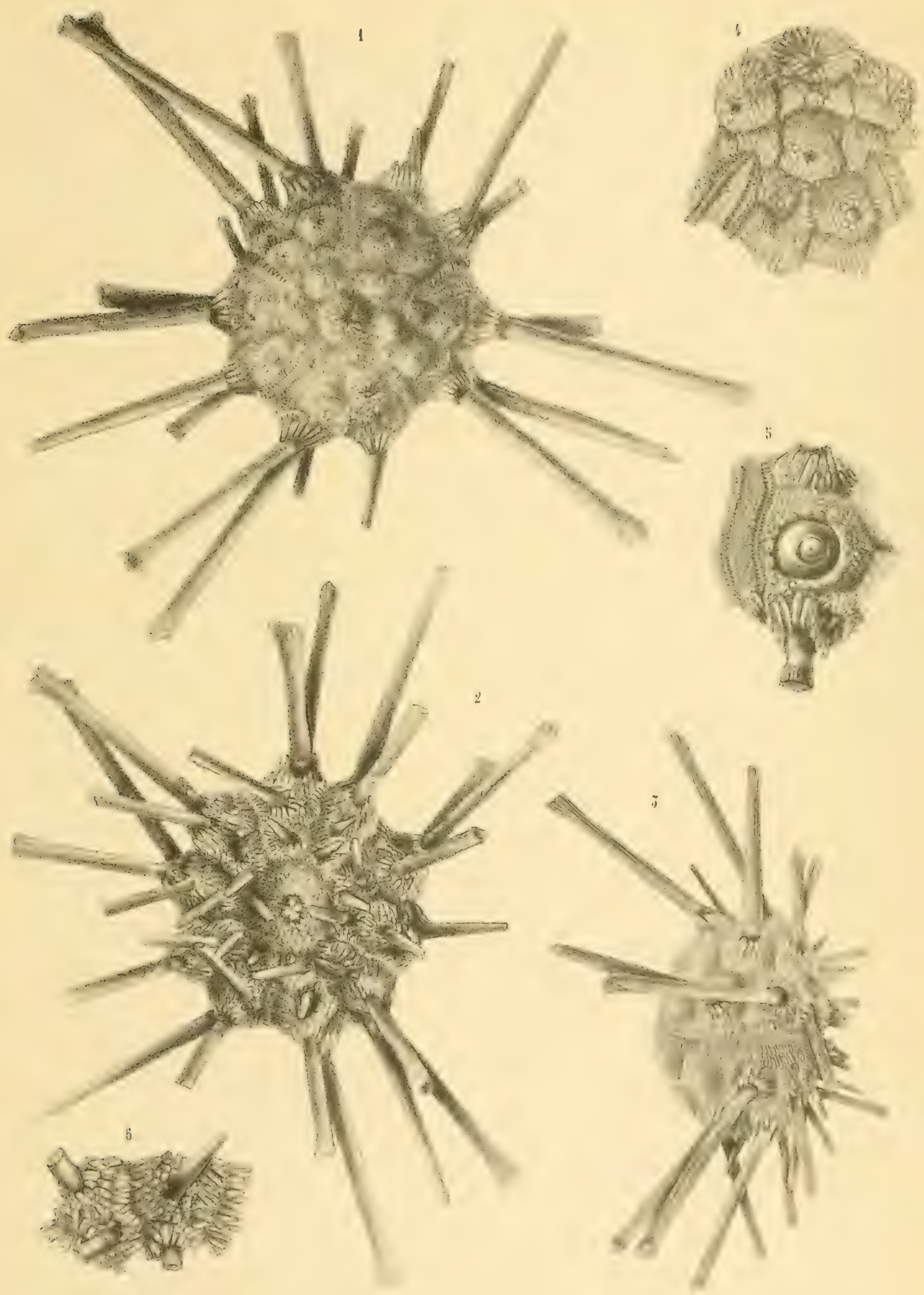





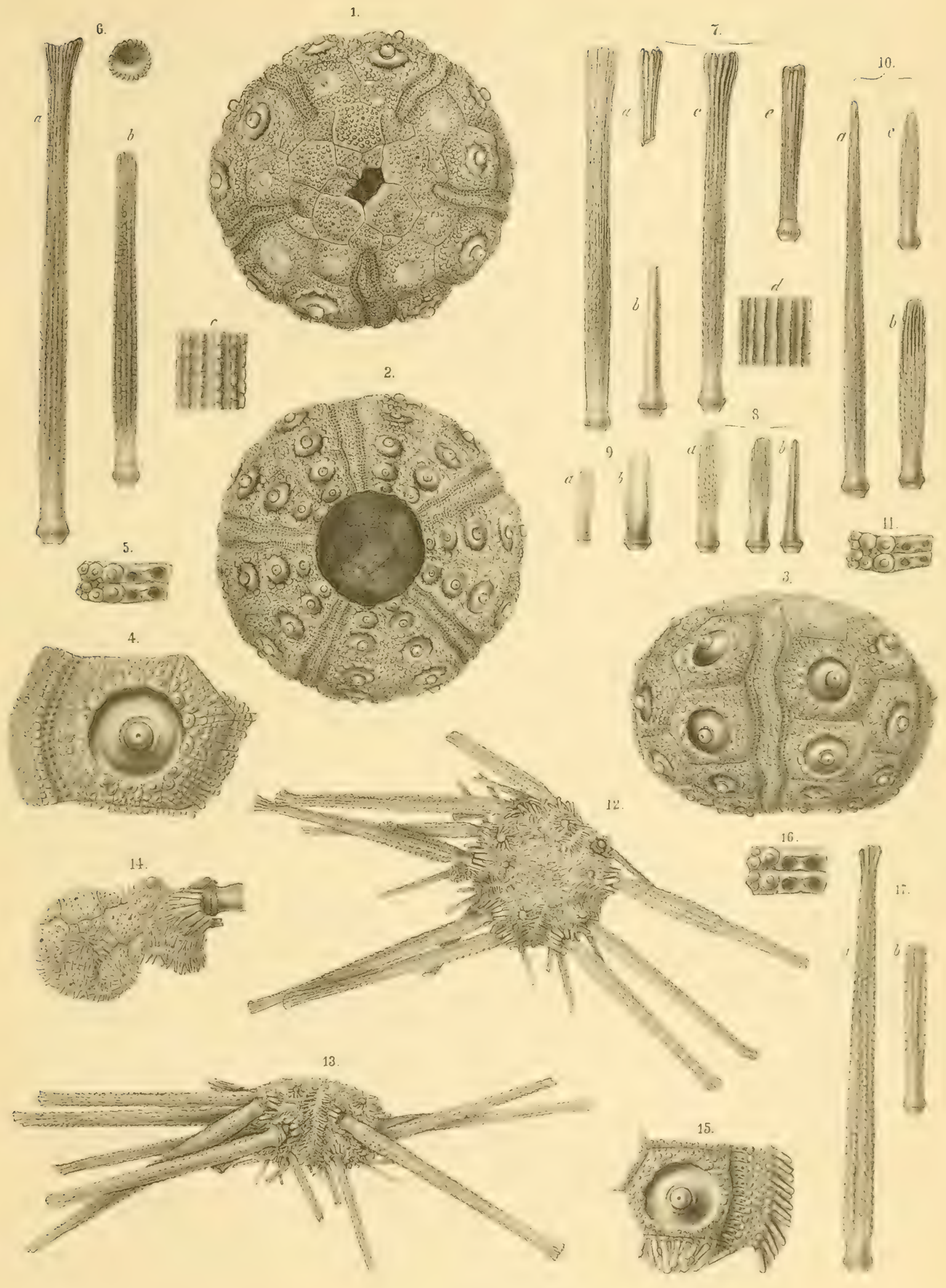



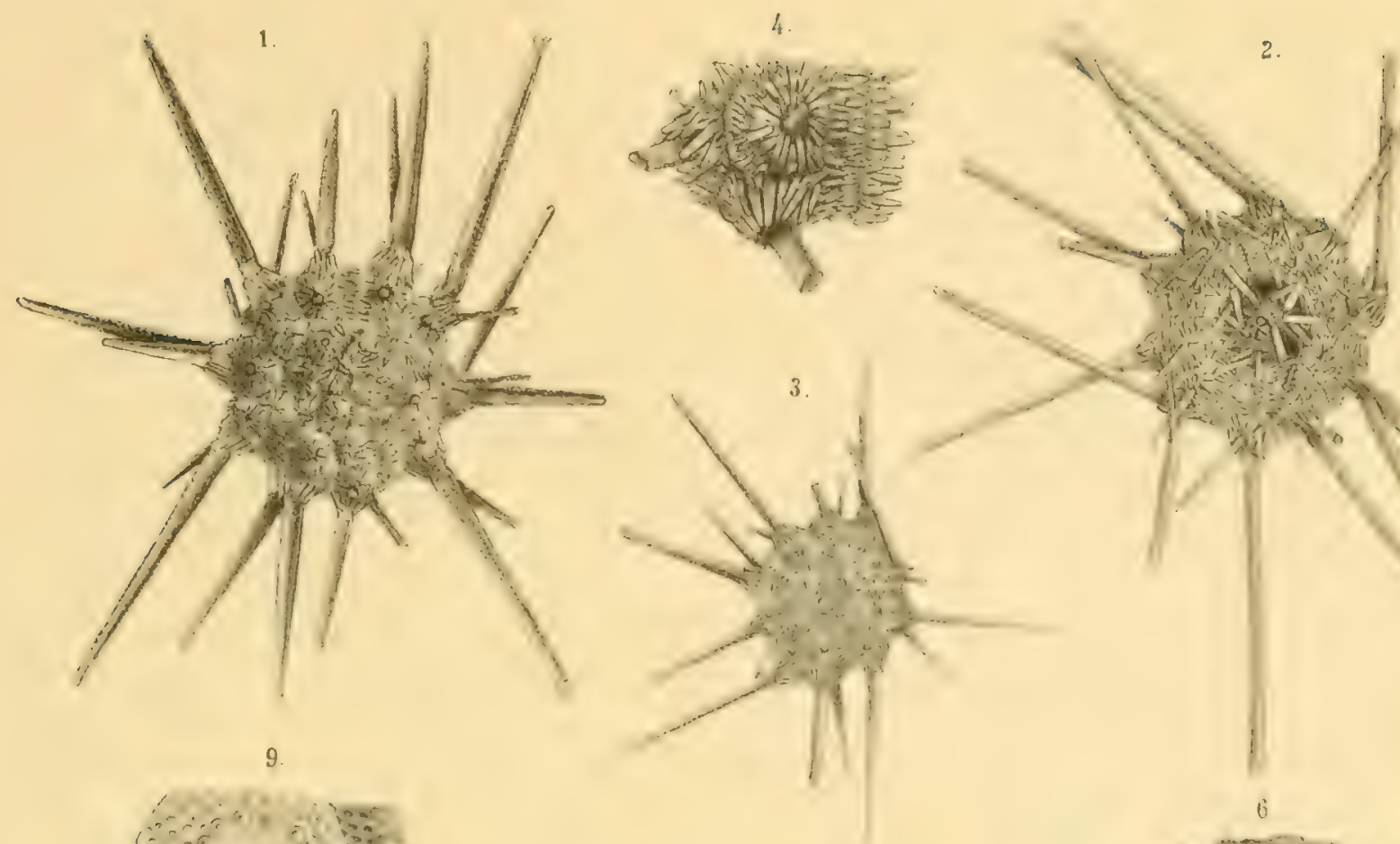

9
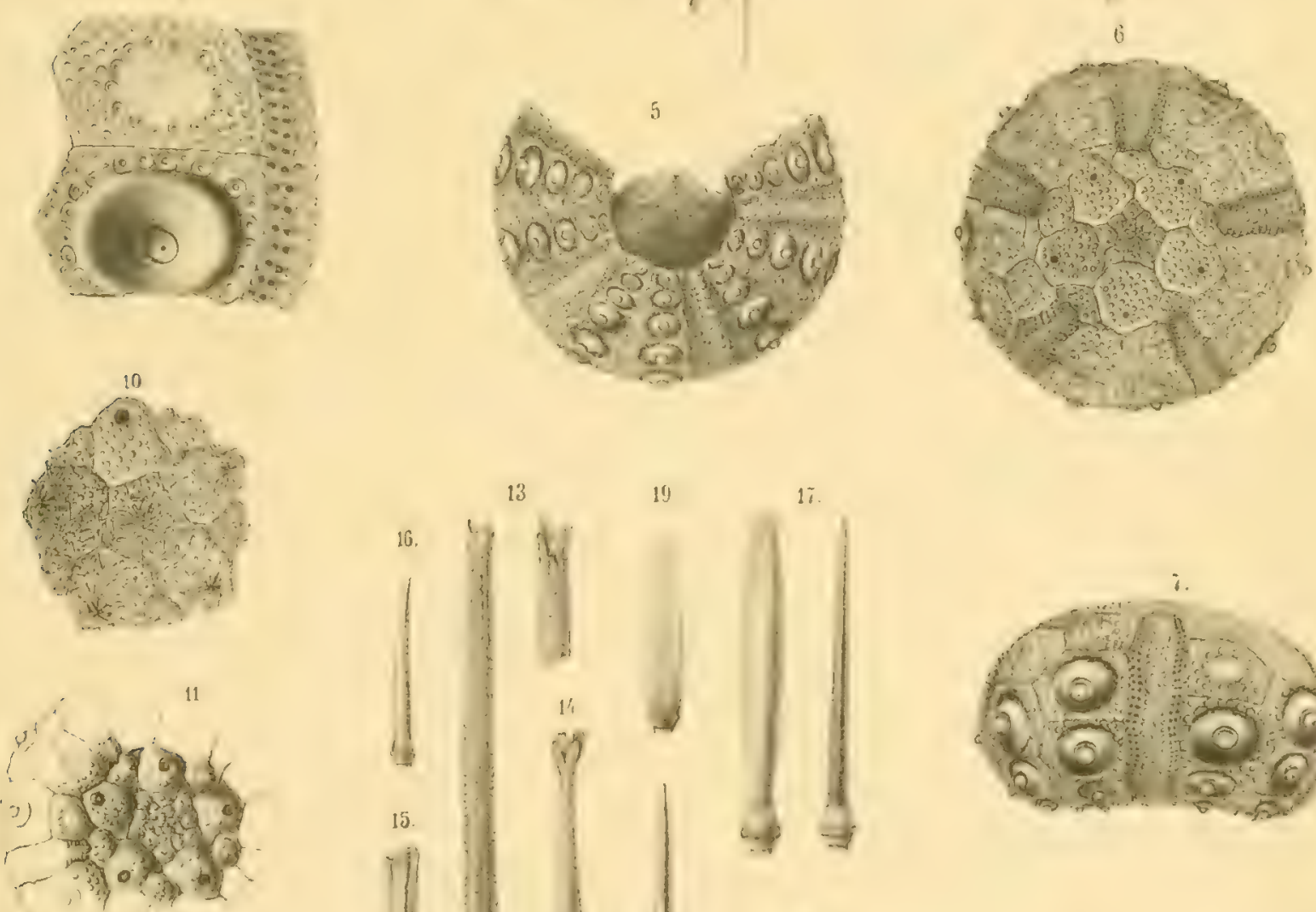

12.
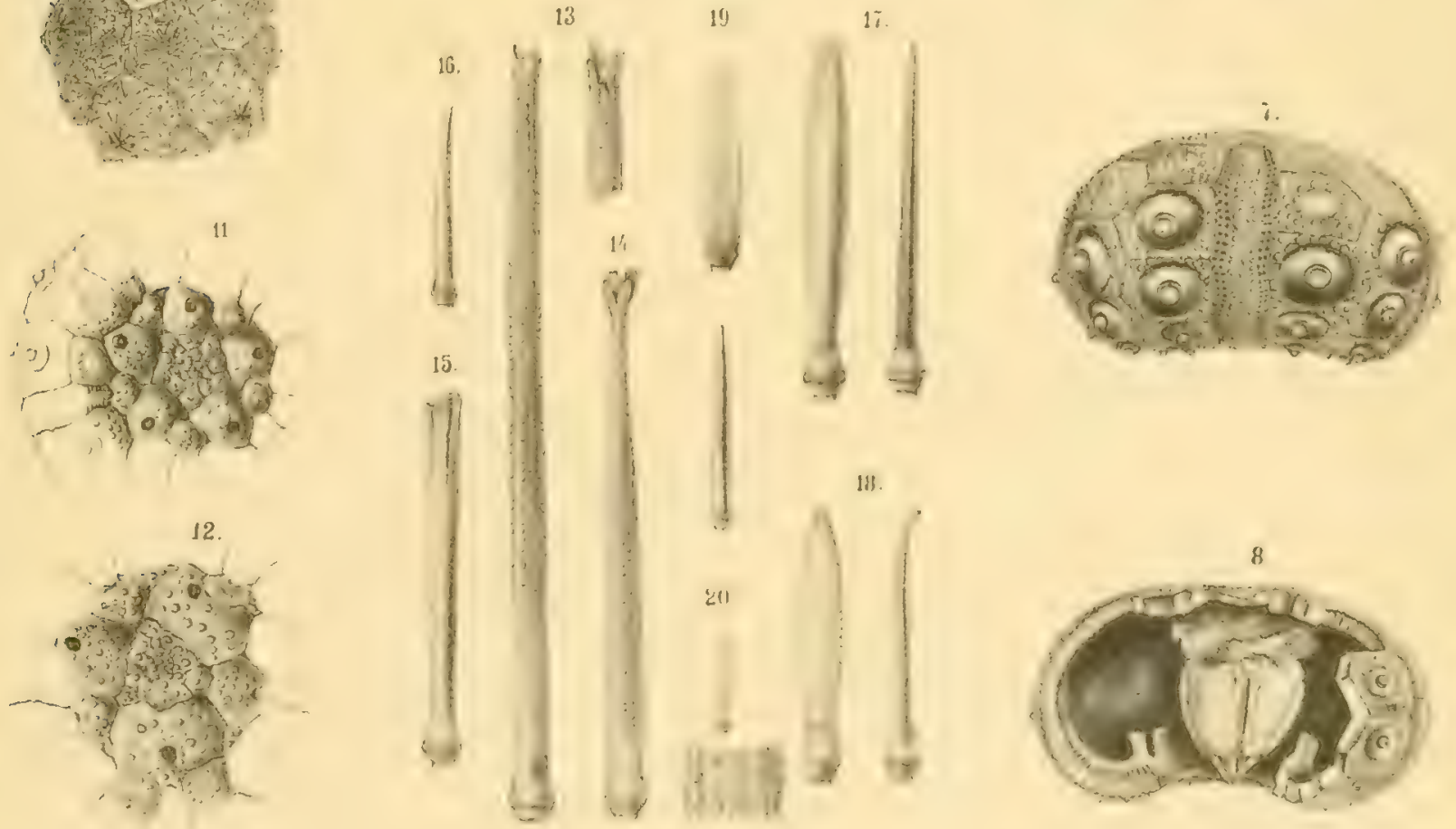



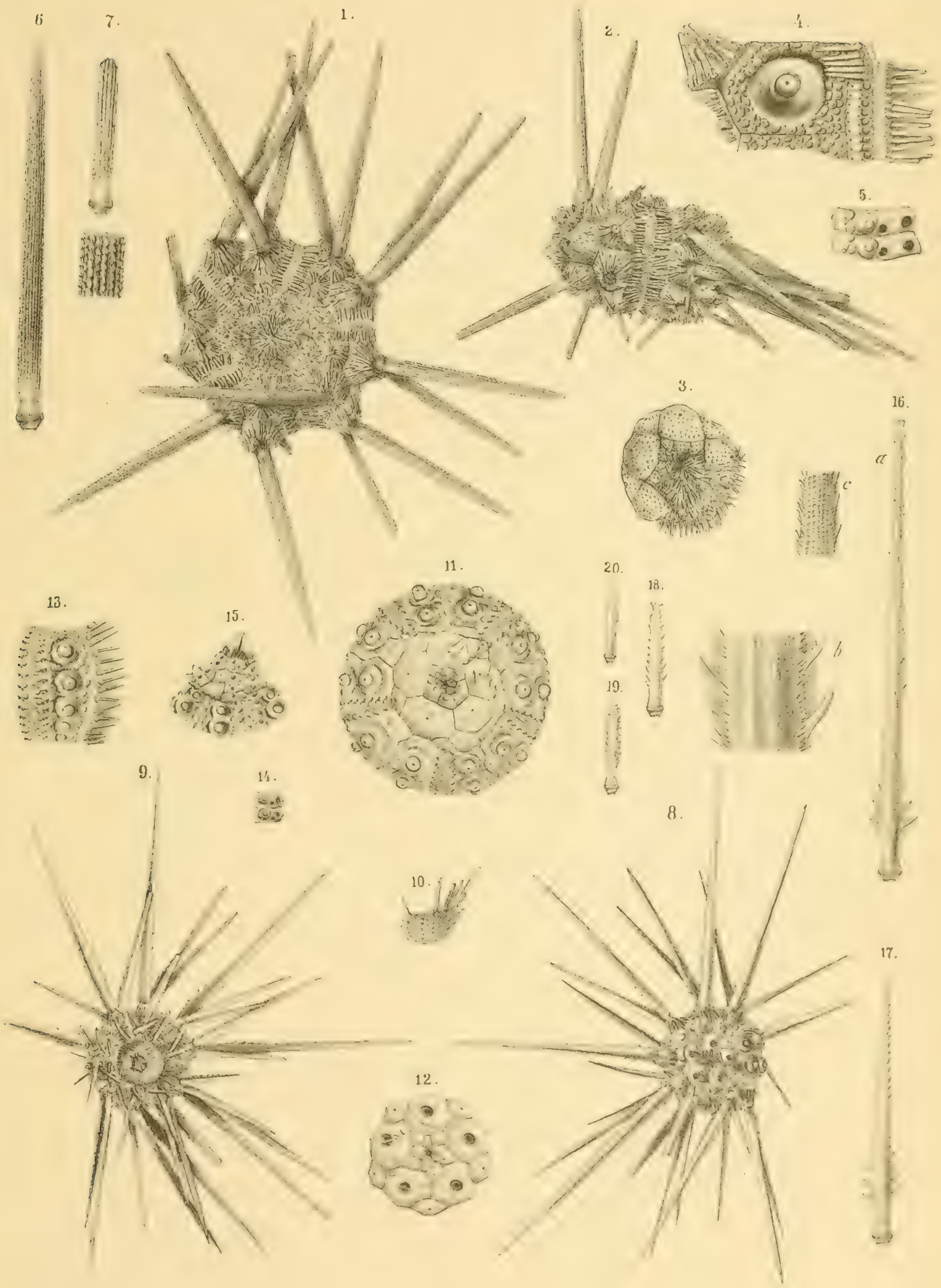



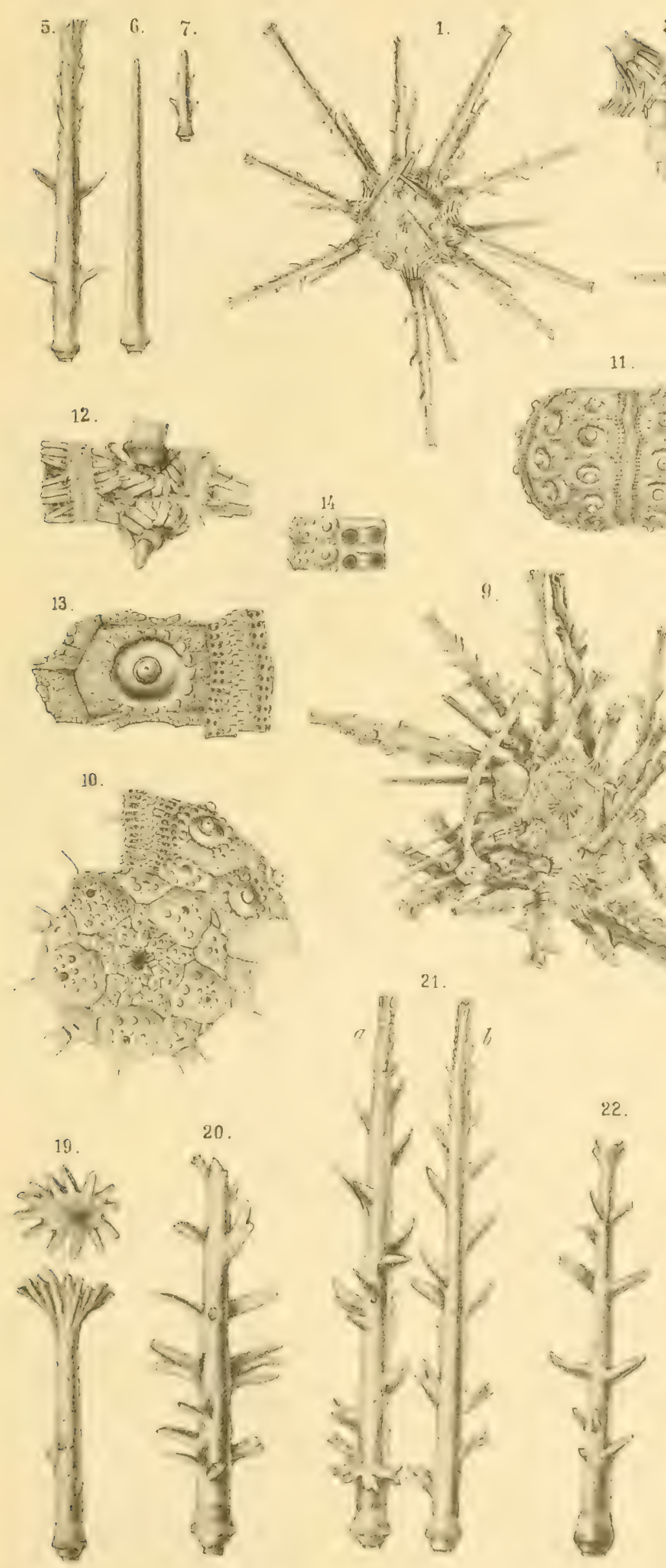

Gez. von Döderlein und Scharfenberger.
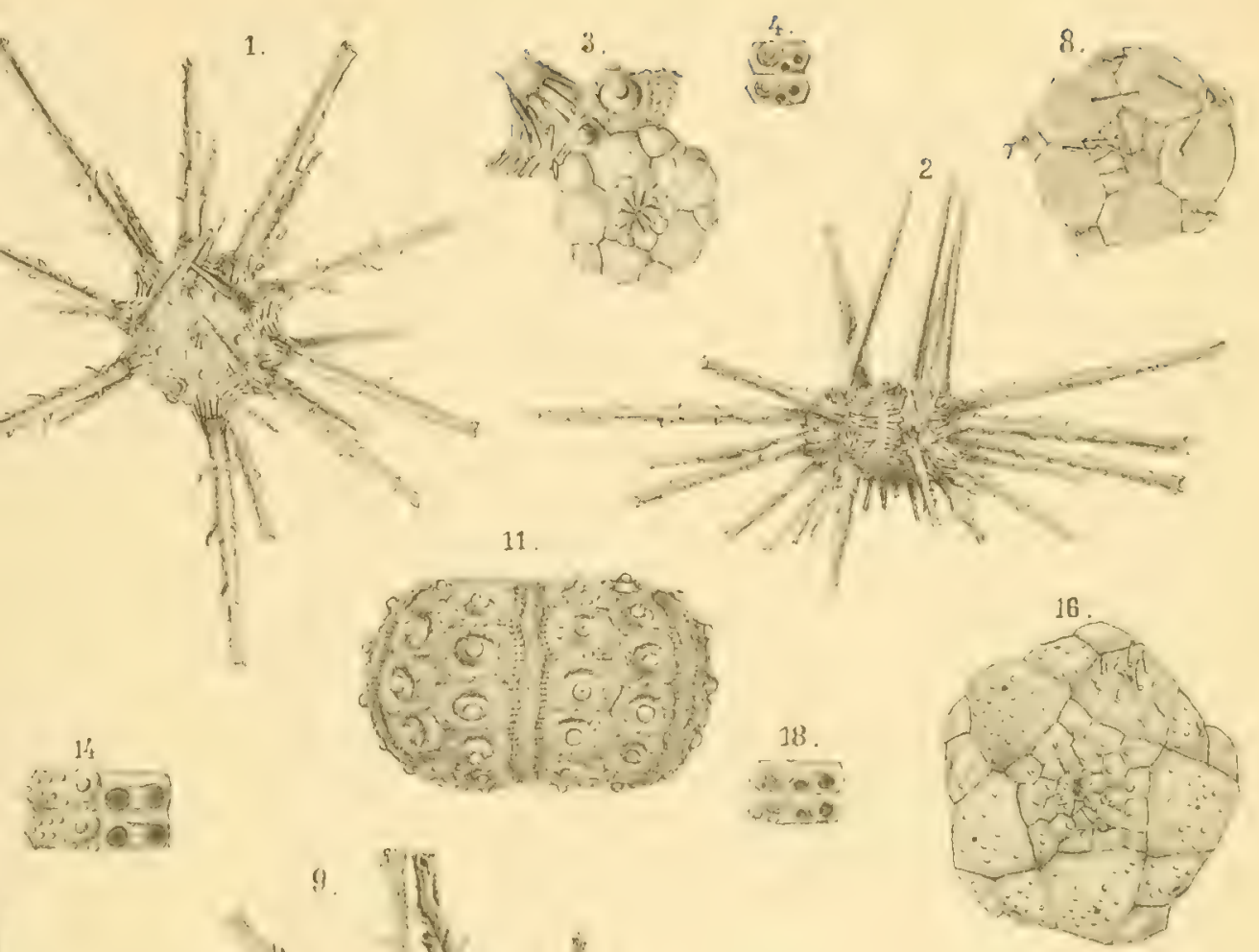

17

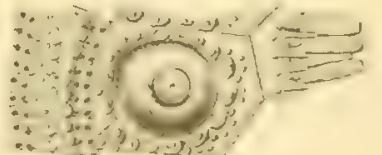

15 .
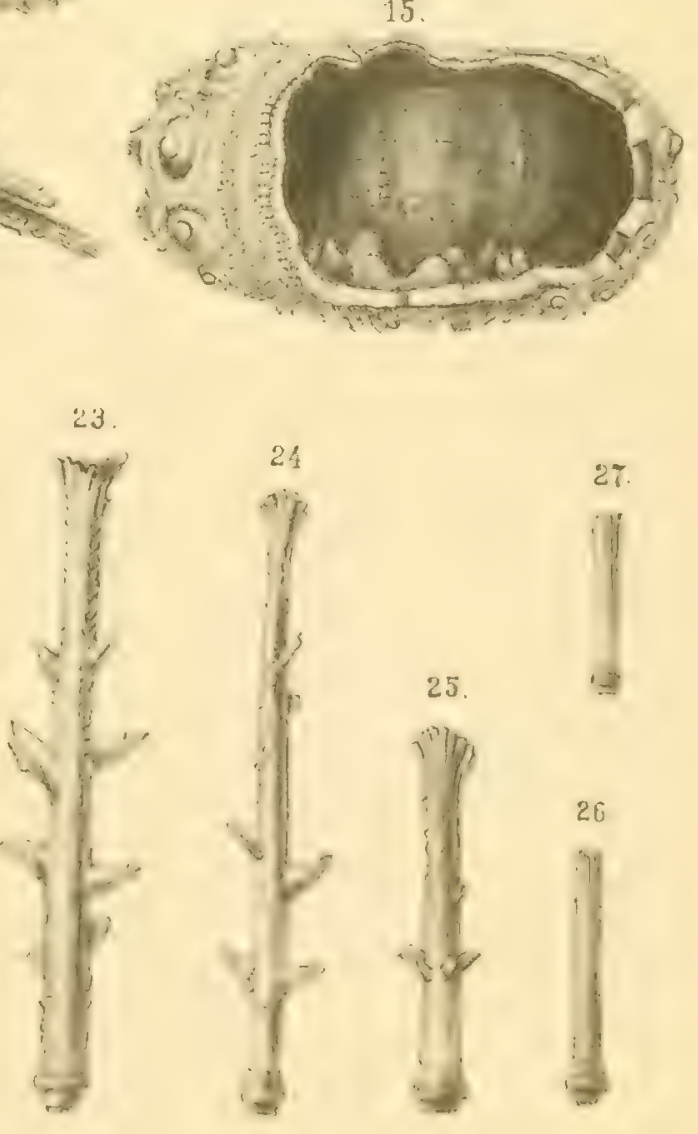

27.
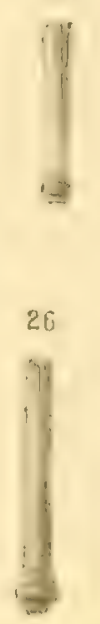



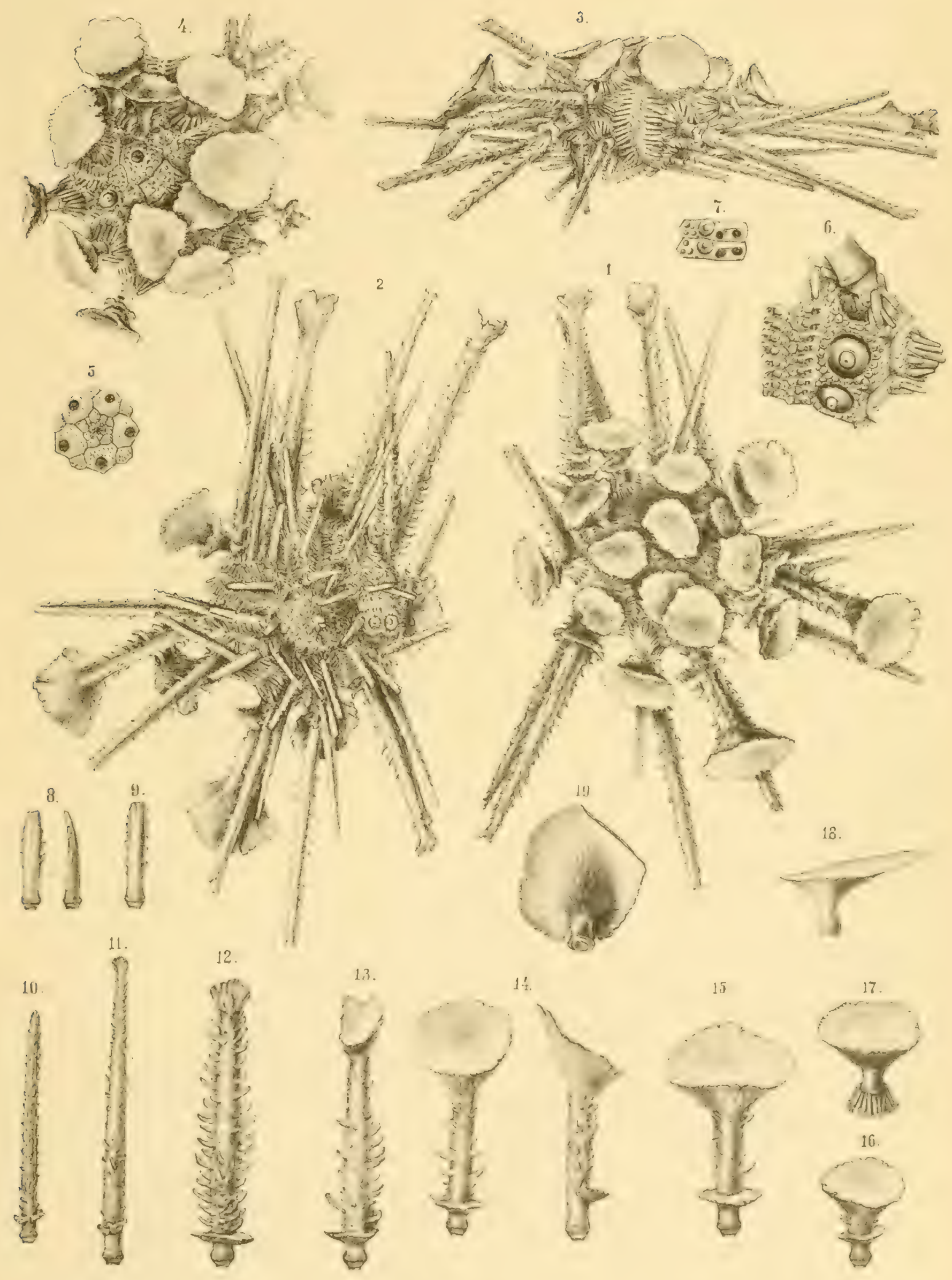




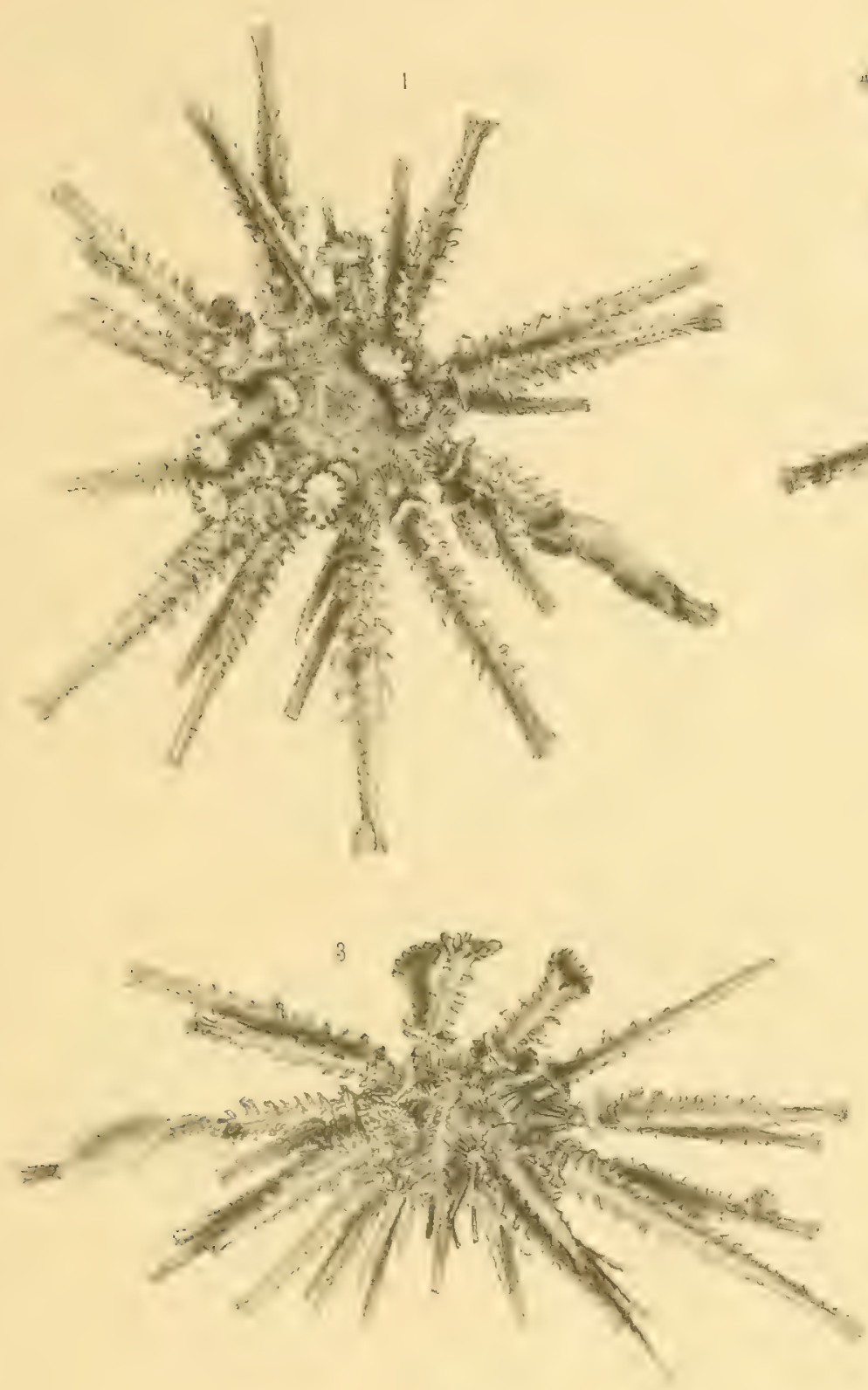
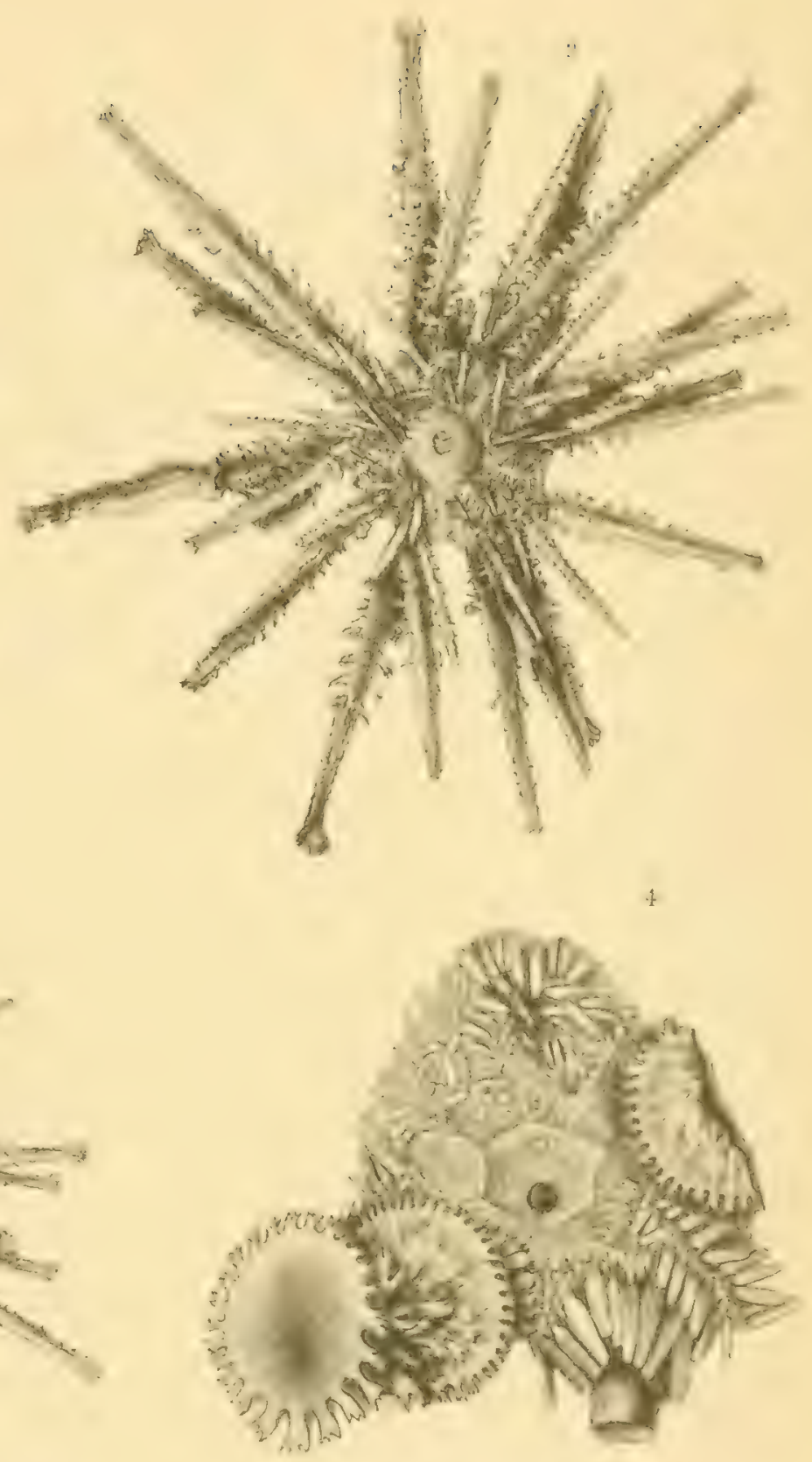

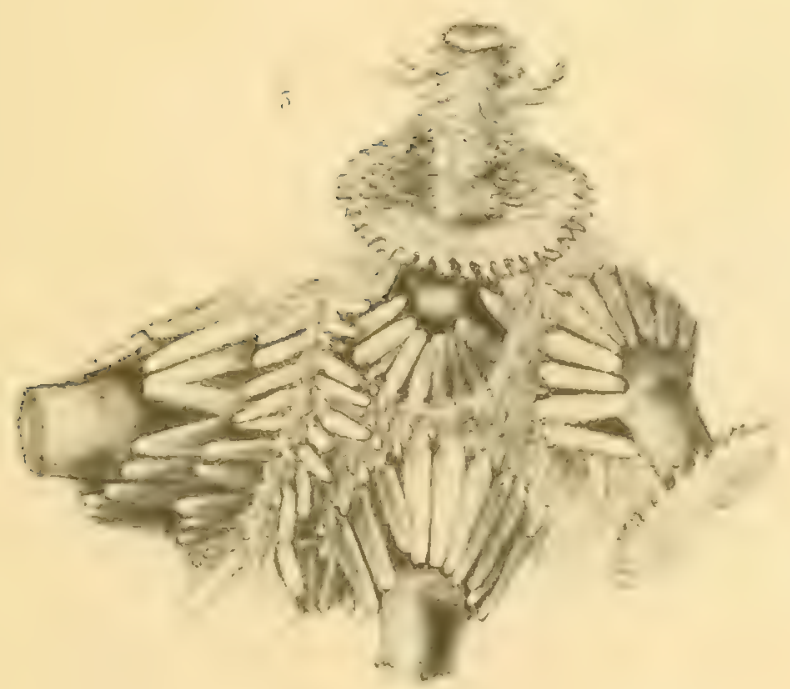

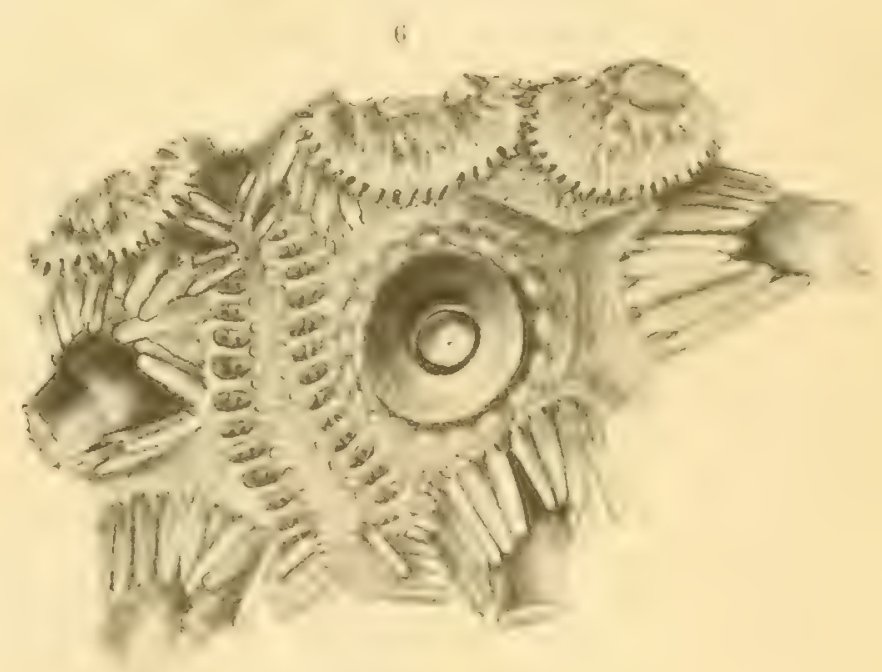

Goniocidaris mikado. 


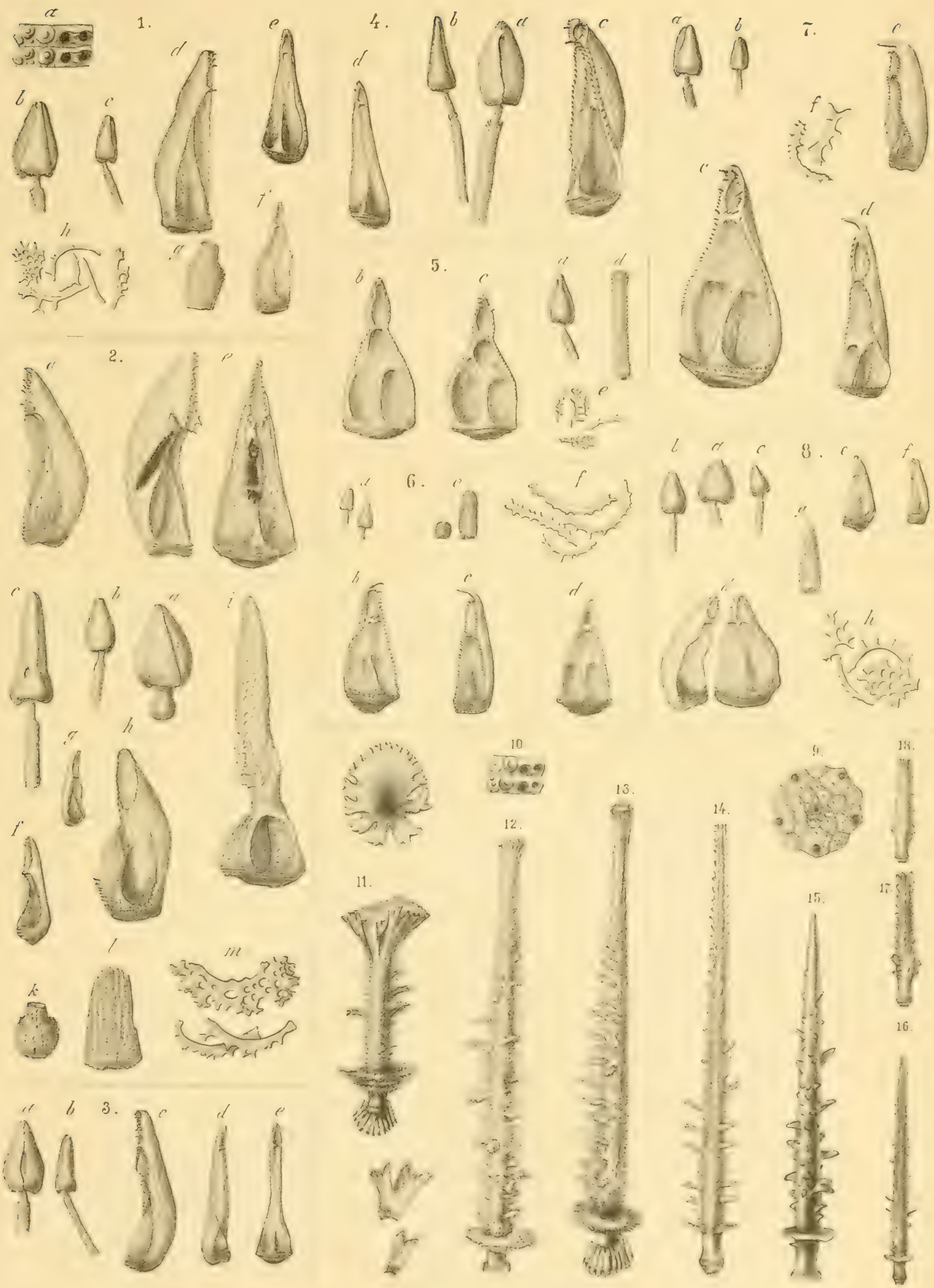

Gez, vou Doderlein und Scharfezberger.

Fig. 1. Stereocidaris japonica. Fig. 2. St. grandis. Fig. 3. St. sceptriferoides. Fig. 4. Dorocidaris Reini.

Fig, 5. Porocidaris gracilis. Fig, 6. 9-18. Goniocidaris mikado. Fig. 7. G. clypeata. Fig. 8. G. biserialis. 

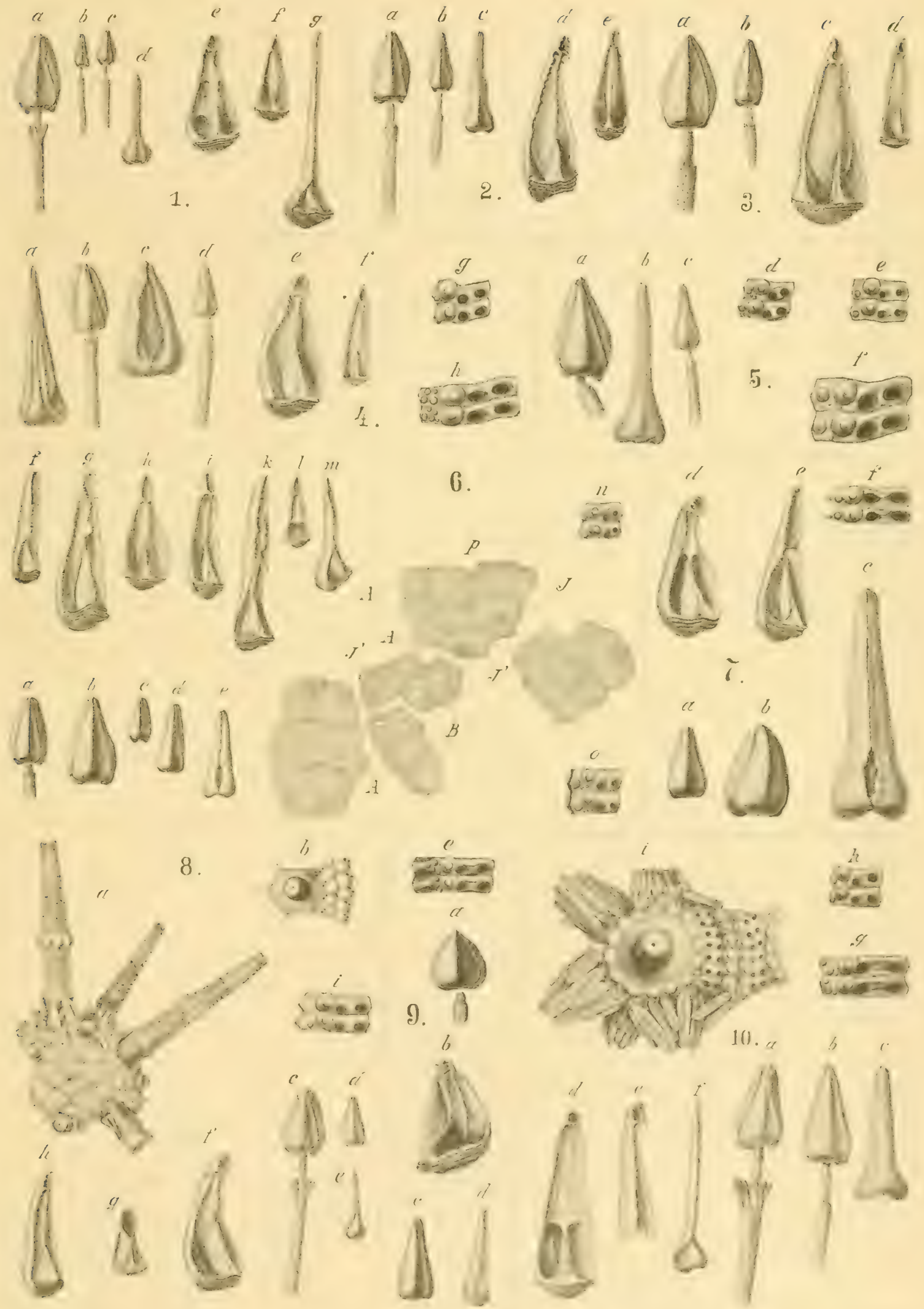

Fig. 1. Eucidaris metularia. 2. E. tribuloides. 3. E. galapagensis. 4. E. thouarsii. 5. Dorocidaris papillata. 6. D. canaliculata. 7. Leiocidaris imperialis. 8. L. verticillata. 9. Goniocidaris tubaria. 10. G. baculosa u. annulifera. 



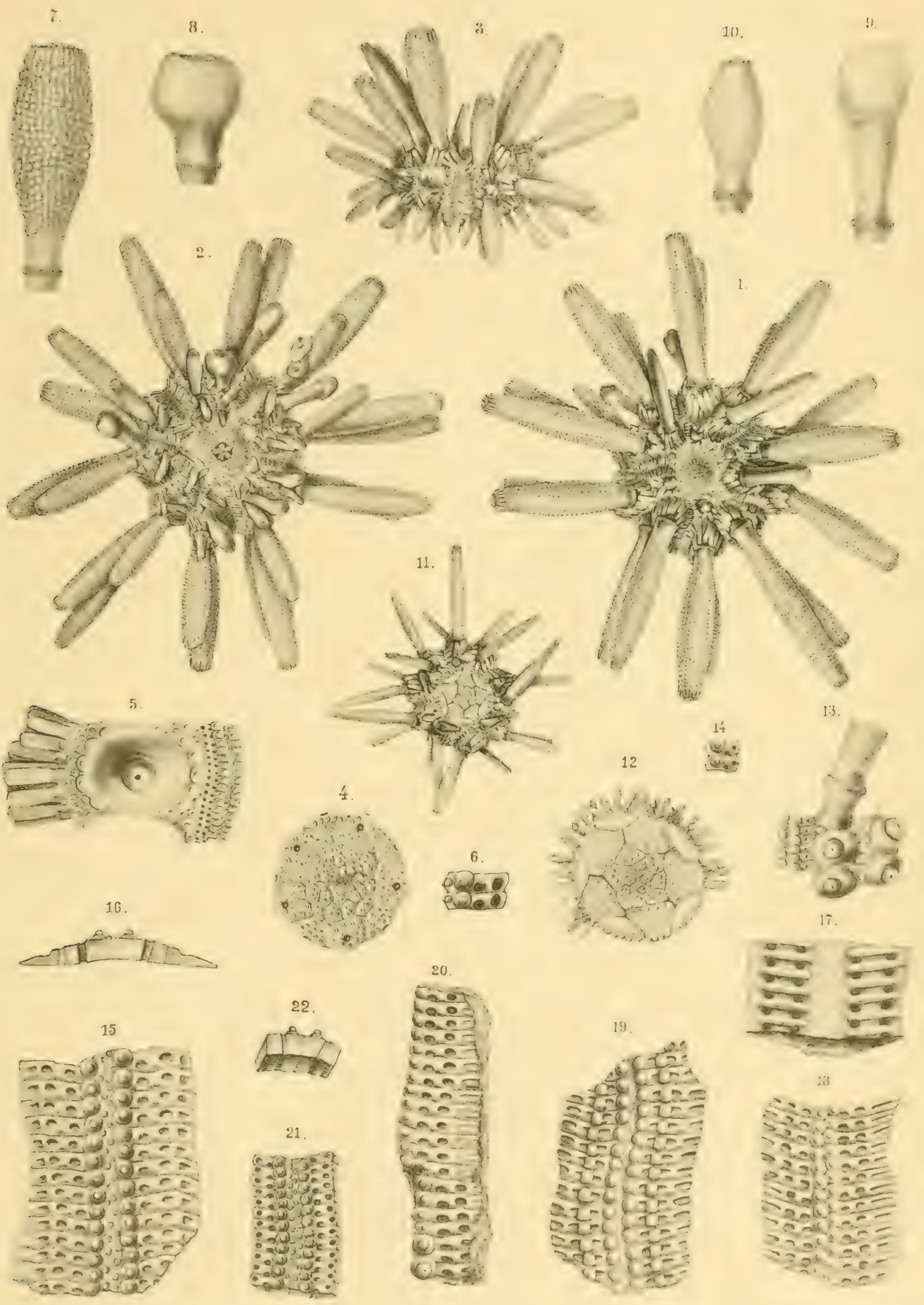




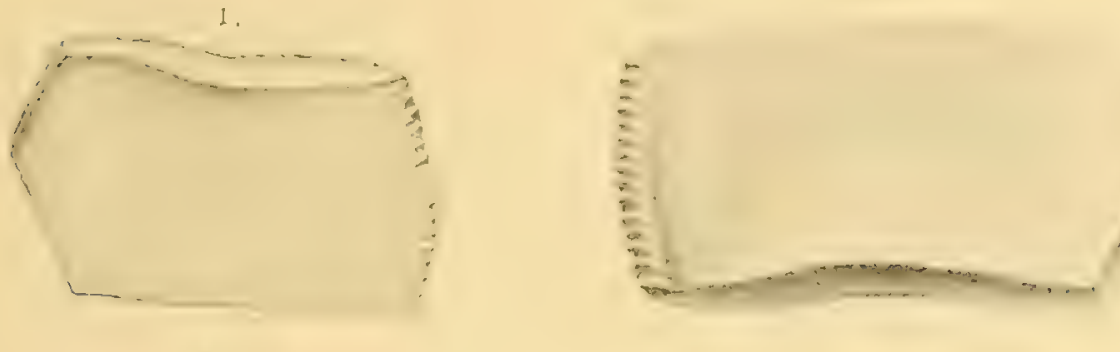

(i.
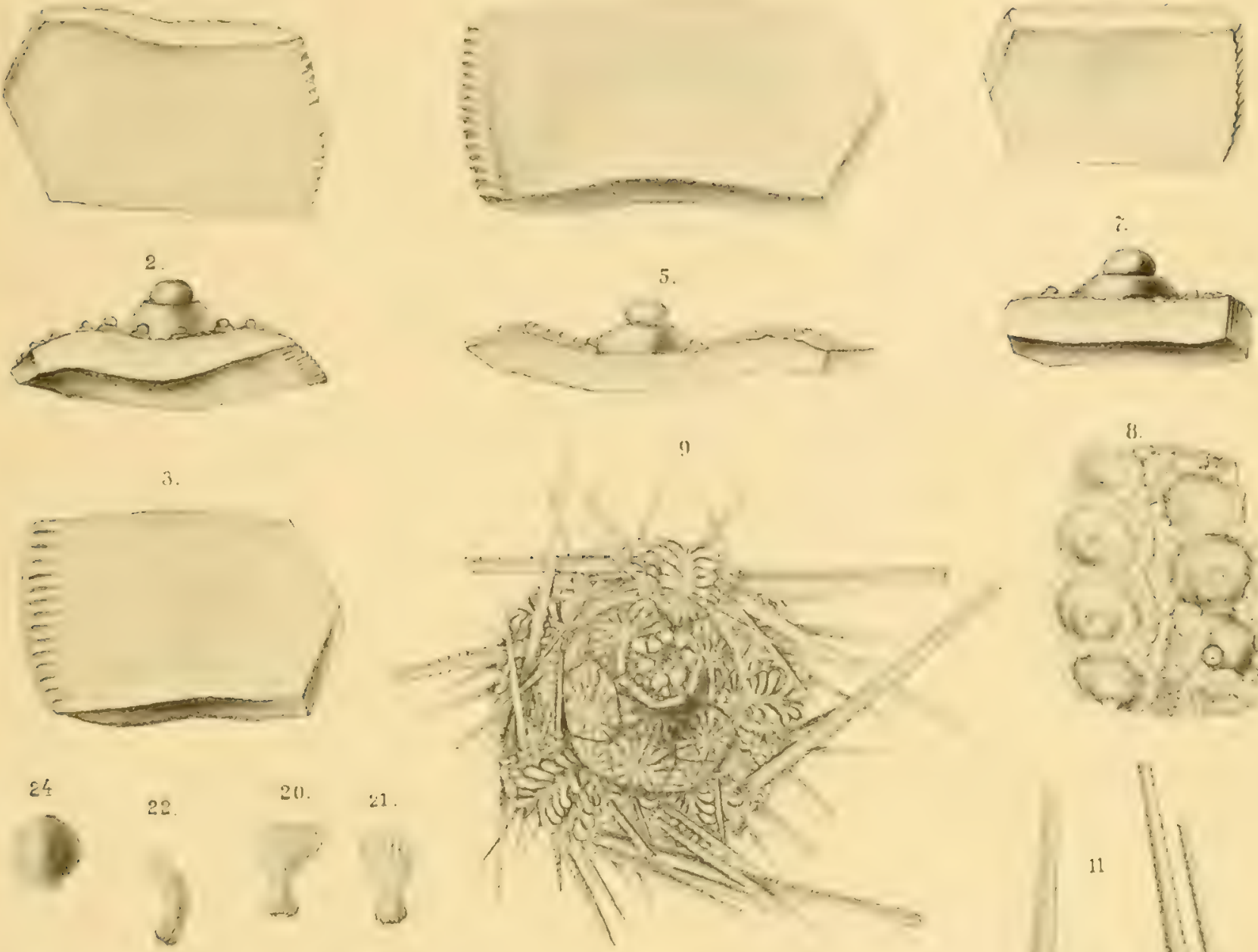

13

14

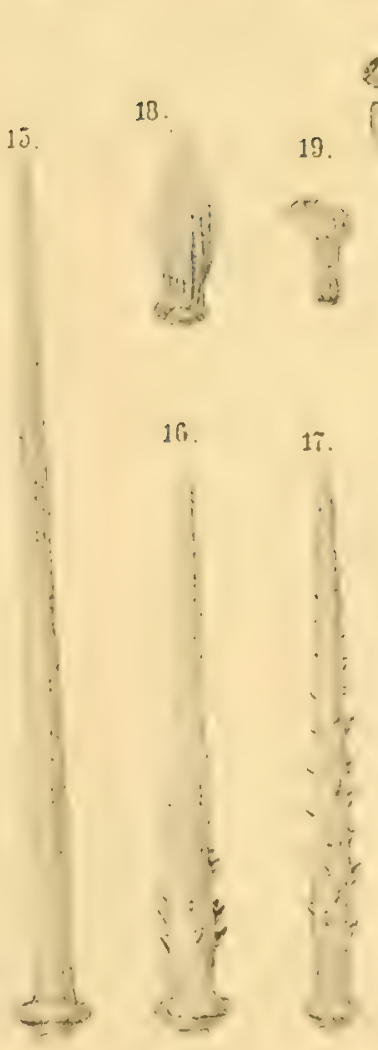

2. $x$ in

23.

in
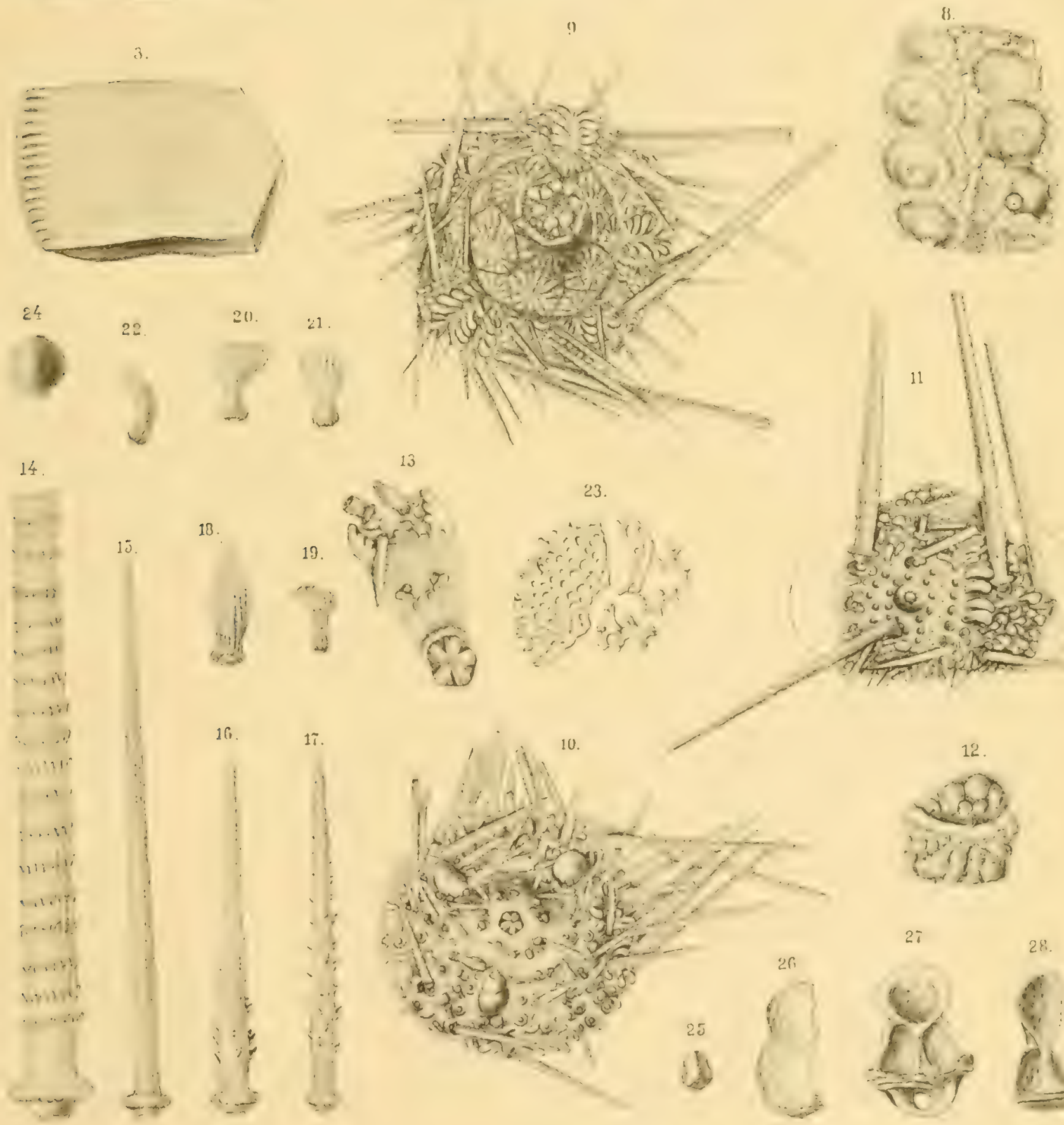

12

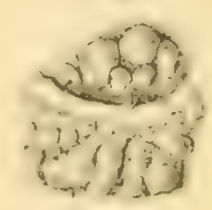

27
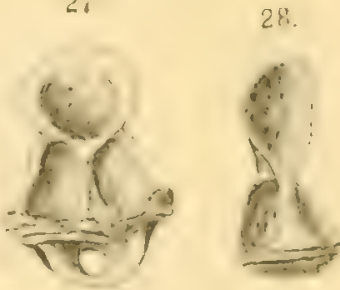

Fig. 8. Eocidaris keyserlingii. Fig, 9-28. Salenia pacifica. 




(3)
(3)

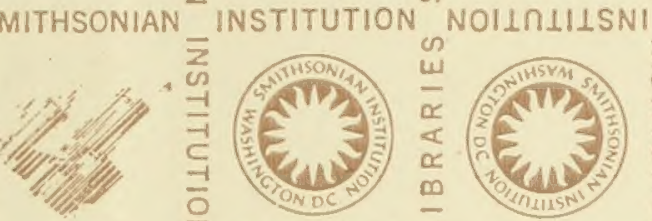
$100 \% 0$
)

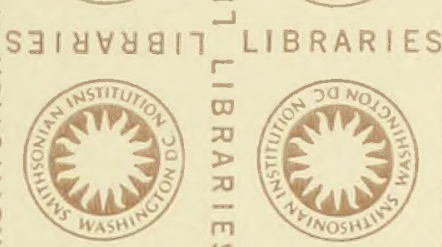

SMITHSONIAN

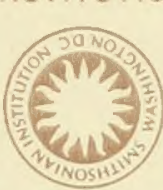

(1) $30^{2}$

ㄴ.

(ivis)

SMITHSONIAN

NSTITUTION NOILIIISNI
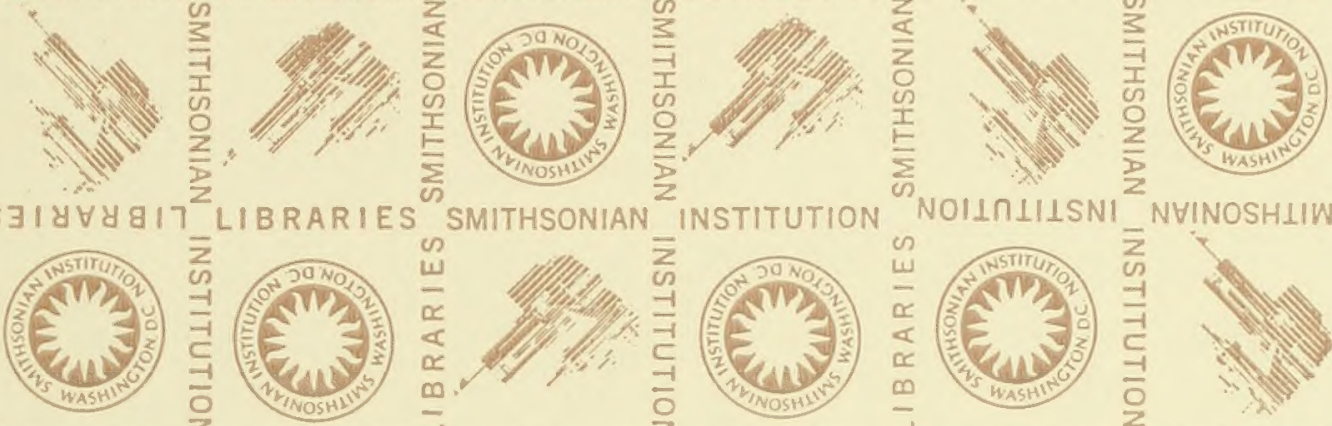

(

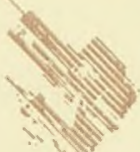

(5)

RIES
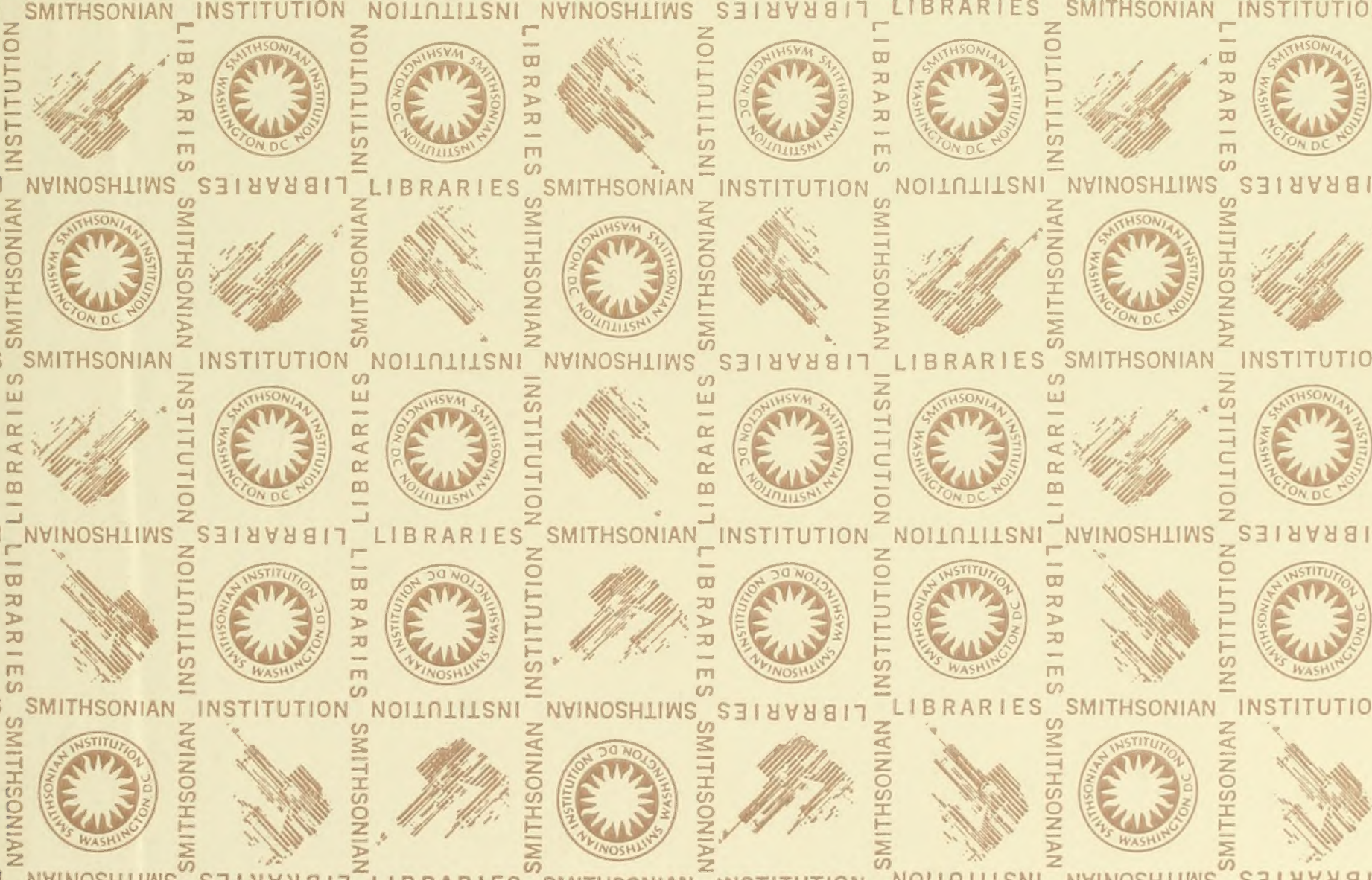

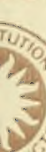
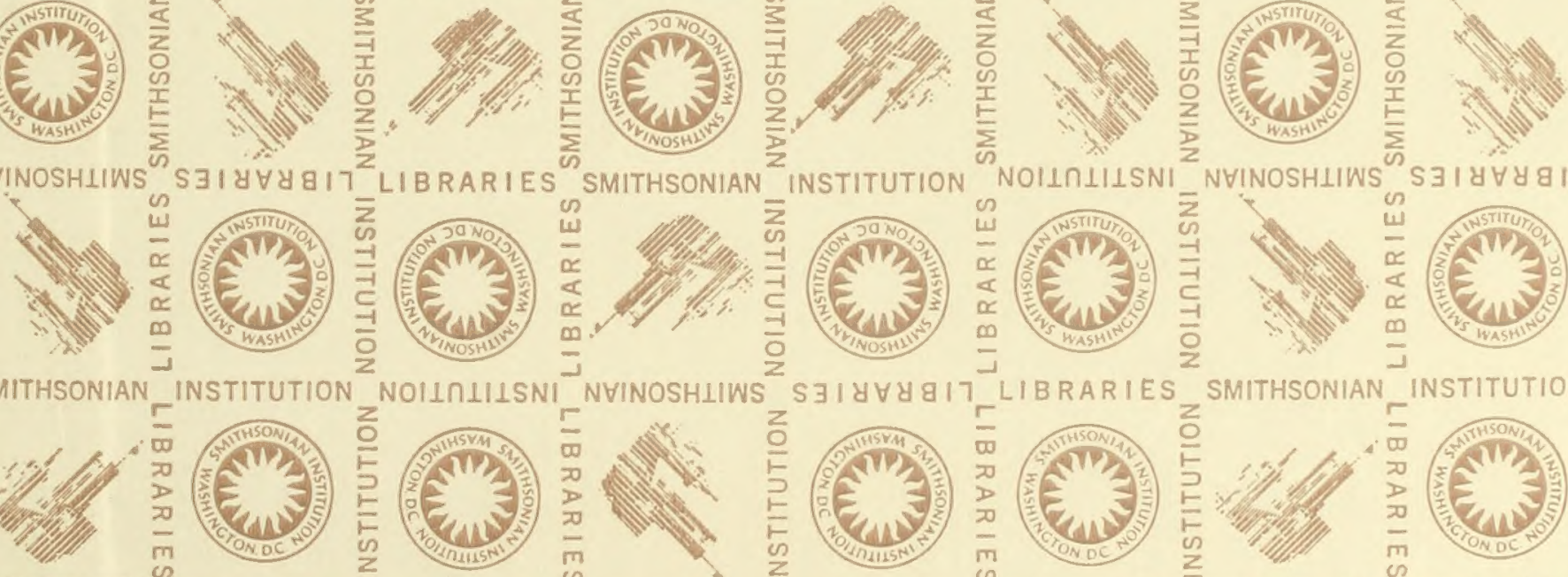

(w)

(IN)

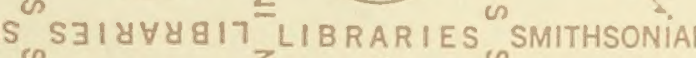


